\title{
Opioid Receptor-Like (ORL1) Receptor Distribution in the Rat Central Nervous System: Comparison of ORL1 Receptor mRNA Expression with ${ }^{125} \mathrm{I}-\left[{ }^{14} \mathrm{~T}\right.$ yr]-Orphanin F Q Binding
}

\author{
CHARLES R. NEAL, JR., ${ }^{1,2 *}$ ALFRED MANSOUR, ${ }^{3}$ RAINER REINSCHEID, \\ HANS-PETER NOTHACKE $R,{ }^{5}$ OLIVIER CIVELLI, ${ }^{5}$ HUDA AKIL, ${ }^{1}$ \\ AND STANLEY J . WATSON, J R. ${ }^{1,6}$ \\ ${ }^{1}$ Mental Health Research Institute, University of Michigan Medical Center, \\ Ann Arbor, Michigan 48109-0720 \\ 2Department of Pediatrics, University of Michigan Medical Center, \\ Ann Arbor, Michigan 48109-0720 \\ ${ }^{3}$ Pharmaco Genesis Corporation, West Bloomfield, Michigan 48322 \\ 4 University Hospital E ppendorf, D-20246 Hamburg, Germany \\ ${ }^{5}$ Department of Pharmacology, College of Medicine, University of California, I rvine, \\ I rvine, California 92697-4625 \\ ${ }^{6}$ Department of Psychiatry, University of Michigan Medical Center, \\ Ann Arbor, Michigan 48109-0720
}

\begin{abstract}
The recently discovered neuropeptide orphanin FQ (OFQ), and its opioid receptor-like (ORL1) receptor, exhibit structural features suggestive of the $\mu, \kappa$, and $\delta$ opioid systems. The anatomic distribution of OFQ immunoreactivity and mRNA expression has been reported recently. In the present analysis, we compare the distribution of orphanin receptor mRNA expression with that of orphanin FQ binding at the ORL1 receptor in the adult rat central nervous system (CNS). By using in vitro receptor autoradiography with ${ }^{125}$ - [ $\left.{ }^{14} T y r\right]-O F Q$ as the radioligand, orphanin receptor binding was analyzed throughout the rat CNS. Orphanin binding sites were densest in several cortical regions, the anterior olfactory nucleus, lateral septum, ventral forebrain, several hypothalamic nuclei, hippocampal formation, basolateral and medial amygdala, central gray, pontine nuclei, interpeduncular nucleus, substantia nigra, raphe complex, locus coeruleus, vestibular nuclear complex, and the spinal cord. By using in situ hybridization, cells expressing ORL1 mRNA were most numerous throughout multiple cortical regions, the anterior ol factory nucleus, lateral septum, endopiriform nucleus, ventral forebrain, multiple hypothalamic nuclei, nud eus of the lateral olfactory tract, medial amygdala, hippocampal formation, substantia nigra, ventral tegmental area, central gray, raphe complex, locus coeruleus, multiple brainstem motor nuclei, inferior olive, deep cerebellar nuclei, vestibular nuclear complex, nucleus of the solitary tract, reticular formation, dorsal root ganglia, and spinal cord. The diffuse distribution of ORL 1 mRNA and binding supports an extensive role for orphanin FQ in a multitude of CNS functions, including
\end{abstract}

\footnotetext{
Grant sponsor: National Institute of Mental Health; Grant number: NIMH 5 T32 MH15794; Grant sponsor: Robert Wood J ohnson Foundation Grant number: RWJ 030811; Grant sponsor: National Institute of Drug Abuse; Grant number: NIDA RO1 DA08920.

*Correspondence to: Charles R. Neal, J r., M.D., Ph.D., Mental Health Research Institute, 205 Zina Pitcher Place, Ann Arbor, MI 48109-0720. E-mail: crnj@umich.edu

Received 2 F ebruary 1999; Revised 21 May 1999; Accepted 26 May 1999
} 
motor and balance control, reinforcement and reward, nociception, the stress response, sexual behavior, aggression, and autonomic control of physiologic processes. J. Comp. Neurol. 412:563-605, 1999. ๑ 1999 Wiley-Liss, Inc.

Indexing terms: receptor autoradiography; in situ hybridization; mRNA; mapping; nociceptin

The initial expressional cloning of the mouse the $\delta$ opioid receptor (Evans et al., 1992; Kieffer et al., 1992) demonstrated that it is a member of the G-protein family of receptors with seven transmembrane domains. This discovery led not only to further characterization of the $\delta$ opioid receptor, but also to the identification of CDNA's encoding $\mu$ and $\kappa$ opioid receptors that were similar to thosecharacterized in brain homogenate binding assays and peripheral tissue bioassays (Chen et al., 1993; Fukuda et al., 1993; Meng et al., 1993; Raynor et al., 1993; Thompson et al., 1993; Wang et al., 1994; Yasuda et al., 1993, 1994; Befort et al., 1994; Kozak et al., 1994). In addition to identifying cDNAs for the $\mu, \kappa$, and $\delta$ opioid receptors, homology screening of CDNA libraries and polymerase chain reaction amplification revealed a novel member of the opioid receptor family referred to as the opioid receptor-like (ORL1) receptor, also known as the orphanin $\mathrm{FQ}$ receptor (Bunzow et al., 1994; Chen et al., 1994; Marchese et al., 1994; Mollereau et al., 1994; Fukuda et al., 1994; Wick et al., 1994; Wang et al., 1994; Lachowicz et al., 1994). Functional studies of this receptor have demonstrated that, similar to opioid receptors, its activation stimulates GTP $\gamma S$ binding and inhibits adenylate cyclase (Wu et al., 1997).

The ORL 1 receptor has an overall amino acid identity of $47 \%$ when compared across the opioid receptors, and within the transmembrane domains, the level of identity increases to $61-64 \%$ (Bunzow et al., 1994). Other structural features that are conserved within the ORL 1 and opioid receptors include the multiple glycosylation sites in the $\mathrm{N}$ terminal domain, aspartate residues in transmembrane regions 2 and 3 that may be important for agonist binding, cyclic AMP-dependent phosphorylation sites in the third intracellular loop, and several postulated palmitoylation sites in the $C$ terminal extracellular domain. In addition to the high levels of amino acid homology across the ORL1 and opioid receptors in the transmembrane domains, the receptors share a high degree of identity in the three cytoplasmic loops. All four receptors are also negatively linked to adenylate cyclase (Bunzow et al., 1994; Fukuda et al., 1994; Lachowic et al., 1994). The greatest amino acid divergence between the receptors is seen in the $\mathrm{N}$ terminal and $\mathrm{C}$ terminal domains, extracellular loops 2 and 3, and transmembrane region 4 (Mollereau et al., 1994). Amino acid mutation analysis suggests that the ORL 1 receptor can bind opioid agonists with single amino acid changes in transmembranes 5, 6, and 7 (Meng et al., 1996; Mollereau et al., 1996a; Seki et al., 1998). Despite the degree of amino acid and structural conservation across the orphanin FQ and opioid receptors, the orphanin FQ receptor does not bind any opioid peptide or alkaloid with high affinity (Bunzow et al., 1994; Chen et al., 1994; F ukuda et al., 1994; Lachowicz et al., 1994; Wick et al., 1994; $\mathrm{Ma}$ et al., 1997; Nicholson et al., 1998). In addition, opioid ligands other than etorphine fail to inhibit forskolin-stimulated cyclase accumulation in cells stably transfected with the orphanin FQ receptor (M ollereau et al., 1994).

Early Northern blot analyses suggested the presence of three ORL 1 receptor transcripts, with mRNA bands of 3.3, 7-10, and 15-23 kb (Fukuda et al., 1994; Lachowicz et al., 1994; Wick et al., 1994). Recent binding studies in mouse brain provide further biochemical evidence for the possible presence of heterogeneous ORL 1 receptors (Mathis et al., 1997), and the identification and differential regional expression of five ORL1 receptor splice variants in the mouse brain has been reported (Pan et al., 1998). The five variants include two previously reported, and three additional splice forms. Insertions noted in the new variants correspond to the region between transmembrane region 1 and the first intracellular loop, a splice site common to the other opioid receptors.

In situ hybridization studies that use CDNA for the ORL 1 receptor suggest that it is widely distributed throughout the rat forebrain, brainstem and spinal cord, but conspicuously absent in the striatum and cerebellum (Bunzow et al., 1994; Fukuda et al., 1994; Lachowicz et al., 1994; Mollereau et al., 1994; Wick et al., 1994). In addition to the central nervous system (CNS), orphanin receptor mRNA has also been detected in the intestine, vas deferens, and spleen, with none found in the heart, kidney, or lung (Wang et al., 1994; Lachowicz et al., 1994). The paucity of orphanin receptor mRNA in the striatum is in marked contrast to $\mu, \delta$, and $\kappa$ receptor binding and mRNA distribution in this region (Mansour et al., 1987, 1993, 1994a,b,c,d, 1995a,b, 1996). Providing further support for a distinct divergence of the ORL1 and opioid receptor systems, antisera directed against the $\mu$ and ORL 1 receptors have been shown to label different fibers in areas involved in pain processing in the rat (Monteillet-Agius et al., 1998).

The endogenous ligand for the ORL 1 receptor binds with high affinity and inhibits forskol in-stimulated CAMP accumulation in stably transfected cells (Meunier et al., 1995; Reinscheid et al., 1995; Saito et al., 1995, 1996, 1997; Civelli et al., 1997). This heptadecapeptide, known as orphanin FQ (OFQ), has a Gly-Gly-Phemotif in amino acid positions 2-4 and an Asn-GIn sequence at the $C$ terminus which are identical to dynorphin $A_{1-17}$, and several positively charged amino acids in the intervening sequence (Meunier et al., 1995; Reinscheid et al., 1995). Orphanin FQ demonstrates specific binding with the ORL 1 receptor (Dooley and Houghten, 1996; Reinscheid et al., 1996; Shimohigashi et al., 1996; Ardati et al., 1997; Butour et al., 1997; Guerrini et al., 1997). Several OF Q fragments with high affinity binding to the ORL 1 receptor al so have been identified (Dooley et al., 1997). Binding of OFQ to the ORL 1 receptor has been shown to stimulate ORL1-induced $\mathrm{Ca}^{2+}$ and $\mathrm{K}^{+}$conductance changes (Conner et al., 1996, 1997; K noflach et al., 1996; Nicol et al., 1996; Vaughan and Christie, 1996; Abdulla and Smith, 1997; I keda et al., 
Abbreviations

\begin{tabular}{|c|c|c|c|}
\hline 3 & oculomotor nucleus & BSTS & bed nucleus of the stria terminalis, supracapsular part \\
\hline 4 & trochlear nucleus & BSTV & bed nucleus of the stria terminalis, ventral division \\
\hline 6 & abducens nucleus & $\mathrm{C} 1$ & C1 adrenaline cells \\
\hline $6 n$ & root of the abducens nerve & $\mathrm{C} 2$ & C2 adrenaline cells \\
\hline 7 & facial nucleus & $\mathrm{C} 3$ & C3 adrenaline cells \\
\hline $7 \mathrm{n}$ & facial nerve & CA1-CA3 & fields CA1-CA3 of Ammon's horn \\
\hline $8 n$ & vestibulocochlear nerve & CA1-3so & fields CA1-CA3 of Ammon's horn, stratum oriens \\
\hline 10 & dorsal motor nucleus of the vagal nerve & CA1-3sp & fields CA1-CA3 of Ammon's horn, stratum pyramidal \\
\hline $10 \mathrm{n}$ & vagus nerve or its root & CA1-3sr & fields CA1-CA3 of Ammon's horn, stratum radiatum \\
\hline 12 & hypoglossal nucleus & CA3sl & field CA3 of Ammon's horn, stratum lucidum \\
\hline $12 \mathrm{n}$ & root of the hypoglossal nerve & ๔C & corpus callosum \\
\hline A1 & Al noradrenaline cells & $\mathrm{Ce}$ & central amygdaloid nucleus \\
\hline A2 & A2 noradrenaline cells & $\mathrm{CeCv}$ & central cervical nucleus \\
\hline A5 & A5 noradrenaline cells & Cel & central amygdaloid nucleus, lateral \\
\hline A7 & A7 noradrenaline cells & $\mathrm{CeM}$ & central amygdaloid nucleus, medial \\
\hline AAA & anterior amygdaloid area & $\mathrm{Cg}$ & cingulate gyrus \\
\hline ac & anterior commissure & CG & central gray \\
\hline $\mathrm{Acb}$ & accumbens nucleus & CGD & central gray, dorsal \\
\hline $\mathrm{AcbC}$ & accumbens nucleus, core & CGPn & pontine central gray \\
\hline AcbSh & accumbens nucleus, shell & $\mathrm{Cl}$ & caudal interstitial nucleus of the medial Iongitudinal fas- \\
\hline ACo & anterior cortical amygdaloid nucleus & & ciculus \\
\hline$A D$ & anterodorsal thalamic nucleus & cic & commissure of the inferior colliculus \\
\hline $\mathrm{AH}$ & anterior hypothalamic area & $\mathrm{ClC}$ & central nucleus of the inferior colliculus \\
\hline $\mathrm{AHi}$ & amygdal ohippocampal area & $\mathrm{Cl}$ & claustrum \\
\hline Al & agranular insular & $\mathrm{CL}$ & centrolateral thalamic nucleus \\
\hline AM & anteromedial thalamic nucleus & $\mathrm{CLi}(\mathrm{B} 8)$ & caudal linear nucleus of the raphe \\
\hline Amb & nucleus ambiguous & $\mathrm{CM}$ & central medial thalamic nucleus \\
\hline AMPO & anterior medial preoptic nucleus & $\mathrm{CnF}$ & cuneiform nucleus \\
\hline AOD & anterior olfactory nucleus, dorsal & $\mathrm{cp}$ & cerebral peduncle, basal \\
\hline $\mathrm{AOE}$ & anterior ol factory nucleus, external & CPO & caudal periolivary nucleus \\
\hline $\mathrm{AOL}$ & anterior ol factory nucleus, lateral & $\mathrm{CPu}$ & caudate putamen (striatum) \\
\hline AOM & anterior ol factory nucleus, medial & $\csc$ & commissure of the superior colliculus \\
\hline AOP & anterior ol factory nucleus, posterior & $\mathrm{ctg}$ & central tegmental tract \\
\hline AOV & anterior ol factory nucleus, ventral & $\mathrm{cu}$ & cuneate fasciculus \\
\hline AP & area postrema & $\mathrm{Cu}$ & cuneate nucleus \\
\hline APir & amygdalopiriform transition area & CXA & cortex-amygdala transition zone \\
\hline APT & anterior pretectal nucleus & $\mathrm{DA}$ & dorsal hypothalamic area \\
\hline APTD & anterior pretectal nucleus, dorsal part & DC & dorsal cochlear nucleus \\
\hline APTV & anterior pretectal nucleus, ventral part & $\mathrm{DClC}$ & dorsal cortex of the inferior colliculus \\
\hline ar & acoustic radiation & dcs & dorsal corticospinal tract \\
\hline Arc & arcuate nucleus & DEn & dorsal endopiriform nucleus \\
\hline ATg & anterior tegmental nucleus & df & dorsal fornix \\
\hline AV & anteroventral thalamic nucleus & DG & dentate gyrus \\
\hline AVDM & anteroventral thalamic nucleus, dorsomedial part & DGgr & dentate gyrus, granule cell layer \\
\hline AVVL & anteroventral thalamic nucleus, ventrolateral part & DGhi & dentate gyrus, hilum \\
\hline AVPO & anteroventral preoptic nucleus & DGmo & dentate gyrus, molecular layer \\
\hline & basal nucleus of Meynert & DGpo & dentate gyrus, polymorph layer \\
\hline BAOT & bed nucleus of the accessory ol factory tract & $\mathrm{DH}$ & dorsal horn of the spinal cord \\
\hline Bar & Barrington's Nucleus & $\mathrm{Dk}$ & nucleus of Darkschewitsch \\
\hline bic & brachium of the inferior colliculus & dlf & dorsal longitudinal fasciculus \\
\hline $\mathrm{BIC}$ & nucleus of the brachium of the inferior colliculus & DLL & dorsal nucleus of the lateral lemniscus \\
\hline $\mathrm{BL}$ & basolateral amygdaloid nucleus & DM & dorsomedial hypothalamic nucleus \\
\hline BLA & basolateral amygdaloid nucleus, anterior part & DMSp5 & dorsomedial spinal trigeminal nucleus \\
\hline BLP & basolateral amygdaloid nucleus, posterior part & DMTg & dorsomedial tegmental area \\
\hline BM & basomedial amygdaloid nucleus & $\mathrm{DP}$ & dorsal peduncular cortex \\
\hline BMA & basomedial amygdaloid nucleus, anterior part & DPGi & dorsal paragigantocellular nucleus \\
\hline BMP & basomedial amygdaloid nucleus, posterior part & DpMe & deep mesencephalic nucleus \\
\hline bsc & brachium of the superior colliculus & DPO & dorsal periolivary nucleus \\
\hline BST & bed nucleus of the stria terminalis & $\mathrm{DR}(\mathrm{B} 6, \mathrm{~B} 7)$ & dorsal raphe \\
\hline BSTi & bed nucleus of the stria terminalis, intermediate division & DRG & dorsal root ganglion \\
\hline BSTIA & $\begin{array}{l}\text { bed nucleus of the stria terminalis, intra-amygdaloid divi- } \\
\text { sion }\end{array}$ & $\begin{array}{l}\text { DTg } \\
\text { ECIC }\end{array}$ & $\begin{array}{l}\text { dorsal tegmental nucleus } \\
\text { external cortex of the inferior colliculus }\end{array}$ \\
\hline BSTI & bed nucleus of the stria terminalis, lateral division & $\mathrm{ECu}$ & external cuneate nucleus \\
\hline BSTId & $\begin{array}{l}\text { bed nucleus of the stria terminalis, lateral division, dorsal } \\
\text { part }\end{array}$ & $\begin{array}{l}\text { Ent } \\
\text { EP }\end{array}$ & $\begin{array}{l}\text { entorhinal cortex } \\
\text { entopeduncular nucleus }\end{array}$ \\
\hline BSTIj & $\begin{array}{l}\text { bed nucleus of the stria terminalis, lateral division, juxta- } \\
\text { capsular part }\end{array}$ & $\begin{array}{ll}\text { EP1 } \\
\text { EW }\end{array}$ & $\begin{array}{l}\text { external plexiform layer, olfactory bulb } \\
\text { Edinger-Westphal nucleus }\end{array}$ \\
\hline BSTIp & bed nucleus of the stria terminalis, lateral division, poste- & f & fornix \\
\hline & rior part & $\mathrm{F}$ & nucleus of the fields of Forel \\
\hline BSTIV & bed nucleus of the stria terminalis, lateral division, ventral & $\mathrm{fr}$ & fasciculus retroflexus \\
\hline BSTma & bed nucleus of the stria terminalis, medial division, ante- & $\begin{array}{l}\mathrm{Fr} \\
\mathrm{g} 7\end{array}$ & genu of the facial nerve \\
\hline & rior part & $\mathrm{G}$ & gelatinosus thalamic nucleus \\
\hline BSTmpl & bed nucleus of the stria terminalis, medial division, postero- & $\mathrm{Gi}$ & gigantocellular reticular nucleus \\
\hline BSTmpm & & $\begin{array}{l}\mathrm{GI} \\
\mathrm{GiA}\end{array}$ & \\
\hline & medial part & GiV & gigantocellular reticular nucleus, ventral \\
\hline BSTmv & bed nucleus of the stria terminalis, medial division, ventral & $\mathrm{Gl}$ & glomerular layer, olfactory bulb \\
\hline & part & GP & globus pallidus \\
\hline
\end{tabular}


Abbreviations (continued)

\begin{tabular}{|c|c|c|c|}
\hline gr & gracile fasciculus & MCPO & magnocellular preoptic nucleus \\
\hline $\mathrm{Gr}$ & gracile nucleus & MD & mediodorsal thalamic nucleus \\
\hline GrO & granular cell layer, olfactory bulb & MDC & mediodorsal thalamic nucleus, central part \\
\hline $\mathrm{Hb}$ & Habenula & MDL & mediodorsal thalamic nucleus, lateral part \\
\hline HDB & nucleus of the horizontal limb of the diagonal band of Broca & MDM & mediodorsal thalamic nucleus, medial part \\
\hline & intercalated nuclei of the amygdala & $\mathrm{MdD}$ & medullary reticular nucleus, dorsal \\
\hline IAD & interanterodorsal thalamic nucleus & $\mathrm{MdV}$ & medullary reticular nucleus, ventral \\
\hline IAM & interanteromedial thalamic nucleus & $\mathrm{Me}$ & medial amygdaloid nucleus \\
\hline IC & inferior colliculus & ME & medial eminence \\
\hline $\mathrm{ICj}$ & islands of Calleja & Me5 & mesencephalic trigeminal nucleus \\
\hline icp & inferior cerebellar peduncle & MeAD & medial amygdaloid nucleus, anterodorsal \\
\hline IF & interfascicular nucleus & MeAV & medial amygdaloid nucleus, anteroventral \\
\hline IG & indusium griseum & Med & medial (fastigial) cerebellar nucleus \\
\hline IL & infralimbic cortex & MedDL & medial cerebellar nucleus, dorsolateral protuberance \\
\hline ILL & intermediate nucleus of the lateral lemniscus & MePD & medial amygdal oid nucleus, posterodorsal \\
\hline IMD & intermediodorsal thalamic nucleus & MePV & medial amygdal oid nucleus, posteroventral \\
\hline IML & intermediolateral cell column & MGN & medial geniculate nucleus \\
\hline IMLF & interstitial nucleus of the medial Iongitudinal fasciculus & $\mathrm{MHb}$ & medial habenula \\
\hline IMM & intermediomedial cell column & $\mathrm{Mi}$ & mitral cell layer, olfactory bulb \\
\hline In & intercalated nucleus of the medulla & MiTg & microcellular tegmental nucleus \\
\hline InCo & intercollicular nucleus & $\mathrm{ml}$ & medial lemniscus \\
\hline IntA & interposed cerebellar nucleus, anterior part & $M L$ & medial mammillary nucleus, lateral part \\
\hline IntDL & interposed cerebellar nucleus, dorsolateral part & $\mathrm{mlf}$ & medial longitudinal fasciculus \\
\hline IntDM & interposed cerebellar nucleus, dorsomedial part & MM & medial mammillary nucleus, medial part \\
\hline IntP & interposed cerebellar nucleus, posterior part & MMn & medial mammillary nucleus, median part \\
\hline 10 & inferior olive & $\mathrm{MnA}$ & median accessory nucleus of the medulla \\
\hline IOA & inferior olive, medial subnucleus A & $\mathrm{MnPO}$ & median preoptic nucleus \\
\hline IOB & inferior olive, medial subnucleus B & $\mathrm{MnR}$ & (Bmedian raphe nucleus5) \\
\hline IOD & inferior olive, dorsal & MO & medial orbital cortex \\
\hline IODM & inferior olive, dorsomedial & Mo5 & motor trigeminal nucleus \\
\hline IOM & inferior olive, medial & $\mathrm{mp}$ & mammillary peduncle \\
\hline IOPr & inferior olive, principal & MPA & medial preoptic area \\
\hline IPAC & interstitial nucleus of the posterior limb of the anterior & MPB & medial parabrachial nucleus \\
\hline & commissure & MPO & medial preoptic nucleus \\
\hline IPC & interpeduncular nucleus, caudal & MPOC & medial preoptic nucleus, central part \\
\hline IPD & interpeduncular nucleus, dorsal & MPT & medial pretectal nucleus \\
\hline IPL & interpeduncular nucleus, lateral & MS & medial septal nucleus \\
\hline $\mid \mathrm{PI}$ & internal plexiform layer, olfactory bulbl & MSO & medial superior olive \\
\hline IPN & interpeduncular nucleus & mt & mammillothalamic tract \\
\hline IPR & interpeduncular nucleus, rostral & MT & medial terminal nucleus of the accessory optic tract \\
\hline IRt & intermediate reticular nucleus & MTu & medial tuberal nucleus \\
\hline KF & Kolliker-Fuse nucleus & MVe & medial vestibular nucleus \\
\hline La & lateral amygdaloid nucleus & MVeV & medial vestibular nucleus, ventral \\
\hline LA & Iateroanterior hypothalamic nucleus & MVPO & medioventral periolivary nucleus \\
\hline Lat & Iateral (dentate) cerebellar nucleus & Oc & occipital cortex \\
\hline LatC & lateral cervical nucleus & opt & optic tract \\
\hline LatPC & Iateral cerebellar nucleus, parvicellular part & OPT & olivary pretectal nucleus \\
\hline LC & locus coeruleus & OT & nucleus of the optic tract \\
\hline Ld & lambdoid septal zone & $\mathrm{Pa}$ & paraventricular hypothalamic nucleus \\
\hline LD & laterodorsal thalamic nucleus & $\mathrm{Pa} 4$ & paratrochlear nucleus \\
\hline LDDM & laterodorsal thalamic nucleus, dorsomedial part & Pa5 & paratrigeminal nucleus \\
\hline LDVL & Iaterodorsal thalamic nucleus, ventrolateral part & Pa6 & para-abducens nucleus \\
\hline LDTg & laterodorsal tegmental nucleus & $\mathrm{Pa}$ & paraventricular hypothalamic nucleus \\
\hline Ifp & Iongitudinal fasciculus of the pons & PaAM & paraventricular hypothalamic nucleus, anterior magnocel- \\
\hline Ifu & lateral funiculus of the spinal cord & & lular part \\
\hline LGN & lateral geniculate nucleus & PaAP & paraventricular hypothalamic nucleus, anterior parvicellu- \\
\hline LH & Iateral hypothalamic area & & lar part \\
\hline $\mathrm{LHb}$ & Iateral habenula & PaDC & paraventricular hypothalamic nucleus, dorsal cap \\
\hline II & lateral lemniscus & PaLM & paraventricular hypothalamic nucleus, lateral magnocellu- \\
\hline LM & lateral mammillary nucleus & & lar part \\
\hline LO & lateral orbital cortex & PaMP & paraventricular hypothalamic nucleus, medial parvicellular \\
\hline 10 & lateral olfactory tract & & part \\
\hline LOT & nucleus of the lateral olfactory tract & PaPo & paraventricular hypothalamic nucleus, posterior part \\
\hline LP & lateral posterior thalamic nucleus & Par & parietal cortex \\
\hline LPB & lateral parabrachial nucleus & PaS & parasubiculum \\
\hline LPGi & lateral paragigantocellular nucleus & $\mathrm{PaV}$ & paraventricular hypothalamic nucleus, ventral part \\
\hline LPO & lateral preoptic area & PBG & parabigeminal nucleus \\
\hline LRt & lateral reticular nucleus & PBP & parabrachial pigmented nucleus \\
\hline LS & lateral septal nucleus & pc & posterior commissure \\
\hline LSD & lateral septal nucleus, dorsal & PC & paracentral thalamic nudeus \\
\hline LSI & lateral septal nucleus, intermediate & PCom & nucleus of the posterior commissure \\
\hline LSO & lateral superior olive & PCRt & parvicellular reticular nucleus \\
\hline LSp & lateral spinal nucleus & PDTg & posterodorsal tegmental nucleus \\
\hline LSV & lateral septal nucleus, ventral & $\mathrm{Pe}$ & periventricular hypothalamic nucleus \\
\hline LVe & lateral vestibular nucleus & $\mathrm{PeF}$ & perifornical nucleus \\
\hline LVPO & lateroventral periolivary nucleus & PF & parafascicular thalamic nucleus \\
\hline MA3 & medial accessory oculomotor nucleus & $\mathrm{PH}$ & posterior hypothalamus \\
\hline MCPC & magnocellular nucleus of the posterior commissure & Pin & pineal gland \\
\hline
\end{tabular}


Abbreviations (continued)

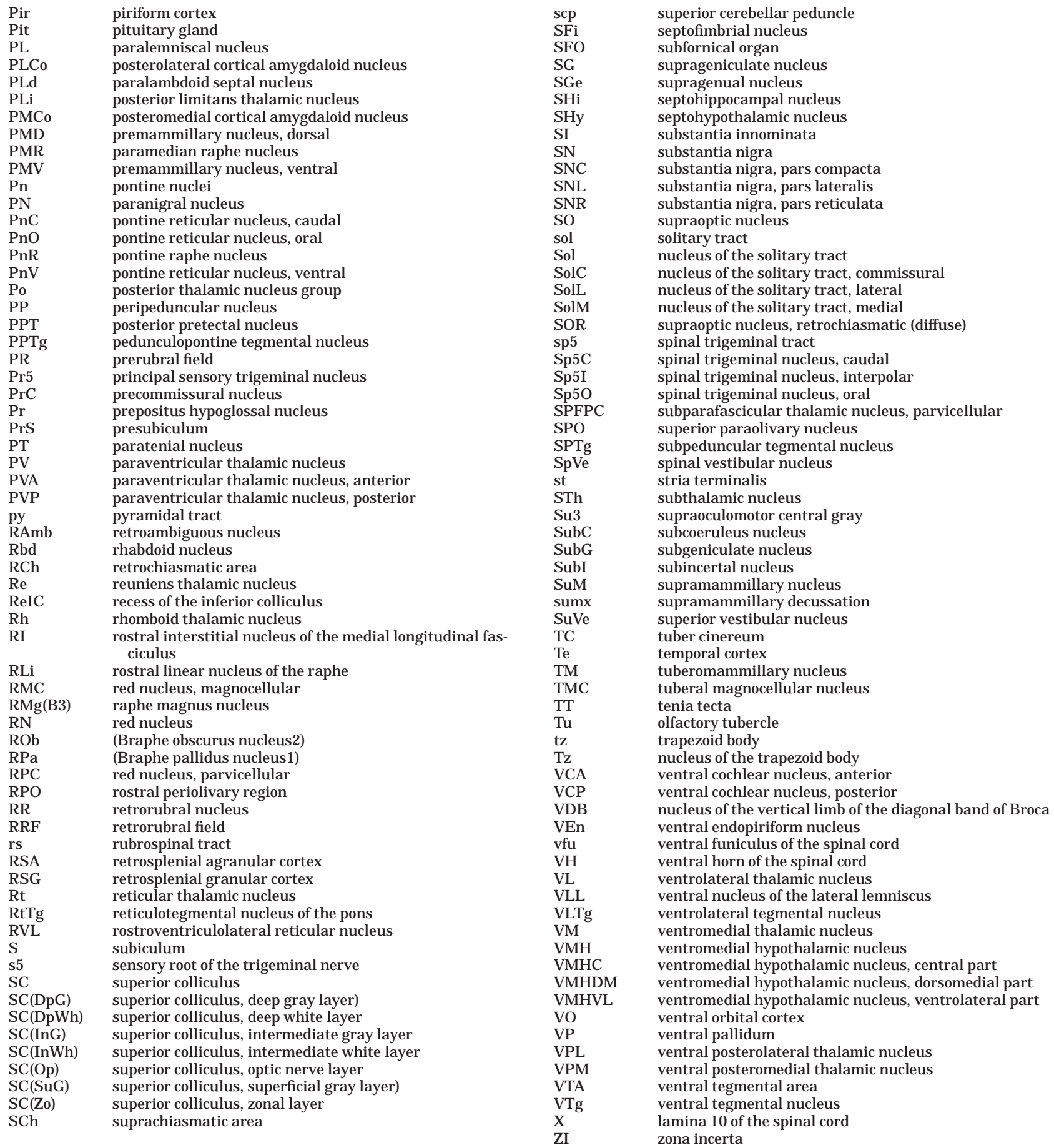

1997; Vaughan et al., 1997; Yu et al., 1997; Wagner et al., 1998), protein kinase C activation (Lou et al., 1997), and to effect the function of other neurotransmitter systems (Faber et al., 1996; Giuliani and Maggi, 1996; Murphy et al., 1996; Wang et al., 1996; Gintzler et al. 1997; Liebel et al., 1997; I noue et al., 1998; Konya et al., 1998). I ntraven- tricular injection of OFQ fails to produce cross-tolerance with morphine (Hao et al., 1997) or conditioned place preference (Devine et al., 1996a), but it has been implicated in various modulatory effects of allodynia (Hara et al., 1997; Minami et al., 1997) and nociception (Grisel et al., 1996; Mogil et al., 1996a,b; Rossi et al., 1996, 1997fa et 
al., 1996; Xu et al., 1996; Dawson-Basoa and Gintzler, 1997; Heinricher et al., 1997; King et al., 1997; Liebel et al., 1997; Morgan et al. 1997; Nishi et al., 1997; Tian et al., 1997a,b; Yamamoto et al., 1997; Zhu et al., 1997), enticing many to refer to this mol ecule as nociceptin. Subsequently, OFQ also has been implicated in many other physiologic and behavioral processes, including pituitary function (Bryant et al., 1998; Doi et al., 1998), cardiovascular control (Champion and Kadowitz, 1997a,b; Champion et al., 1997; Gumusel et al., 1997; Chu et al., 1998), sodium balance (Kapusta et al., 1997), feeding (Pomonis et al., 1996; Stratford et al., 1997), learning (Sandin et al ., 1997), Iocomotion (Devine et al., 1996b; Florin et al., 1996, 1997a), stress response (J enck et al., 1997), and sexual behavior (Sinchak et al., 1997).

Orphanin FQ is derived from a larger precursor, and is flanked by Lys-Arg proteolytic cleavage sites, similar to dynorphin $\mathrm{A}_{1-17}$ (Mollereau et al., 1996b; Houtani et al., 1996; Nothacker at al., 1996; Pan et al., 1996). The precursor, also known as prepro-orphanin, contains two other neuropeptides that may be biologically active; a 35-amino acid peptide upstream of the orphanin FQ peptide, and a second 17-amino acid sequence immediately downstream. Interestingly, this 17-amino acid sequence, presently referred to as orphanin FQ2, has demonstrated analgesic activity in high doses in mice (Rossi et al., 1998). Prepro-orphanin closely shares structural homology to the opioid peptide precursors prodynorphin and preproenkephalin, and it has been suggested recently that a coordinated mechanism of evolution has separated the orphanin FQ and opioid systems (Reinscheid et al., 1998).

Given the potential physiological significance of the orphanin system, elucidating the distribution of OF Q and the ORL 1 receptor within the CNS is critical to identify specific neuroanatomic systems which may be influenced by orphanin $\mathrm{FQ}$. A detailed analysis of the distribution of OFQ peptide immunoreactivity and prepro-orphanin mRNA expression in the CNS of the rat has been reported recently (Neal et al., 1999). Additionally, the distribution of ORL 1 receptor immunoreactivity in the rat CNS has been reported in detail (Anton et al., 1996), as have general descriptions of OF Q-stimulated GTP $\gamma \mathrm{S}$ binding in the rat and guinea pig brain (Sim et al., 1996; Sim and Childers, 1997), [ ${ }^{3} \mathrm{H}$ ]orphanin receptor binding in the mouse (Florin et al., 1997b), 125 -labeled orphanin binding in the rat and human hypothalamus (Makman et al., 1997), and preproOFQ and ORL 1 mRNA distribution in the developing mouse brain (Ikeda et al., 1998). However, no detailed analysis of receptor binding or expression of mRNA encoding the ORL 1 receptor throughout the rat CNS has been reported to date. The present study was carried out to characterize the detailed distribution of ORL1 mRNA expression and orphanin FQ binding sites in the adult rat. A ${ }^{14}$ Tyrosine substitute analog of the orphanin peptide was 125I-label ed by using the chloramineT method (Hunter and Greenwood, 1962). By using this ${ }^{125}$-[14Tyr]-OFQ peptide as a ligand, receptor autoradiographic methods were used to visualize orphanin $\mathrm{FQ}$ receptor binding sites throughout the rat CNS. In addition, by using a ${ }^{35} \mathrm{~S}-U T P-$ and ${ }^{35} \mathrm{~S}-\mathrm{CTP}$-labeled CRNA riboprobe to the ORL 1 receptor, in situ hybridization techniques were used to visualize ORL 1 mRNA-expressing neurons in these same tissues.

\section{MATERIALS AND METHODS}

\section{Animals}

Adult male Sprague-Dawley rats (Charles River, Wilmington, MA; 250-300 g) were used for all in situ and autoradiography studies. Handling and use of all animals strictly conformed to $\mathrm{NIH}$ guidelines. Additionally, the university unit for lab animal medicine (ULAM) at the University of Michigan Medical Center approved protocols for animal use in this study.

\section{Tissue preparation}

For in situ hybridization and autoradiography, adult male Sprague-Dawley rats were killed by decapitation and their brains and spinal cords were removed and immediately frozen in isopentane at $-30^{\circ} \mathrm{C}$. In addition to whole brains, at thetime of killing, pituitaries were also removed and frozen in Lipshaw M-1 embedding matrix on powdered dry ice. Brain, spinal cord, and pituitary tissue were stored at $-80^{\circ} \mathrm{C}$ until sectioning. All CNS material was sectioned coronally on a Bright cryostat at $15 \mu \mathrm{m}$ and thaw mounted on polylysine-subbed microscope slides, then stored at $-80^{\circ} \mathrm{C}$ until used. Adjacent brain and pituitary sections were used for in situ hybridization and receptor autoradiography.

\section{lodination}

An orphanin FQ peptide analog was synthesized with the leucine residue in position 14 substituted with a tyrosine for subsequent iodination (14Tyr-OFQ). The ${ }^{125}$ [14Tyr]-OFQ peptide was labeled by the chloramine $T$ method (Hunter and Greenwood, 1962) and purified by reverse-phase high performance liquid chromatography. The monoiodinated species was obtained as a single peak with an estimated specific activity of $2,200 \mathrm{Ci} / \mathrm{mmol}$ on the day of iodination. The ${ }^{125} \mathrm{I}-\left[{ }^{14} \mathrm{~T} y \mathrm{r}\right]-\mathrm{OFQ}$ radioligand was then stored in its elution buffer at $-20^{\circ} \mathrm{C}$ until used for receptor binding studies. Recent binding analyses have demonstrated that ${ }^{125}$ - [ ${ }^{14} \mathrm{Ty}$ r]-OF Q exhibits identical binding characteristics at the ORL 1 receptor as $\left[{ }^{3} \mathrm{H}\right] \mathrm{OFQ}$, making this a suitable radioligand for pharmacologic analysis of the ORL 1 receptor by using in vitro assays (Ardati et al., 1997).

\section{Receptor autoradiography}

Before incubation with the iodinated orphanin FQ peptide, brain, spinal cord, and pituitary sections were brought to room temperature $\left(22^{\circ} \mathrm{C}\right)$ and placed in incubation chambers to maintain ambient temperature and humidity (60-80\%). Theincubation buffer consisted of the ${ }^{125}$ - [14Tyr]OFQ peptide, $50 \mathrm{mM}$ Tris $\left(\mathrm{pH}=7.0,22^{\circ} \mathrm{C}\right), 1 \mathrm{mM}$ ethylenediaminetetraacetic acid, $0.1 \%$ bovine serum albumin, and protease inhibitor $(0.1 \mathrm{mM}$ phenylmethylsulfonyl fluoride, $1 \mu \mathrm{g} / \mathrm{ml}$ aprotinin, $1 \mu \mathrm{g} / \mathrm{ml}$ leupeptin, $1 \mu \mathrm{g} / \mathrm{ml}$ pepstatin, and $1 \mathrm{mM}$ iodoacetamide). Incubation was terminated by four consecutive washes, four minutes each, in $50 \mathrm{mM}$ Tris $\left(\mathrm{pH}=7.0,0^{\circ} \mathrm{C}\right)$, followed by a distilled water rinse. Scatchard analysis suggested a $0.1 \mathrm{nM} \mathrm{K}_{d}$ for the ${ }^{125} \mathrm{I}$-[ $\left.{ }^{14} \mathrm{Tyr}\right]-O F \mathrm{Q}$ peptide. Therefore, a concentration of 0.1$0.13 \mathrm{nM}$, which corresponds to a $50 \%$ receptor occupancy, was chosen as a labeling concentration for the competition and anatomic mapping studies. 
U pon completion of tissuetreatment with the ${ }^{125}$-[14Tyr]OF Q ligand, brain and pituitary sections used for receptor autoradiography were apposed to Kodak XAR-5 X-ray film for 1-3 days, then subsequently dipped in NTB2 liquid emulsion (Herkenham and Pert, 1982). B efore emulsion dipping, sections were exposed to paraformaldehyde vapors at $80^{\circ} \mathrm{C}$ for 2 hours in an evacuated desiccator. Lipids were then removed by a series of ethanol washes (70$100 \%)$, five xylene washes, a second series of ethanol washes (100-70\%), followed by distilled water rinse. The slides were then dipped in emulsion, sealed in light-tight boxes, and developed three days later.

Emulsion dipped sections were $\mathrm{Nissl}$ counterstained with cresyl violet, dehydrated in graded alcohols followed by xylene, and cover-slipped with Permount. Tissue sections were analyzed by using a "Dark-Lite" darkfield stage-light on a Leitz DM RD microscope with camera attachment. Representative sections were photographed and images from negatives were generated on high quality Kodak Photographic Paper for illustrations. All processing was done under identical darkroom conditions.

\section{Receptor autoradiography controls}

Competition studies were performed on slide-mounted forebrain and midbrain sections. Each brain section was incubated with $200 \mu \mathrm{l}$ of ${ }^{125}$ - [ [14Tyr]-OF Q peptide in incubation buffer for 60 minutes at $22^{\circ} \mathrm{C}$, and a minimum of eight competing ligand concentrations were examined $(0.03$ $\mathrm{nM}$ - $10 \mu \mathrm{M})$. Nonspecific binding was evaluated by treating adjacent brain sections with the same concentration of ${ }^{125}$-[ [ $\left.{ }^{14} \mathrm{~T} y \mathrm{r}\right]$-OF Q peptide and a $1 \mu \mathrm{M}$ final concentration of unlabeled native orphanin FQ peptide. To pharmacologically characterize ORL 1 receptor binding sites, a series of $\mu$ (morphine, naloxone), $\delta$ (DADL, DPDPE), and $\kappa$ (bremazocine, U69,593) agonists were evaluated. In addition, the affinity of $\beta$-endorphin and OFQ peptide was examined. Receptor binding was quantified by liquid scintillation spectrophotometry.

\section{CRNA probe}

Hybridization of CNS tissue was performed by using a ${ }^{35} \mathrm{~S}-U T P$ and ${ }^{35}$ S-CTP-label ed riboprobe generated to the $5^{\prime}$ region of the rat ORL 1 receptor. The CRNA riboprobe was generated from a 700-base cDN A that extended from the 5' UT region to 611 bases within the protein coding region of the ORL 1 receptor (Bunzow et al., 1994; Chen et al., 1994; Mollereau et al., 1994; Fukuda et al., 1994; Wick et al., 1994; Wang et al., 1994; Lachowicz et al., 1994).

\section{In situ hybridization}

The in situ hybridization technique used in this study has been described previously for detection of opioid receptor mRNA (Mansour et al., 1993, 1994a,b,d) and prepro-orphanin FQ mRNA (Neal et al., 1999) in the rat CNS. Adjacent sections of frozen brain, spinal cord, and pituitary were removed from $-80^{\circ} \mathrm{C}$ storage and placed into $4 \%$ paraformal dehyde for 60 minutes at room temperature. Sections were next given threefive-minute rinses in a solution of $300 \mathrm{mM}$ sodium chloride and $30 \mathrm{mM}$ sodium citrate, pH 7.2 ( $2 \times$ standard saline citrate [SSC]), followed by treatment with proteinase $\mathrm{K}(1 \mu \mathrm{g} / \mathrm{ml}$ in $100 \mathrm{mM}$ Tris and $50 \mathrm{mM}$ ethylenediaminetetraacetic acid, $\mathrm{pH}$ 8.0) for 10 minutes at $37^{\circ} \mathrm{C}$. Sections were rinsed once in water then treated with $0.1 \mathrm{M}$ triethanolamine containing acetic anhydride diluted to $400: 1 \mathrm{vol} / \mathrm{vol}$, $\mathrm{pH} 8.0$, for 10 minutes at room temperature. Sections were rinsed again in water, dehydrated in graded alcohols, and then air-dried.

Prepared tissue was hybridized with a ${ }^{35}$ S-UTP and ${ }^{35} \mathrm{~S}-\mathrm{CTP}$-labeled riboprobe generated to the rat ORL 1 receptor as described above. The cRNA probe was diluted by using a hybridization buffer composed of $75 \%$ formamide, $10 \%$ dextran sulfate, $3 \times$ SSC, $0.1 \mathrm{mg} / \mathrm{ml}$ yeast tRNA, $1 \times$ Denhardt's, and $10 \mathrm{mM}$ dithiothreitol in $50 \mathrm{mM}$ $\mathrm{Na}_{2} \mathrm{PO}_{4}\left(\mathrm{pH}\right.$ 7.4). The activity of ${ }^{35} \mathrm{~S}$-labeled cRNA used for hybridization was in the range of $1-2 \times 10^{6} \mathrm{cpm} / 35 \mu \mathrm{l}$. F or hybridization, $35 \mu$ of diluted probe was applied to tissue sections and coverslips were placed to keep the hybridization buffer in contact with tissue. Tissue sections were then placed in sealed humidifying chambers containing $50 \%$ formamide and hybridized overnight in a VRW Scientific 1535 incubator (Cornelius, OR) at $55^{\circ} \mathrm{C}$.

On day 2, glass coverslips were removed and slides were rinsed two times in $2 \times$ SSC for 5 minutes, then treated with RNase $A$ for 60 minutes at $37^{\circ} \mathrm{C}(200 \mu \mathrm{g} / \mathrm{ml}$ RNase $A$ and $0.5 \mathrm{M} \mathrm{NaCl}$ in $100 \mathrm{mM}$ Tris, pH 8.0). After RNase $A$ treatment, sections were washed in $2 \times$ SSC for five minutes, followed by $1 \times$ SSC for 5 minutes and $0.5 \times$ SSC for five minutes, all at room temperature. The low salt wash was completed with incubation in $0.1 \times$ SSC for 60 minutes at $65^{\circ} \mathrm{C}$. Sections were then rinsed in water, dehydrated through graded alcohols, and air-dried.

Upon completion of hybridization, slide-mounted sections were opposed to Kodak XAR-5 X-ray film for five days, then dipped in NTB2 film emulsion. Brain sections were then developed after a 57-day exposure to NTB2 emulsion. The exposure time was chosen to maximize the detection of in situ hybridization grains, and was determined empirically by means of periodic development of test slides of tissue sections dipped in the NTB2 emulsion. After development of the NTB2 film emulsion, all slides were rinsed in running water at room temperature for 30 minutes and Nissl counterstained with cresyl violet. Slides were dehydrated in graded alcohols followed by xylene, and cover-slipped with Permount. Hybridized tissue was analyzed by using a "Dark-Lite" darkfield attachment on a Leitz DM RD microscope with camera attachment. Representative sections were photographed, and images from negatives were generated on high-quality Kodak Photographic Paper for illustrations. As with autoradiography images, all processing was done under identical darkroom conditions.

\section{In situ hybridization controls}

Several controls were performed to test the specificity of the in situ hybridization results. First, in situ hybridization studies were performed with a cRNA probe generated to a different region of the rat ORL 1 receptor (transmembrane regions $(\mathrm{II}-\mathrm{VI})$ to determine whether the results obtained were the same as with the more 5'-derived cRNA probe. Second, after 60 minutes in 4\% paraformaldehyde, sections from representative brain regions were incubated in RNase A for 60 minutes at $37^{\circ} \mathrm{C}(200 \mu \mathrm{g} / \mathrm{ml}$ RNase A and $0.5 \mathrm{M} \mathrm{NaCl}$ in $100 \mathrm{mM}$ Tris, pH 8.0) before treatment with proteinase $\mathrm{K}$. They were then run through the entire hybridization procedure with ${ }^{35}$ S-labeled CRNA as described above. Third, a separate set of adjacent, represen- 
tativebrain regions were run through the entire hybridization procedure as described above with the exception that a ${ }^{35}$ S-labeled mRNA (sense strand) was used for the hybridization. Other than the alterations described above (RNase A and sense controls), all control tissues were treated identically, and run along side adjacent sections under normal conditions for comparison.

\section{RE SULTS In situ hybridization controls}

In situ hybridization that used two cRNA probes generated against different regions of the orphanin $\mathrm{FQ}$ receptor produced the same mRNA localization at all levels of the neuroaxis. Compare, for example, the in situ hybridization image generated by using a cRNA directed against the $5^{\prime} \cup T$, including 611 bases in the protein coding region ( $\mathrm{Fig}$. $1 \mathrm{~A})$, to that produced with a CRNA probe directed to transmembrane 3-6 of the orphanin FQ receptor (F ig. 1C). The ORL 1 receptor $M R N A$ distributions are indistinguishable, regardless of the cRNA probe used. In the remaining figures, the 5'UT cRNA probe was used for comparisons to orphanin FQ receptor binding. Virtually no mRNAexpressing cells were detected in tissues hybridized with a ${ }^{35} \mathrm{~S}$-labeled mRNA (sense strand) directed to the 5'UT or the transmembrane 3-6 portion of the ORL1 CDNA sequence. Messenger RNA levels in these tissues were negligible in all levels of the brain and spinal cord, with the only exceptions being the cerebellar lobules and area CA1 of Ammon's horn, where labeling was nonspecific and unreliable (Fig. 1A,B). In addition, no mRNA expression was detected in tissues pretreated with RNase $A$ before in situ hybridization by using ${ }^{35} \mathrm{~S}-$-labeled CRNA directed to the 5'UT or the transmembrane 3-6 portion of the ORL 1 cDNA sequence. Similar to the sense strand control, these tissues contained no mRNA-expressing cells at all levels studied (Fig. 1C,D). Taken together, the results suggest that the mRNA distribution that follows represents specific hybridization to orphanin $\mathrm{FQ}$ receptor $\mathrm{mRNA}$.

\section{Pharmacologic characterization of receptor binding}

Under the receptor autoradiographic conditions used in the present study, only OF $Q_{(1-17)}$ peptide had high affinity (IC50 $=0.39 \mathrm{nM})$ for the orphanin receptor binding site (Table 1). Specific binding by ${ }^{125}$-[ ${ }^{14}$ Tyr]-OF Q represents greater than $85 \%$ of total binding, as measured by liquid scintillation spectrophotometry (Fig. 2). Prototypical $\mu$ (morphine), $\delta$ (DPDPE, DADLE), or $\kappa$ (bremazocine, U69,593) agonists failed to compete for the orphanin receptor sites, even at a $10 \mu \mathrm{M}$ concentration. Similarly, the opiate antagonist naloxone and the endogenous peptide $\beta$-endorphin $(1-31)$, failed to displace OFQ binding, suggesting that the orphanin peptide is not labeling $a$ classic opioid binding site. These findings are consistent with homogenate binding studies by using ${ }^{125} \mathrm{I}-\left[{ }^{14} \mathrm{Tyr}\right]-$ OFQ (Ardati et al., 1997) and suggest that this ligand selectively labels ORL 1 binding sites under the autoradiographic conditions used in this study.

In situ hybridization controls and OFQ binding data demonstrated high specificity of the ${ }^{35} \mathrm{~S}$-labeled ORL 1 receptor riboprobes and ${ }^{125}$-[14Tyr]-OFQ peptide used in this study. Results demonstrate that the orphanin FQ receptor is diffusely distributed throughout the rat brain and spinal cord. Orphanin receptor binding and mRNA distributions vary markedly from previously reported $\mu, \delta$, and $\kappa$ receptor localization (Mansour et al., 1995b), suggesting the labeling of a unique mRNA and binding site. The anatomic distribution that follows is qualitative and designed to provide an overview of the distribution of ORL 1 mRNA (Figs. 3-5) and the orphanin F Q binding sites (Figs. 6-10) in the brain and spinal cord. Anatomic descriptions and nomenclature primarily are based on those described for the rat CNS by Paxinos and Watson (1997). Descriptive anatomy of some CNS structures relies on previous nomenclature (Paxinos and Watson, 1986), particularly the neocortex and several ventral mesencephalic structures. Such areas are noted in the descriptive text. A detailed summary of the distribution of ORL 1 mRNA and ${ }^{125}$-[14Tyr]OFQ binding throughout the rat CNS is also provided (Table 2).

\section{Cortex}

In situ hybridization. Orphanin FQ receptor mRNA expression is very dense in the neocortex throughout its rostral to caudal extent. Cells containing ORL 1 mRNA are dense in layers II , IV, and VI, most numerous in layer IV. Based on neocortical nomenclature by Paxinos and Watson (1986), mRNA expression is slightly decreased in the parietal and temporal cortices, compared with high expression levels in the frontal and occipital regions. In all neocortical regions, mRNA expression is negligible to sparse in layer V, and only slightly higher in layer II. No mRNA expression is observed in layer I of the neocortex or in the corpus callosum.

In other cortical regions, mRNA expression is also high. Rostrally, the olfactory bulb contains low to sparse mRNA expression in the mitral cell layer, extending into the external anterior olfactory nucleus. No ORL1 message expression is noted in other olfactory bulb layers. Moderate mRNA expression is seen in the medial, lateral, and ventral orbital cortices, highest in layer II. In general, prefrontal cortical regions contain high mRNA expression. Rostrally, ORL mRNA expression is low to moderate in the infralimbic and dorsal peduncular cortical regions, persisting into the ventral tenia tecta. Message expression in the cingulate cortex is high and generally denser in area 1 than in areas 2 and 3. Cingulate ORL 1-containing cells are greatest in layers III and IV, slightly less in layer and II and undetectable in layer I (Figs. 3A, 6D). This high mRNA expression persists caudally into the retrosplenial cortices, remaining high in layers II and IV of both the granular and agranular parts (Figs. 3D, 6A). In the insular cortex, mRNA expression is high in both the granular and agranular parts, heaviest in layers II and IV. In the piriform cortex, mRNA expression is generally dense. No mRNA expression is observed in layer I, and only sparse expression is seen in layer II. Moderate mRNA expression in rostral layer III increases caudally to become high (Figs. $3 A, 6 B, D)$. In the entorhinal cortex, mRNA expression is high in layers II , IV, V, and VI (Figs. 4B,C).

Orphanin $\mathbf{F} \mathbf{Q}$ binding. Orphanin receptor binding is robust throughout the neocortex, most dense in more caudal regions. Binding is observed throughout the frontal cortex, dense in layer IV, moderate in layer VI, and low in the remaining layers. Labeling in the parietal cortex is similar, but markedly diminished in layers IV and VI (Figs. 6A,C, 7A). In the temporal cortex, orphanin binding is the weakest of all neocortical regions, but still dense. No 


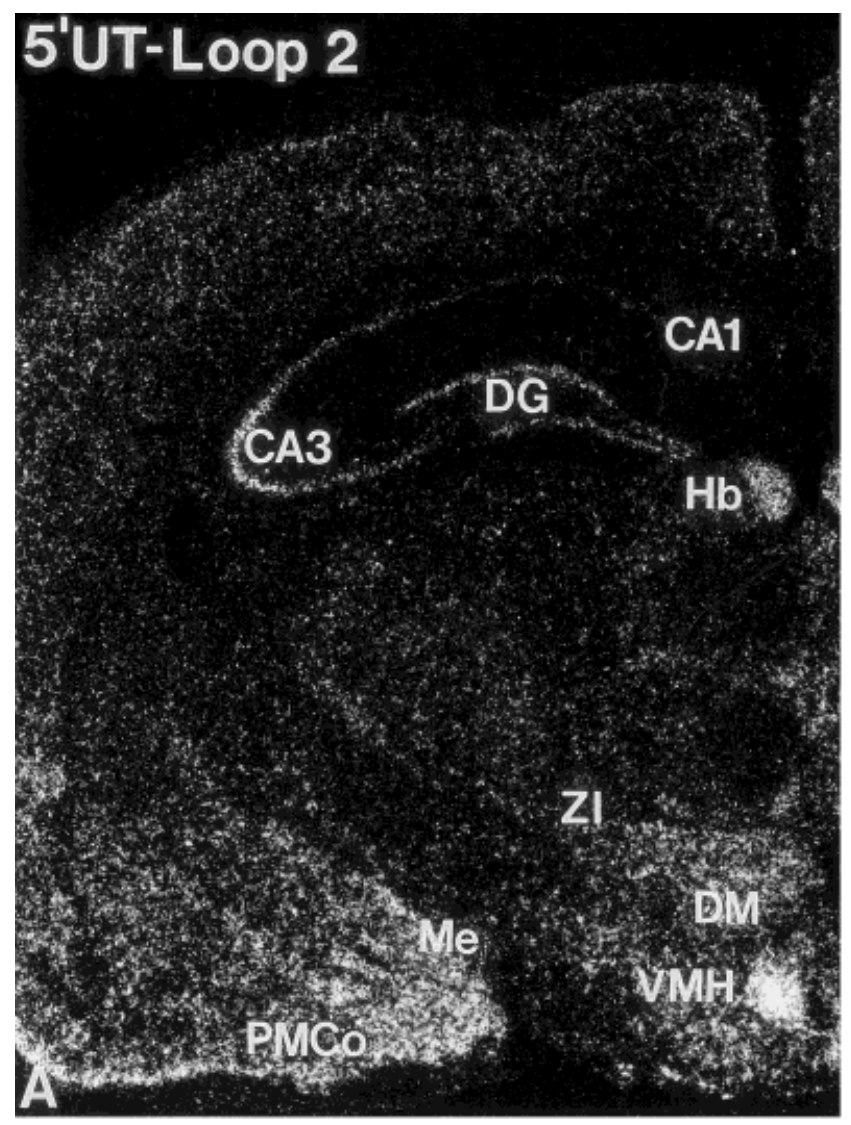

Sense

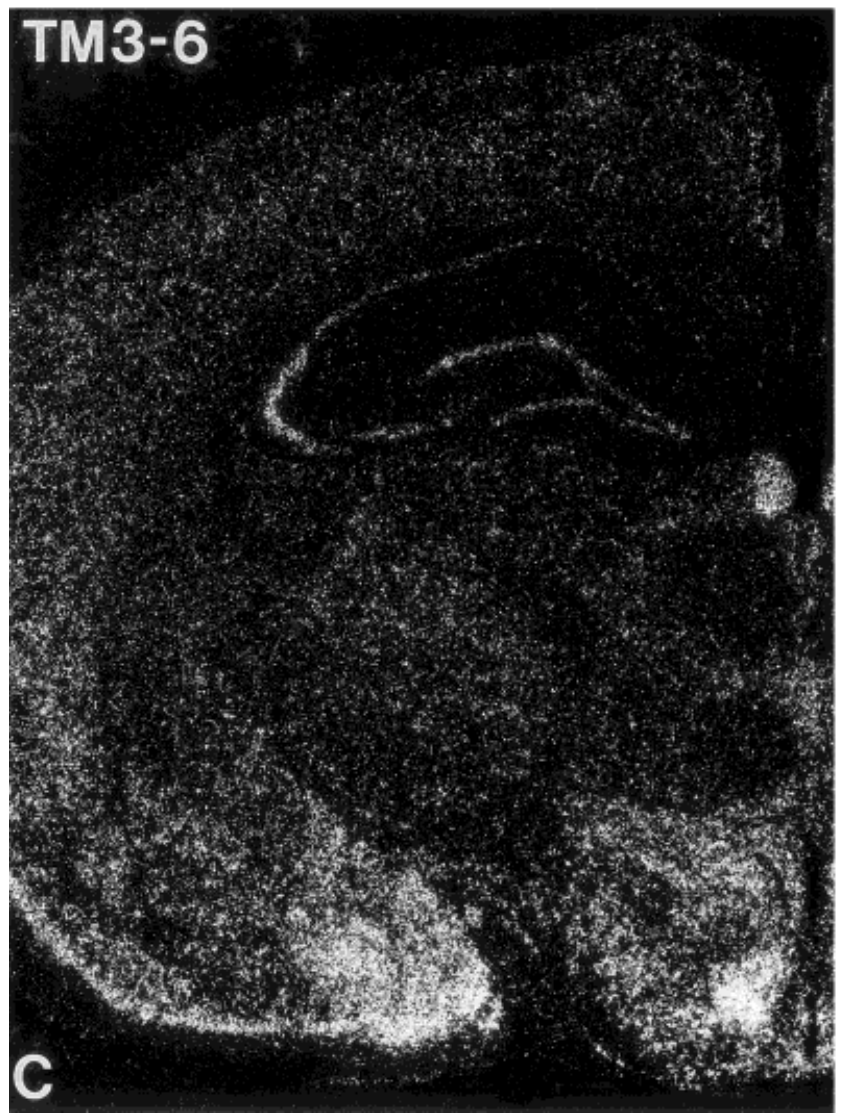

RNase

Fig. 1. Darkfield images of in situ hybridization controls. A: Orphanin FQ receptor mRNA expression obtained after hybridization with a ${ }^{35} \mathrm{~S}$-labeled cRNA (antisense strand) generated against the 5'UT portion of the ORL1 sequence. B: Labeling is absent in an adjacent section hybridized with a ${ }^{35}$ S-labeled mRNA (sense strand) generated against the same region of the orphanin receptor. Note

nonspecific labeling in area CA1 of Ammon's horn. C: Orphanin FQ receptor mRNA expression obtained after hybridization with a ${ }^{35} \mathrm{~S}-$ label ed riboprobe generated against the transmembrane 3-6 region of the ORL1 sequence. D: Labeling is absent in an adjacent section treated with RNase A before in situ hybridization. For abbreviations, see list. Scale bar $=500 \mu \mathrm{m}$ in D (applies to A-D). 
TABLE 1. Orphanin Receptor Competition Studies ${ }^{1}$

\begin{tabular}{lc}
\hline Morphine & $>10,000$ \\
Naloxone & $>10,000$ \\
Bremazocine & $>10,000$ \\
U69,593 & $>10,000$ \\
DADLE & $>10,000$ \\
DPDPE & $>10,000$ \\
$\beta$-Endorphin & $>10,000$ \\
Orphanin Fi-31) & 0.39 \\
\hline
\end{tabular}

${ }^{1}$ Results of competition studies $\left(\mathrm{IC}_{50} \mathrm{nM}\right)$ comparing affinity of several opi oid compounds to that of orphanin $\mathrm{FQ}$ peptide at the orphanin receptor. None of the opioid agonists or antagonists tested were able to compete for the orphanin receptor binding site Prototypical $\mu$ (morphine), $\delta$ (DPDPE, DADLE), or к (bremazocine, U69,593) agonists failed to compete for the orphanin receptor sites, even at a $10 \mu \mathrm{M}$ concentration. Similarly the opiate antagonist naloxone and the endogenous peptide $\beta$-endorphin failed to displace binding. In contrast, orphanin $F Q_{11}$ peptide had high failed to displace binding. In contrast, orphanin $\mathrm{FQ}_{(1-17)}$ peptide had high affinity
$\left(\mathrm{IC}_{50}=0.39 \mathrm{nM}\right)$ for the orphanin receptor binding site.

labeling is observed in layer I, and moderate binding is seen in layers II, III, and IV (Fig. 8A,C). Binding in temporal layers $\mathrm{V}$ and $\mathrm{VI}$ is moderate and becomes dense in the occipital cortex. Orphanin binding in the occipital cortex is low to moderate in layers I-IV, and dense in layers $\mathrm{V}$ and $\mathrm{VI}$, persisting to the occipital pole (Fig. 8C). No binding is observed in the corpus callosum.

In other cortical regions, the rostral olfactory bulb contains dense binding in the glomerular layer, with binding low to moderate in the mitral cell layer. Orphanin binding is negl igiblein the remainder of the olfactory bulb. Moderate binding is observed in the medial, lateral, and ventral orbital cortices, primarily in superficial layers. In the prefrontal cortical region, moderate binding is observed in the infralimbic and dorsal peduncular cortices, densest in layers $\mathrm{V}$ and $\mathrm{VI}$. The adjacent ventral tenia tecta contains only sparse labeling in layers I and III, with no binding in layer II. Orphanin binding in the cingulate cortex is the densest of all cortical regions (Figs. 6A, C, 7A). Dense binding is observed in deeper layers and densest in cingulate area 1 . This pattern persists caudally, slightly increasing into the retrosplenial cortices, where dense binding is observed in the deeper layers of both the granular and agranular parts (Fig. 7C). In the piriform cortex, orphanin binding is negligible in layer I, moderate in layer II, and dense in layer III, persisting to its caudal extent (Fig. 6A). Binding in the agranular and granular insular cortex is moderate to dense, densest in layers II, $\mathrm{III}$, and $\mathrm{VI}$. In the entorhinal cortex, orphanin binding is low in layers I and IV and moderate in layers $\mathrm{V}$ and $\mathrm{VI}$ (Fig. 8A,C).

\section{Ventral forebrain}

In situ hybridization. Orphanin FQ receptor mRNA expression is generally low throughout the ventral forebrain region. Rostrally, ORL 1 mRNA expression is sparse in the external anterior olfactory nucleus, and remains low in the medial ventral and lateral parts. Message expression becomes moderate in its dorsal part, and this pattern persists to its caudal extent. The posterior division contains low mRNA expression. There are no mRNA-containing neurons observed in the rostral pole of nucleus accumbens. As accumbens differentiates into core and shell components, scattered neurons with sparse mRN A expression are observed in the accumbens shell throughout its rostral to caudal extent, with fewer mRNA-containing neurons in accumbens core (Fig. 6B). The olfactory tubercle contains no mRNA expression in layer $\mathrm{I}$, sparse labeling in the pyramidal layer (layer II) and low labeling scattered throughout the polymorph layer (layer III).
Medial to the accumbens shell, the islands of Calleja, including the major island, are devoid of mRNA expression. At the level of the diagonal band, mRNA-expressing cells extending from the medial septum are lightly scattered in the ventral diagonal band and ventral pallidum (Fig. 3A). Caudally, a moderate number of ORL 1-containing neurons are observed in the horizontal diagonal band (Fig. 3A,B). Messenger RNA expression is sparse to low in the interstitial nucleus of the posterior limb of the anterior commissure, and the substantia innominata.

Orphanin FQ binding. In contrast to ORL 1 mRNA expression, orphanin binding is quite dense throughout the ventral forebrain. Throughout the anterior olfactory nudeus OFQ binding is dense. Rostrally, binding is dense in the external division, mostly in its dorsal part. Throughout the remainder of the nucleus, binding is dense in the ventral division, moderate in the dorsal and lateral divisions, and low to moderate in the posterior division. At the emergence of nucleus accumbens, the olfactory tubercle contains moderate to dense binding, primarily in the plexiform layer (Fig. 6A,C). No binding is observed in the islands of Calleja. At the level of the rostral nucleus accumbens, low binding is observed in small patches in the accumbens core, persisting throughout (Fig. 6A). In the accumbens shell, binding increases slightly, becoming moderate at caudal levels. J ust caudal to nucleus accumbens, binding becomes moderate, filling the interstitial nucleus of the posterior limb of the anterior commissure. Low binding is observed throughout the vertical limb of the diagonal band, with moderate binding in the horizontal limb of the diagonal band. The substantia innominata contains negligible binding rostrally, adjacent to the horizontal diagonal band, and dense binding further caudal at the level of the amygdala.

\section{Septum}

In situ hybridization. Orphanin receptor mRNA expression in this region is moderate to dense. Rostrally, moderate expression is observed in the intermediate lateral septum, with moderate to dense mRNA expression in its ventral part (Figs. 3A,B, 6D). At this level, mRNA expression extends medially from the intermediate and dorsal lateral septum into the septohippocampal nucleus, where it becomes high. The dorsal lateral septum contains moderate mRNA expression throughout its rostral to caudal extent. The medial septum contains a moderate number of mRNA-expressing neurons, with low expression in the adjacent lambdoid septal zone and sparse, scattered mRNA-expressing neurons in the paralambdoid septal nucleus. Caudal to the medial septum, the septofimbrial nucleus and dorsal fornix are devoid of mRNA expression. A population of ORL1-containing neurons in the caudal part of the ventral lateral septal nucleus extends ventromedially to the crossing of the anterior commissure. This ventromedial cell group (previously described as the septohypothalamic nucleus by Paxinos and Watson, 1986) contains moderate mRNA expression.

Orphanin FQ binding. Similar to ORL 1 mRNA expression, orphanin binding in the lateral septum is also moderate. Adjacent to the caudal dorsal peduncular cortex, the dorsal tenia tecta contains moderate binding. At this rostral level, the ventral lateral septal nucleus contains only sparse binding and the intermediate lateral septum is devoid of binding. Further caudal, the septohippocampal nucleus emerges with low binding, and binding 


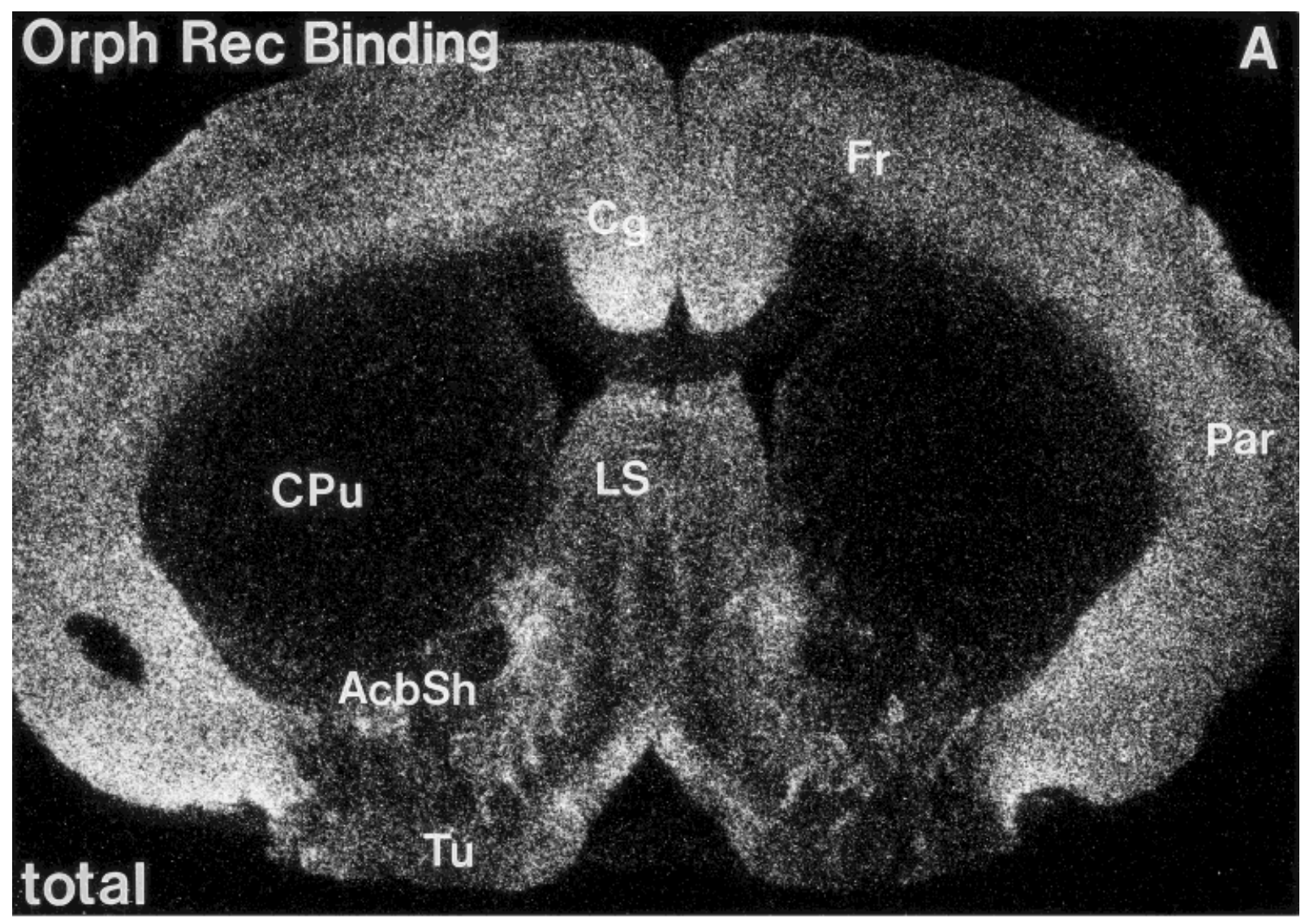

\section{nonspecific}

Fig. 2. A: Darkfield image of orphanin FQ receptor binding obtained in the rostral forebrain by using ${ }^{125}$-[14Tyr]-OFQ as the radioligand. B: Addition of a saturating concentration of unlabeled
OFO to the ${ }^{125}$-[14Tyr]-OFO receptor binding assay generates negligible nonspecific labeling. For abbreviations, see list. Scale bar $=500$ $\mu \mathrm{m}$ in B (applies to A,B) 

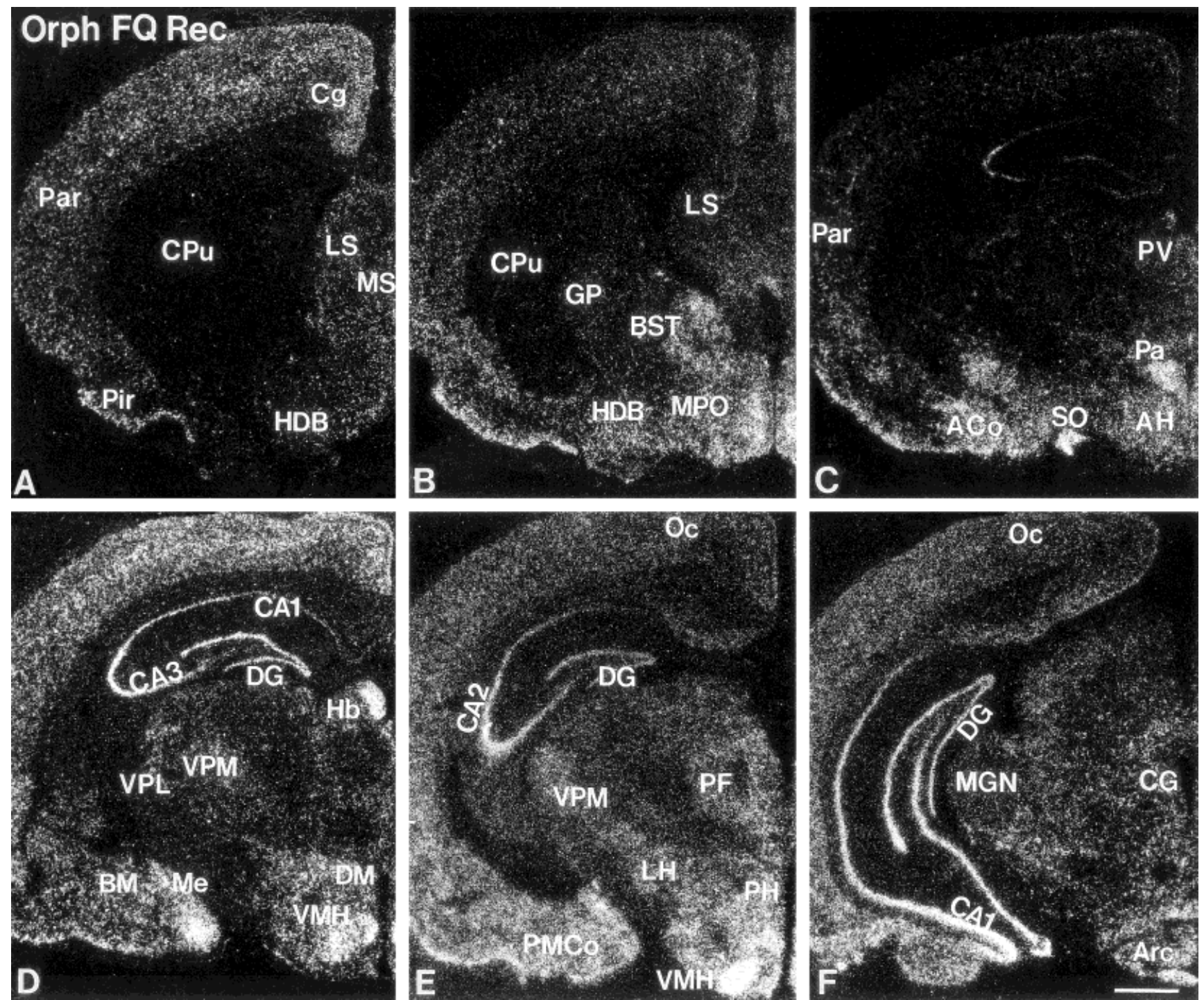

Fig. 3. A-F: Darkfield autoradiograms of orphanin FQ receptor mRNA distribution in representative coronal sections through the forebrain. For abbreviations, seelist. Scalebar $=500 \mu \mathrm{m}$ in F (applies to A-F).

in the dorsal lateral septal nucleus is moderate. At this level, low to moderate binding is observed in the ventral lateral septal nucleus, with sparse binding in the intermediate part (Fig. 6A,C). This pattern persists to the caudal extent of the lateral septal complex. In the medial septum, orphanin binding is also low, with only sparse binding in the adjacent lambdoid nucleus, and no binding in the paralambdoid nucleus. Low to moderate binding is observed in the region of the septofimbrial nucleus. The region corresponding to the septohypothalamic nucleus is devoid of OF Q binding.

\section{Basal ganglia}

In situ hybridization. At the level of the caudal anterior olfactory nucleus, the dorsal endopiriform nucleus emerges with moderate ORL1 mRNA expression. This pattern persists to the level of the preoptic region, where mRNA expression is highest in both this nucleus and the ventral endopiriform nucleus (Fig. 3A,B). High mRNA expression persists in both nuclei to their caudal extent. In the rostral forebrain, mRNA expression is low in the claustrum, with ORL1-containing neurons scattered throughout this structure at all levels. The striatum contains even fewer mRNA-expressing cells, with negligible to sparse mRNA expression throughout its extent (Figs. 3A,B,C, 6B,D). Sporadic mRNA-containing neurons that are observed in this structure are confined to the dorsolateral part.

In marked contrast to the paucity of mRNA expression in the striatum, large neurons with abundant mRNA expression are scattered throughout the globus pallidus (Fig. 3B). Although few to moderate in number, these neurons are large and contain abundant mRNA signal intensity. This expression pattern persists to the caudal extent of the globus pallidus. Adjacent to the globus pallidus, mRNA expression in the basal nucleus of Meynert is moderate to high and in the entopeduncular nucleus mRNA expression is low. In the caudal forebrain, 

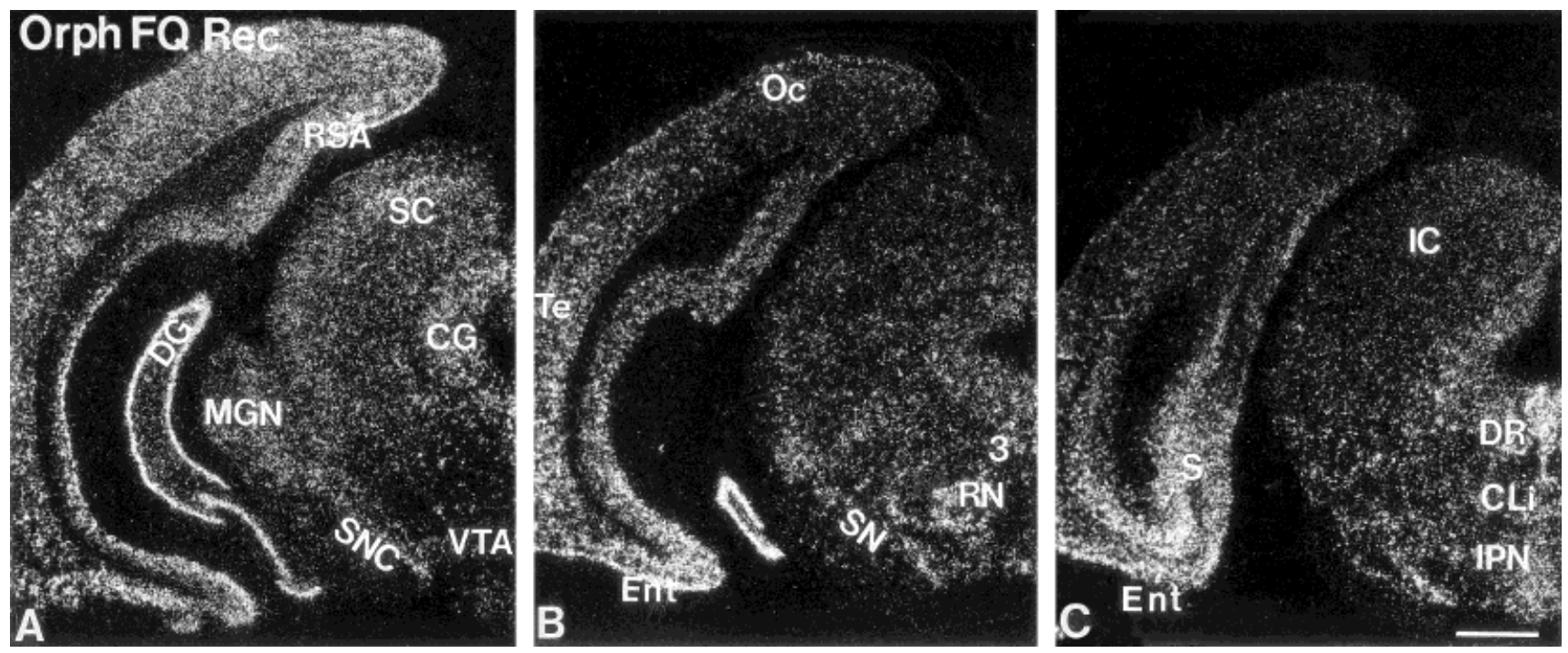

Fig. 4. A-C: Darkfield autoradiograms of orphanin $F Q$ receptor mRNA distribution in representative coronal sections through the mesencephalon. For abbreviations, see list. Scale bar $=500 \mu \mathrm{m}$ in C (applies to $A-C)$.

the subthalamic nucleus contains a moderate number of ORL 1-containing neurons. At this level, mRNA expression is low to moderate in the substantia nigra, pars reticulata, with large ORL 1-containing neurons scattered throughout this region (Fig. 8B). Messenger RNA expression increases significantly in pars compacta, where numerous cells with high mRNA expression are noted, most heavily in its ventromedial aspects (Figs. 4A,B, 8D). In the dorsal pars compacta, ORL 1 expression abates somewhat, with low mRNA expression observed in pars lateralis.

Orphanin $\mathbf{F} \mathbf{Q}$ binding. At the emergence of the dorsal endopi riform nucleus, dense orphanin binding is observed. Receptor binding fills the nucleus and persists to its caudal extent. The ventral endopiriform nucleus contains sparse to low levels of binding throughout (Fig. 6A). The claustrum emerges adjacent to the dorsal endopiriform nucleus in the rostral forebrain with dense binding that persists throughout this structure. In contrast to the claustrum, binding in the caudate-putamen is generally negligible, except for occasional sparse patches of binding located dorsomedially, adjacent to thelateral ventricle (Fig. 6A,C). At the emergence of the globus pallidus moderate binding is observed in a diffuse, reticular pattern throughout the nucleus. At the level of the caudal globus pallidus, the basal nucleus of Meynert and entopeduncular nucleus are devoid of OF Q binding. In the caudal forebrain, there are low levels of binding in the subthalamic nucleus. This pattern persists caudally into the substantia nigra, pars reticulata, where moderate to heavy OFQ binding is observed in its rostral half (Fig. 8A). Orphanin binding decreases to become sparse in the caudal part of pars reticulata. Pars compacta contains moderate binding throughout (Fig. 8C), extending into pars lateralis, where orphanin binding is very low.

\section{Basal telencephalon}

In situ hybridization. At the level of the crossing of the anterior commissure, high mRNA expression is observed in the median preoptic nucleus (Fig. 3B). Orphanin receptor-expressing cells extend from this nucleus ven- trally intothe periventricular hypothalamic nucleus, where moderate mRNA expression is observed. Dense mRNA expression is also observed ventrally in the anteromedial preoptic nucleus. The anteroventral preoptic nucleus contains a moderate number of mRNA-expressing neurons at this level, extending into the adjacent horizontal limb of the diagonal band. Within the medial preoptic area, mRNA expression is moderate and diffuse, with more numerous mRNA-expressing neurons in its ventral part. In the lateral preoptic area, mRNA expression is moderate in its more medial portion, and sparse to low laterally. Adjacent to the horizontal diagonal band, the magnocellular preoptic nucleus contains scattered neurons with low mRNA expression. Caudally, the medial preoptic nucleus contains moderate mRNA expression, becoming dense in its ventral part and sparse to low in its central part (Fig. 3B). At the caudal boundary of the preoptic region, sparse to low mRNA expression is observed in layers I and III of the nucleus of the lateral olfactory tract. In contrast, high mRNA expression is observed diffusely throughout layer II of this nucleus, to its caudal extent.

The bed nucleus of the stria terminalis has a varied mRNA expression pattern but is predominantly dense (Fig. 3B). In the rostral pole of the bed nucleus, scattered neurons are observed with sparse mRNA expression. At this level, sparse expression is noted in the lateral division and low mRNA expression in the ventral division. At the level of the anterior commissure crossing, theanterior part of the medial division contains low mRNA expression, with a moderate number of mRNA-expressing cells observed in the dorsal part of the lateral division. No mRNA expression is observed in the juxtacapsular part of the lateral division, adjacent to the internal capsule. The ventral division and ventral part of the lateral division contain only scattered mRNA-expressing cells. At the level of the rostral thalamus, mRNA expression becomes high, primarily in the posterior parts of the medial and lateral divisions. High mRNA expression is observed in the posteromedial and posterolateral parts of the medial division and in the posterior part of the lateral division. 

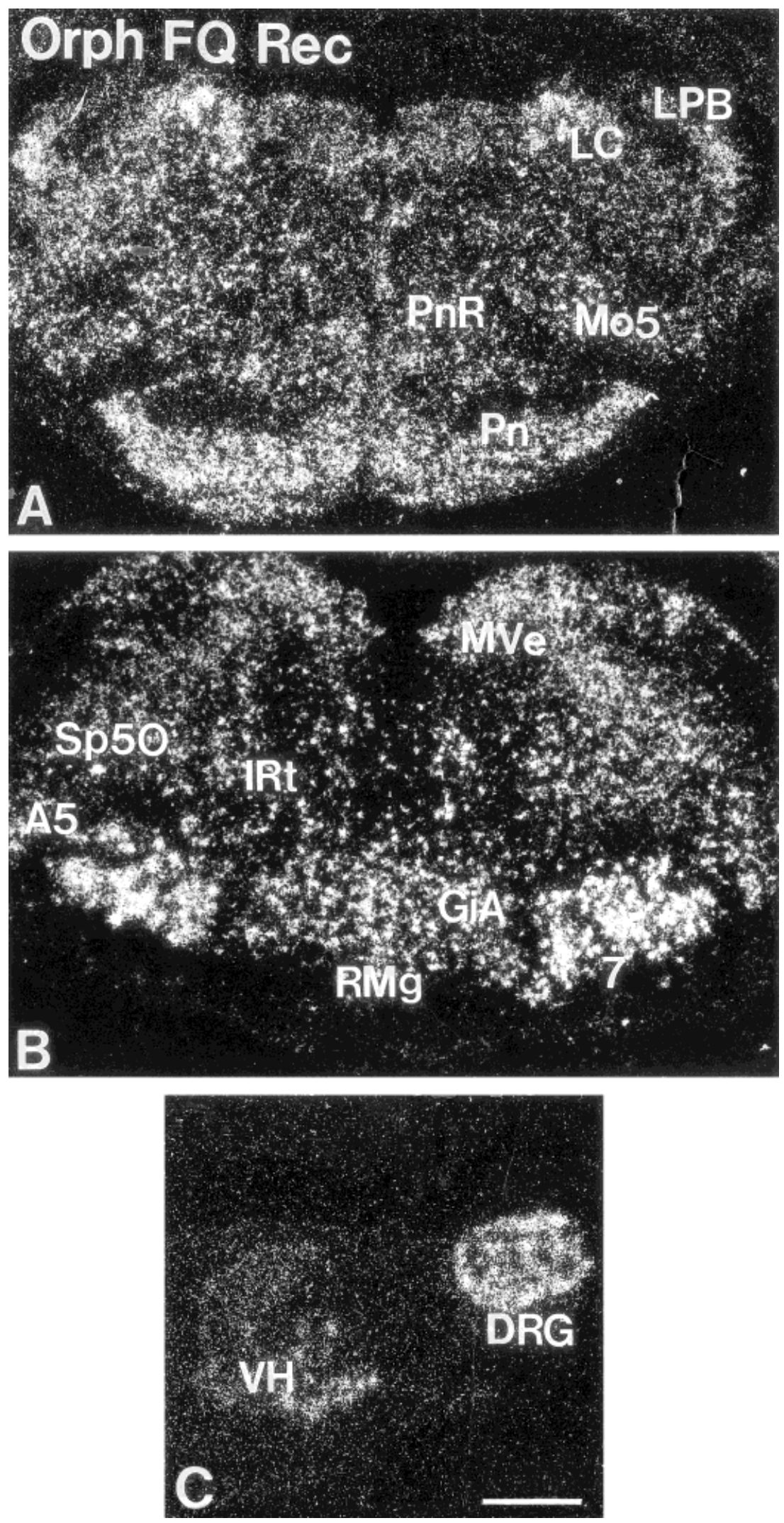

Fig. 5. A-C: Darkfield autoradiograms of orphanin $\mathrm{FQ}$ receptor $\mathrm{mRNA}$ distribution in repre sentative coronal sections at the level of the metencephal on, myelencephal on and spinal cord including the dorsal root ganglion. For abbreviations, see list. Scale bar $=500 \mu \mathrm{m}$ in A (applies to A-C).

Orphanin FQ binding. Compared with ORL1 mRNA expression, binding in the basal telencephal on is low. At the emergence of the rostral preoptic region, OF Q binding is negligible. At this level, the periventricular hypothalamic nucleus is also devoid of binding. Labeling increases in intensity caudally, becoming low to moderate in the 


\section{Orph Rec Binding}
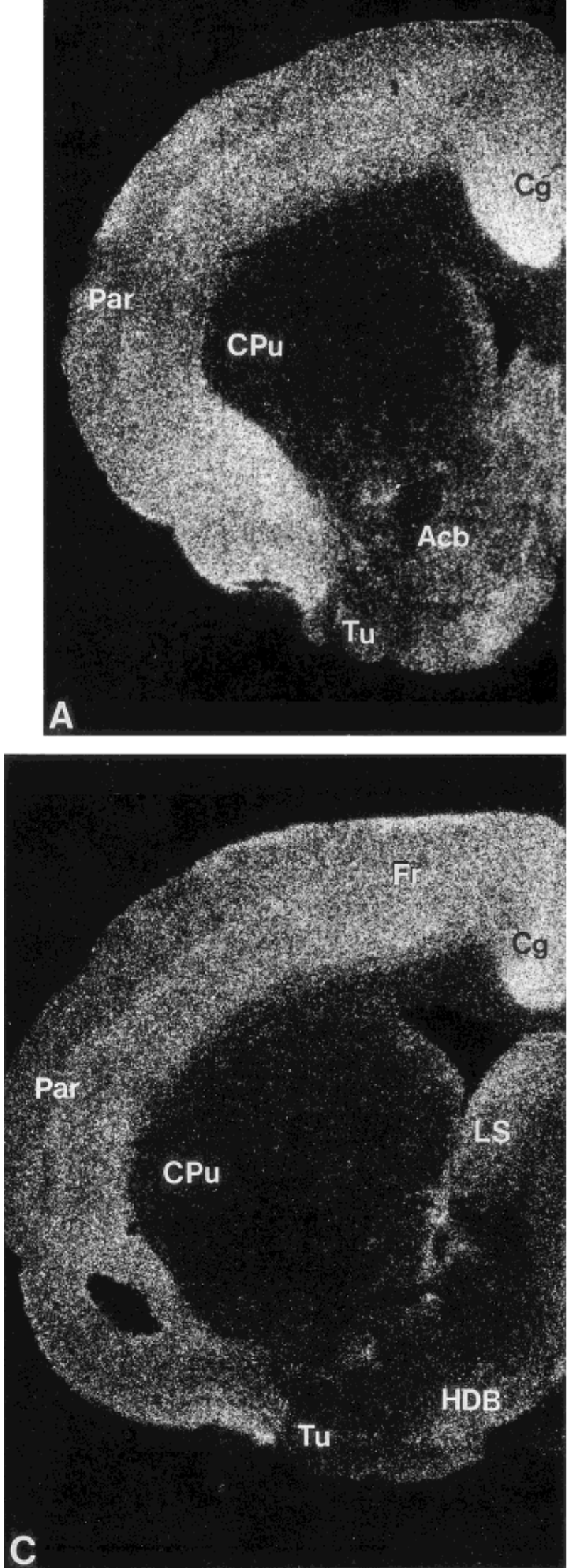
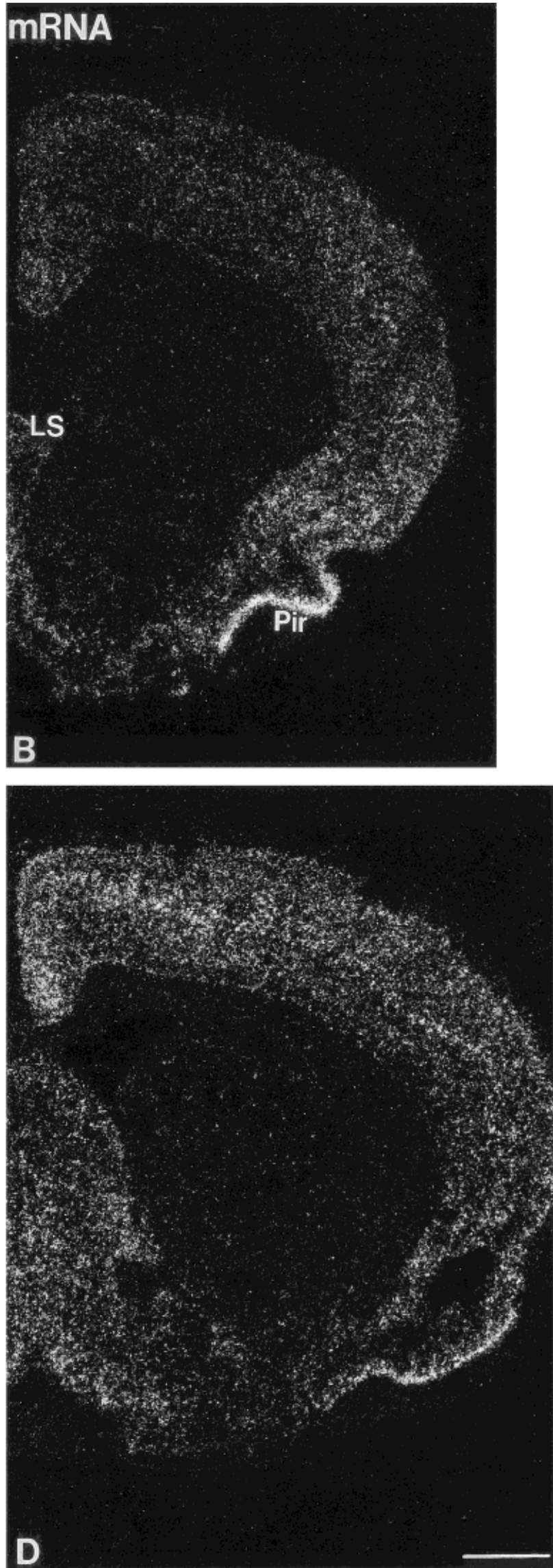

Fig. 6. Darkfield autoradiograms comparing ${ }^{125}$-[14 $\left.{ }^{14} \mathrm{Tr}\right]-\mathrm{OFQ}$ binding $(\mathbf{A}, \mathbf{C})$ and orphanin receptor mRNA expression (B,D) at representative levels of the rostral forebrain. For abbreviations, see list. Scale bar $=500 \mu \mathrm{m}$ in D (applies to A-D). 

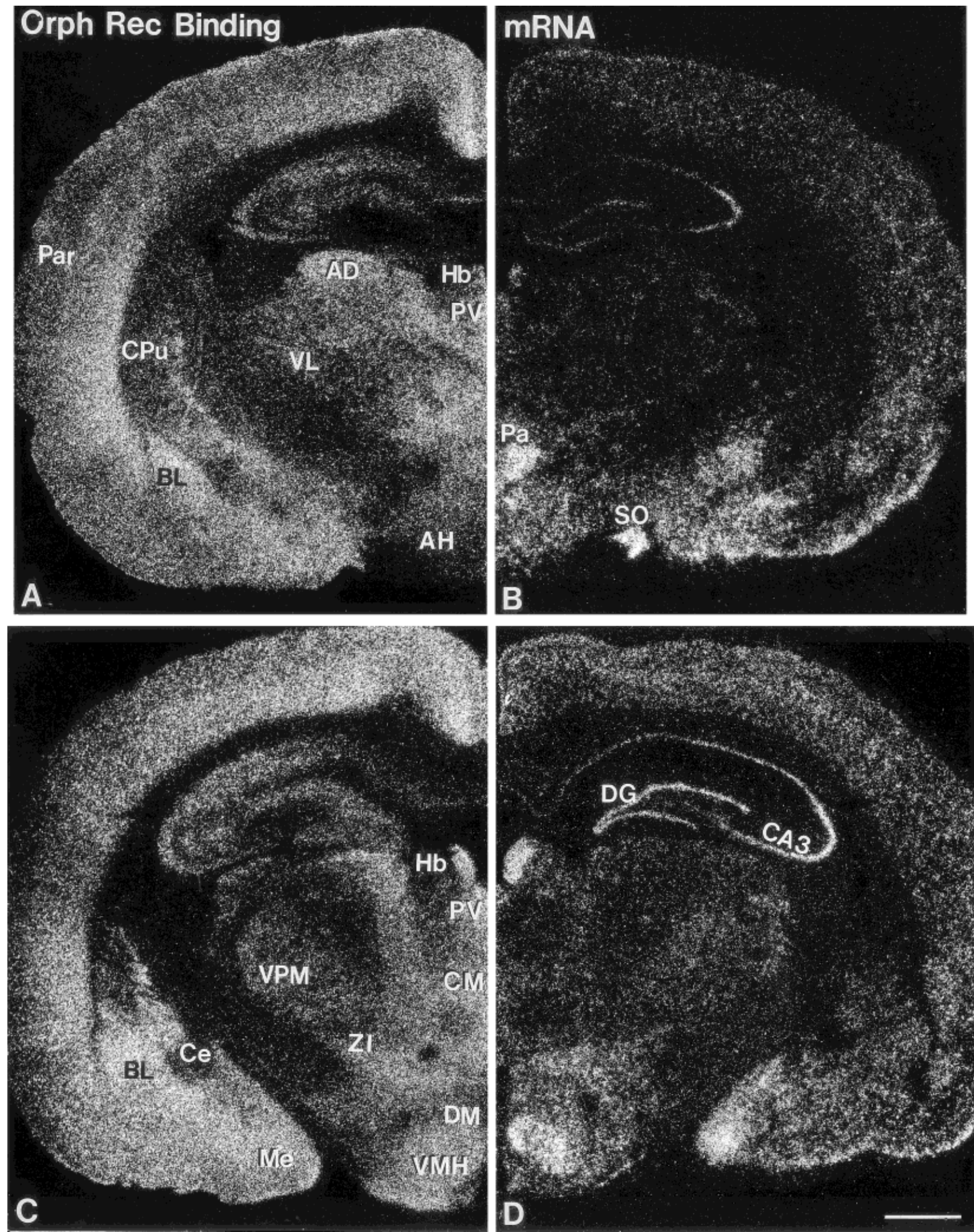

Fig. 7. Darkfield autoradiograms comparing ${ }^{125}$-[ $\left[{ }^{14}\right.$ Tyr]-OFQ binding $(\mathbf{A}, \mathbf{C})$ and orphanin receptor mRNA expression (B,D) at representative levels of the mid-and mid-caudal forebrain. For abbreviations, see list. Scale bar $=500 \mu \mathrm{m}$ in D (applies to A-D). 

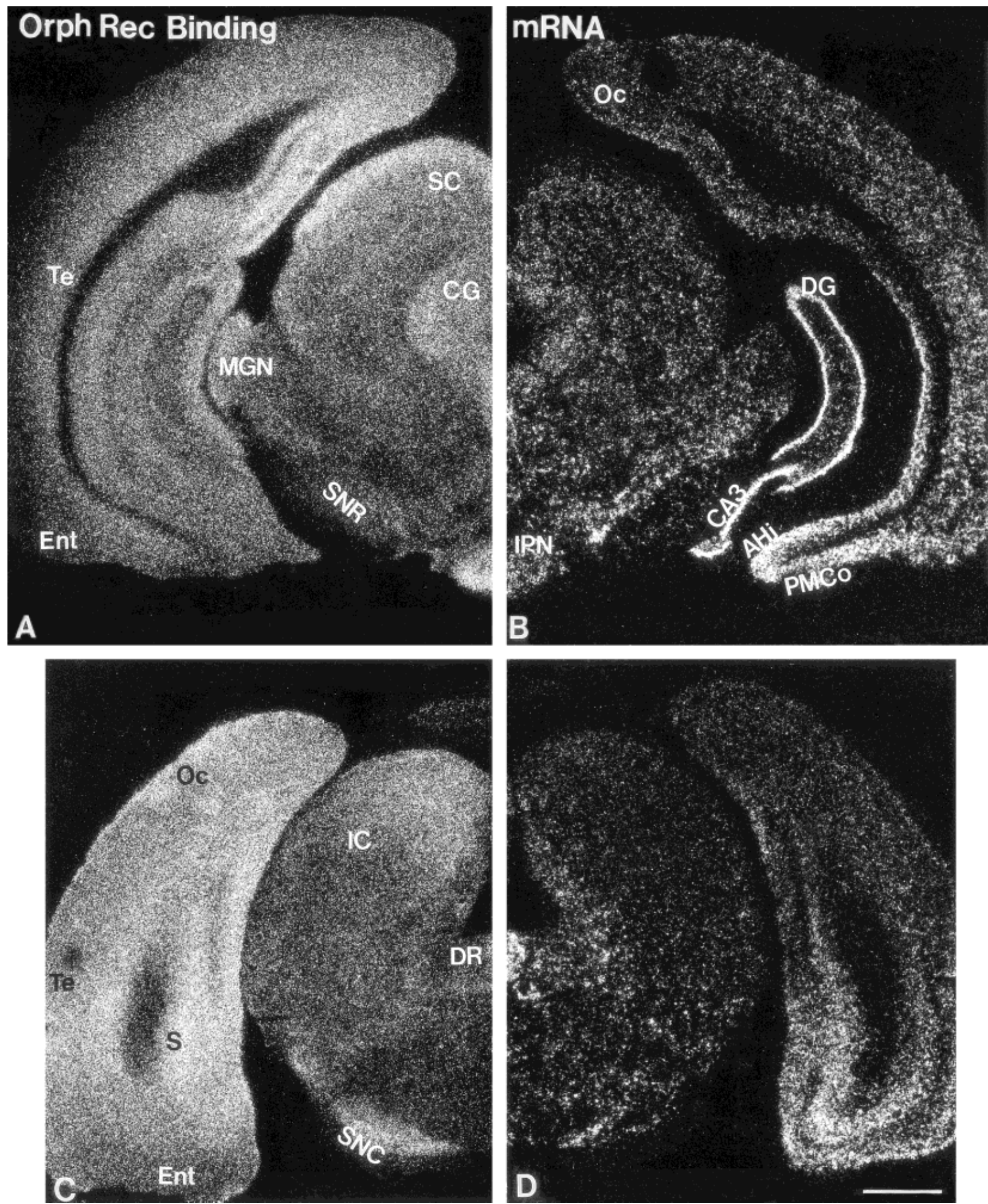

Fig. 8. Darkfield autoradiograms comparing ${ }^{125}$ - $\left[{ }^{14}\right.$ Tyr]-OFQ binding $(\mathbf{A}, \mathbf{C})$ and orphanin receptor mRNA expression (B,D) at representative levels of the midbrain. For abbreviations, see list. Scale bar = $500 \mu \mathrm{m}$ in D (applies to A-D). 

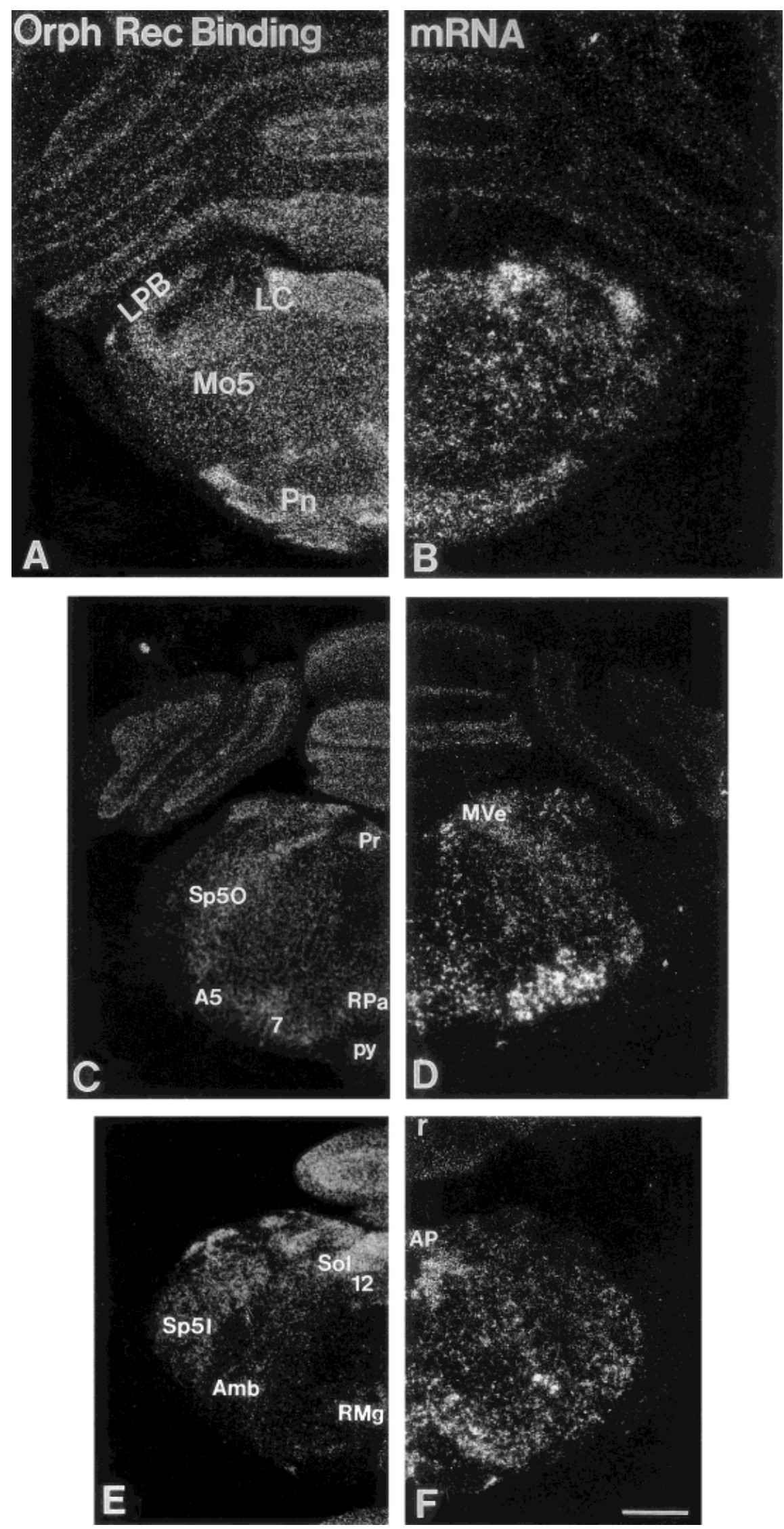

Fig. 9. Darkfiel d autoradiograms comparing ${ }^{125}$ I- [14Tyr]-OF Q binding $(\mathbf{A}, \mathbf{C}, \mathbf{E})$ and orphanin receptor mRNA expression (B,D,F at representative levels of the pons (A-D) and mid-medulla (E, F). Note that, as discussed in the text, all mRNA expression and OF Q binding shown in the cerebellar lobules is nonspecific. For abbreviations, see list. Scale bar $=500 \mu \mathrm{m}$ in $\mathrm{F}$ (applies to $\mathrm{A}-\mathrm{F}$ ). 

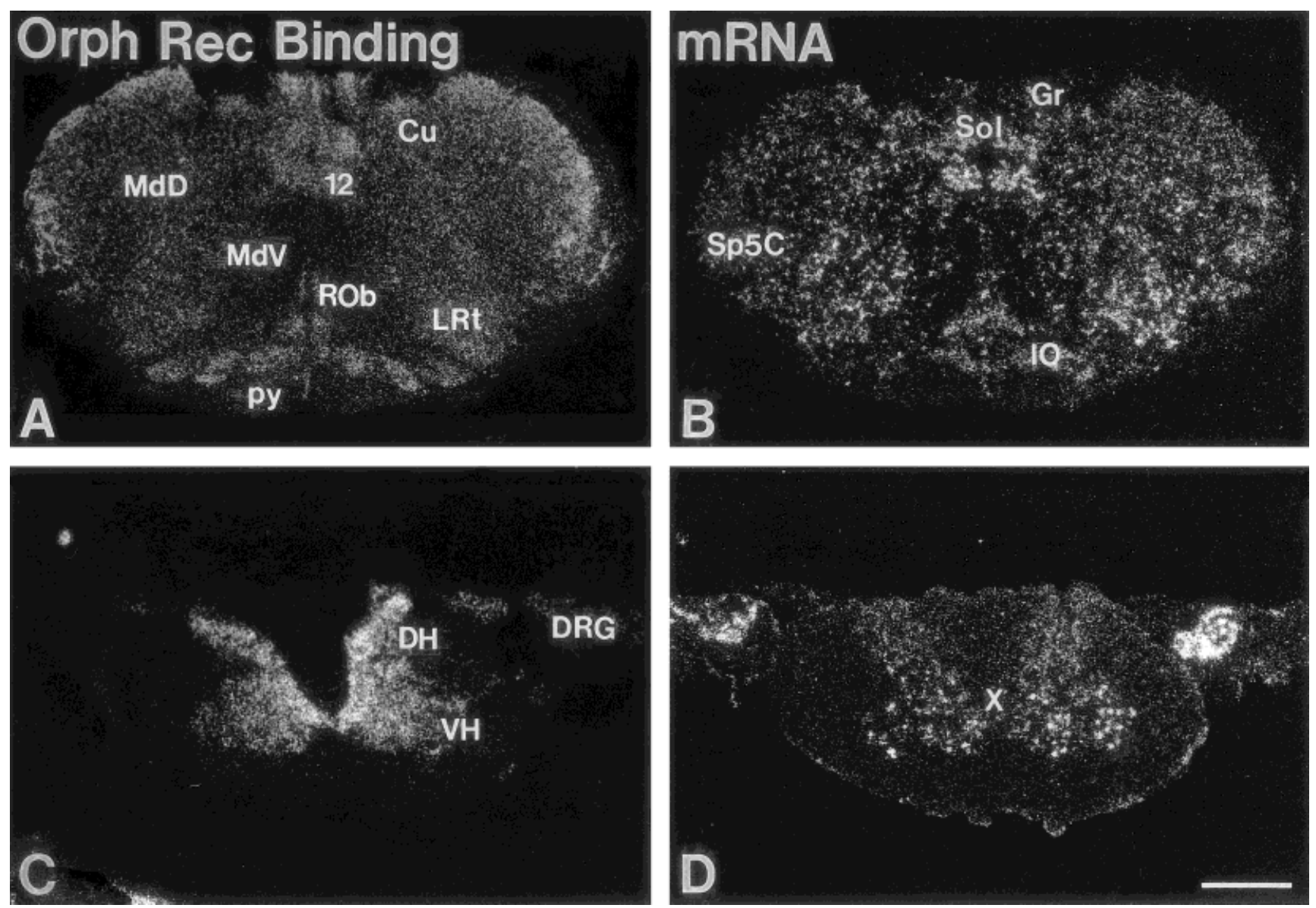

Fig. 10. Darkfield autoradiograms comparing ${ }^{125}$-[14Tyr]-OFQ binding $(\mathbf{A}, \mathbf{C})$ and orphanin receptor mRNA expression (B,D) in the caudal medulla (A,B) and spinal cord with dorsal root ganglion (C,D). For abbreviations, see list. Scale bar $=500 \mu \mathrm{m}$ in D (applies to A-D)

medial preoptic area proper, mostly in its ventral part. The anteromedial preoptic nucleus contains only sparse binding rostrally, low to moderate caudally. Moderate binding is observed throughout the anteroventral preoptic nucleus. Orphanin binding in the median preoptic nucleus is dense throughout, in both its dorsal supracommissural and ventral parts. The lateral preoptic region contains diffuse, low binding at all levels. In the caudal preoptic region, binding remains low to moderate in the ventral medial preoptic area, with negligible binding noted in the medial preoptic nucleus. Binding in the magnocellular preoptic nudeus is low. The nucleus of the lateral olfactory tract contains dense binding. In contrast to the high mRNA expression noted in layer II of this structure, binding is dense in layer I and only low to moderate in layers II and III.

Orphanin binding in the bed nucleus of the stria terminalis is generally moderate. At the most rostral levels of this region, only sparse OFQ binding is noted in the rostral bed nucleus, persisting with only low levels of binding in the adjacent anterior part of the medial division sparse binding is observed in the ventral division. The septohypothalamic nucleus at this level contains low levels of OFQ binding. At the level of the anterior commissure crossing, binding intensity increases in the lateral division of the bed nucleus. Moderate binding is observed in the dorsal and ventral parts of the lateral division. Thejuxtacapsular part of the lateral division is devoid of binding. At the level of the rostral thalamus, the posteromedial part of the medial division and posterior part of the lateral division of the bed nucleus of the stria terminalis are devoid of binding, whereas the posterolateral and posterointermediate parts of the medial division contain moderate to dense binding. This pattern persists to its caudal boundaries.

\section{Hypothalamus}

In situ hybridization. In the hypothalamic region, no mRNA expression is observed in the median eminence. The anterior pituitary, intermediate pituitary, and pineal gland are also devoid of ORL1 mRNA expression. Rostrally, in the ventral part of the hypothalamus, numerous ORL 1-expressing neurons are observed in the supraoptic nudeus (Figs. 3C, 7B). These neurons fill the nucleus throughout its extent. At this level, the suprachiasmatic nucleus contains low mRNA expression, with neurons lightly scattered in a circumferential manner throughout the nucleus. Expression is sparse in the retrochiasmatic region. Further caudal, a sparse number of mRNAexpressing cells is noted in the tuber cinereum, slightly increased in the medial tuberal nucleus. At the emergence of the arcuate nucleus, mRNA expression increases dramatically, becoming high throughout this nucleus. Al- 
TABLE 2. Distribution of ORL 1 mRNA Expression and ${ }^{125}$-[14Tyr]-OFQ Binding in the Central Nervous System of the Adult Male Rat ${ }^{1}$

\begin{tabular}{lcc}
\hline CNS Region & ORL1 mRNA & $\begin{array}{c}125 I-[14 T y r]-O F Q \\
\text { Binding }\end{array}$ \\
\hline
\end{tabular}

Neocortex

Frontal

Layer I

Layer III

Layer IV

Layer V

Parietal

Layer I

Layer II

Layer II

Layer IV

Layer V

Layer $\mathrm{V}$

Temporal

Layer I

Layer II

Layer IV

Layer V

Occipital

Layer I

Layer II

ayer III

Layer IV

Layer V

Other cortical regions

Al

CC
$\mathrm{Cg}$
$\mathrm{DP}$

Ent

EP1

IPI

G1

$\mathrm{GrO}$

IL

$\mathrm{Mi}$

$\mathrm{MO}$
$\mathrm{Pir}$

RSA

RSG

TT

Ventral forebrain

ac

$\mathrm{AcbC}$

AcbS

AOD

AOE

$\mathrm{AOL}$

$A O M$

AOP

AOV

HDB

ICj
IPAC

SI

Tu

VDB

Septum

df

LSD

LSV

MS

PLd

$\mathrm{SH}$

SHy

B

$\mathrm{Cl}$

DEn

SNC

SNL

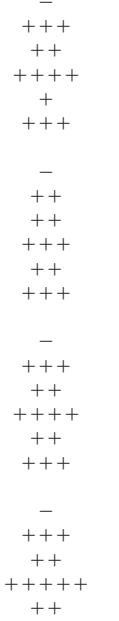

++
+++

$+++$

$+++$

++
++++

$++$

$+$

-

$+$

++
++

+++
++++

$++++$

$++++$

$+++$

$+++$

$+$

+
+++

++
++

++
++

++
++
++

++
+++

$-$

+
+
+

++
++

++
++
++

-
++

+
++
++

++
++
+++

$++$

$+++$

$+$

+++
++

++
+

$+++$

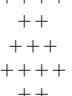

$++$

++
++
$++++$

+++
+++

$-$

-
+++

+
++
+++

$+$

++
+++

+++
++

$+++$

$++++$

+++++
+++++

$++$

++
+++
TABLE 2. (continued)

\begin{tabular}{|c|c|c|}
\hline & & ${ }^{125} \mid-\left[{ }^{14} \mathrm{Tyr}\right]-O F Q$ \\
\hline CNS Region & ORL 1 mRNA & Binding \\
\hline
\end{tabular}

Basal ganglia (continued)

STh
VEn

Basal telencephalon

AMPO

AVPO

BSTI

BST1

BSTlj

BSTlp

BSTIV

BSTma

BSTmpl

BSTmpm

BSTmv

BSTV

LOT

LT

Layer II

Layer III

LPO

$\mathrm{MCPO}$

$\mathrm{MnPO}$

MPA

MPO
MPOC

$\mathrm{Pe}$

Hypothalamus

$\begin{array}{cc}- & \text { AH } \\ +++++ & \text { ArC }\end{array}$

$++\quad \mathrm{Pe}$

$+++\quad \mathrm{PeF}$

$\begin{array}{cc}+++ & \mathrm{PH} \\ ++++ & \mathrm{Pin}\end{array}$

+++ Pit

++++ PMD

$++\quad$ PMV

$+++\quad \mathrm{RCh}$

$\begin{array}{cl}+++ & \mathrm{SCh} \\ - & \mathrm{SO}\end{array}$

$+++\quad$ SOR

$\begin{array}{cc}- & \text { SuM } \\ ++++ & \text { Sumx }\end{array}$

$+++\quad$ TC

+ TM

TMC

VMHC

VMHDM

VMHVL

AAA

ACO

$\mathrm{AHi}$
APir

BAOT

$B L$

BLA

BLP

BM

BMA

BMP

BSTIA
CeL

CeM

CXA
$+++$

$+++$

$+++$

++
+

$+++$

$+++$

++
++

++
+++
++++

$++$

$+$

++
++++

$++$

$++1+++$

$++$

$++++$

+++
++++

$++$

$++$

$++$

$+++$

+
++

$++$

+++
++

$+$

$+++$

$-$

$+++$

$+++$

+++
+++
++

++
+++

$++$

++
+++

$+++$

+
++

-
+
++

++
+

+
+++

$+++$

$+++$

$+$

$+++$

+
+++++

$++++$

$+++++$

$++++$

$+$

++
++

$++$

++
++

$++$

$++$

+++
+++

$++$

$+$

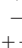

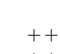

$++$

$++$

$+++$

+++
+++

$+++$

-
+++

$+$

$+$

$++$

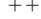

$++$

$++$

++
+++
++

$++$

$+$

$+$

$++$

$-$

$+++$

$-$

$+$

$+$

$++$

$++$

++
++

$+++$

+
+++

$++$

$-$

$+$

++
+++
++

$+$

$++$

$+$ 
ORL1 RECEPTOR DISTRIBUTION IN THE RAT BRAIN

TABLE 2. (continued)

\begin{tabular}{|c|c|c|c|c|c|}
\hline CNS Region & ORL1 mRNA & $\begin{array}{c}\text { 125I-[14Tyr]-OFQ } \\
\text { Binding }\end{array}$ & CNS Region & ORL1 mRNA & $\begin{array}{c}125 \text {-[14Tyr]-OFQ } \\
\text { Binding }\end{array}$ \\
\hline Amygdala (continued) & & & Mesencephalon (continued) & & \\
\hline La & + & ++ & CGD & ++++ & ++++ \\
\hline MeAD & ++ & +++ & cic & - & - \\
\hline MeAV & ++++ & ++ & $\mathrm{CIC}$ & + & + \\
\hline MePD & ++ & - & $\mathrm{CLi}$ & ++++ & +++ \\
\hline MePV & ++++ & +++ & $\mathrm{CnF}$ & - & - \\
\hline opt & - & - & $\mathrm{cp}$ & - & - \\
\hline PLCO & ++ & - & $\csc$ & - & - \\
\hline PMCo & ++ & +++ & $\mathrm{ctg}$ & - & - \\
\hline Hippocampal formation & & & $\mathrm{DCIC}$ & +++ & ++ \\
\hline CAlso & - & + & $\mathrm{Dk}$ & ++ & + \\
\hline CAlsp & $-1+$ & - & dlf & - & - \\
\hline CAlsr & - & - & DLL & ++ & ++ \\
\hline CA2so & ++ & ++ & DpMe & ++ & + \\
\hline CA2sp & ++ & - & DR & +++++ & ++++ \\
\hline $\mathrm{CA} 2 \mathrm{sr}$ & + & + & DTg & - & - \\
\hline CA3s1 & + & ++ & $\mathrm{EClC}$ & ++ & + \\
\hline CA3so & +++ & ++++ & EW & ++++ & ++++ \\
\hline CA3sp & ++++ & - & fr & - & - \\
\hline CA3sr & + & - & IF & ++ & ++ \\
\hline DGgr & ++++ & - & ILL & + & - \\
\hline DGhi & + & - & IMLF & ++ & - \\
\hline DGmo & - & +++ & InCo & ++ & + \\
\hline DGpo & ++ & - & IPC & +++ & ++++ \\
\hline IG & + & +++ & IPD & - & - \\
\hline $\mathrm{PaS}$ & + & ++ & IPL & ++ & ++++ \\
\hline $\mathrm{PrS}$ & + & ++ & IPR & + & - \\
\hline $\mathrm{s}$ & +++ & ++++ & LDTg & ++ & +++ \\
\hline SFO & +++ & ++ & Ifp & - & - \\
\hline Thalamus & & & $\|$ & - & - \\
\hline$A D$ & + & +++ & MA3 & +++ & ++ \\
\hline AM & + & - & MCPC & +++ & - \\
\hline ar & - & - & MiTg & + & - \\
\hline AV & + & ++++ & $\mathrm{ml}$ & - & - \\
\hline AVDM & + & ++ & $\mathrm{MnR}$ & ++++ & +++ \\
\hline AVVL & ++ & +++ & $\mathrm{mp}$ & - & - \\
\hline BSTS & - & +++ & MPT & ++ & ++ \\
\hline $\mathrm{CL}$ & + & ++ & MT & +++ & +++ \\
\hline$C M$ & - & ++ & OPT & + & +++ \\
\hline $\mathrm{F}$ & + & ++ & OT & + & - \\
\hline G & - & - & $\mathrm{Pa} 4$ & - & - \\
\hline IAD & + & ++ & PBG & +++ & + \\
\hline IAM & - & ++ & PBP & +++ & + \\
\hline IMD & + & ++ & $\mathrm{pc}$ & - & - \\
\hline LD & + & +++ & PCom & ++ & ++ \\
\hline LDDM & + & +++ & $\mathrm{PF}$ & ++++ & +++ \\
\hline LDVL & + & +++ & $\mathrm{PL}$ & +++ & - \\
\hline LGN & ++ & +++ & PMR & +++ & +++ \\
\hline LHb & ++ & ++ & $\mathrm{Pn}$ & ++++ & ++++ \\
\hline LP & + & ++ & PN & ++++ & + \\
\hline MD & - & - & $\mathrm{PnO}$ & + & ++ \\
\hline MDC & - & - & PP & ++ & +++ \\
\hline $\mathrm{MDL}$ & - & - & PPT & + & ++ \\
\hline MDM & - & - & PPTg & ++ & + \\
\hline MGN & + & + & $P R$ & +++ & ++ \\
\hline $\mathrm{MHb}$ & +++ & ++++ & $\mathrm{Rbd}$ & +++ & - \\
\hline $\mathrm{mt}$ & - & - & RelC & ++ & - \\
\hline PC & $-1+$ & +++ & $\mathrm{RLi}$ & +++ & +++ \\
\hline $\mathrm{PF}$ & +++ & +++ & RMC & +++++ & + \\
\hline PLi & + & - & RPC & ++++ & + \\
\hline Po & - & ++ & $\mathrm{RR}$ & ++ & - \\
\hline PR & +++ & ++ & RRF & ++ & - \\
\hline PrC & +++ & - & rs & - & - \\
\hline PT & ++ & +++ & RtTg & ++ & + \\
\hline PVA & ++++ & ++++ & $\mathrm{SC}(\mathrm{DpG})$ & + & ++ \\
\hline PVP & +++ & +++ & SC(DpWh) & + & - \\
\hline $\mathrm{Re}$ & ++ & +++ & $\mathrm{SC}(\operatorname{InG})$ & ++ & + \\
\hline $\mathrm{Rh}$ & ++ & ++ & SC(InWh) & ++ & - \\
\hline $\mathrm{RI}$ & +++ & ++ & SC(Op) & ++ & - \\
\hline $\mathrm{Rt}$ & ++ & +++ & SC(SuG) & - & ++++ \\
\hline SG & + & + & $\mathrm{SC}(\mathrm{Zo})$ & - & ++++ \\
\hline SPFPC & ++ & - & scp & - & - \\
\hline Subl & +++ & + & SG & + & + \\
\hline VL & + & ++ & SPTg & ++ & - \\
\hline VM & + & +++ & Su3 ${ }^{9}$ & +++ & ++++ \\
\hline VPL & ++ & + & VLL & + & - \\
\hline VPM & ++ & - & VLTg & -+++ & - \\
\hline $\mathrm{Zl}$ & ++ & +++ & VTA & +++ & $+1++$ \\
\hline Mesencephalon & & & VTg & + & - \\
\hline 3 & +++ & - & Cerebellum & r & \\
\hline 4 & ++++ & - & Lobules & - & - \\
\hline APT & ++ & + & IntA & +++ & - \\
\hline APTD & ++ & + & IntDL & ++ & - \\
\hline APTV & ++ & - & IntDM & ++ & - \\
\hline ATg & ++ & ++ & IntP & ++ & - \\
\hline bic & - & - & Lat & ++++ & ++ \\
\hline $\mathrm{BIC}$ & ++ & + & LatPC & +++ & - \\
\hline bsc & - & - & Med & +++ & + \\
\hline CG & +++ & +++ & MedDL & ++ & + \\
\hline
\end{tabular}


TABLE 2. (continued)

\begin{tabular}{|c|c|c|}
\hline CNS Region & ORL 1 mRNA & $\begin{array}{c}125 \mid-\left[{ }^{14} \mathrm{~T} y r\right]-O F \mathrm{Q} \\
\text { Binding }\end{array}$ \\
\hline \multicolumn{3}{|l|}{ Metencephalon } \\
\hline 6 & ++++ & ++ \\
\hline $6 n$ & - & - \\
\hline 7 & +++++ & +++ \\
\hline $7 n$ & - & - \\
\hline $8 n$ & - & - \\
\hline A5 & +++ & ++ \\
\hline A7 & ++ & ++ \\
\hline Bar & - & + \\
\hline CGPn & ++ & +++ \\
\hline $\mathrm{CPO}$ & ++ & ++ \\
\hline DC & ++ & ++++ \\
\hline DMTg & - & - \\
\hline DPO & +++ & + \\
\hline DTg & - & - \\
\hline g7 & - & - \\
\hline GiA & +++ & - \\
\hline icp & - & - \\
\hline IRt & ++ & - \\
\hline $\mathrm{KF}$ & + & ++ \\
\hline LC & +++++ & ++++ \\
\hline LPB & ++++ & +++ \\
\hline LPGi & $-1+$ & - \\
\hline LSO & ++++ & - \\
\hline LVe & +++ & - \\
\hline LVPO & +++ & _- \\
\hline $\mathrm{Me} 5$ & ++++ & - \\
\hline mlf & - & - \\
\hline Mo5 & ++++ & ++ \\
\hline MPB & + & + \\
\hline MSO & - & - \\
\hline $\mathrm{MVeV}$ & +++ & ++ \\
\hline $\mathrm{MVe}$ & +++ & +++ \\
\hline MVPO & +++ & - \\
\hline $\mathrm{Pa} 6$ & +++ & - \\
\hline PCRt & + & ++ \\
\hline PDTg & + & - \\
\hline $\mathrm{PnC}$ & ++++ & + \\
\hline $\mathrm{PnR}$ & +++ & - \\
\hline PnV & +++ & ++ \\
\hline Pr5 & +++++ & ++++ \\
\hline RPO & ++ & +++ \\
\hline s5 & - & - \\
\hline $\mathrm{scp}$ & - & - \\
\hline $\mathrm{SGe}$ & - & ++++ \\
\hline Sp50 & ++++ & +++ \\
\hline SPO & +++ & + \\
\hline SpVe & +++ & ++ \\
\hline $\operatorname{SubC}(\alpha)$ & ++ & ++ \\
\hline SuVe & ++ & ++ \\
\hline $\mathrm{Tz}$ & +++ & +++ \\
\hline $\mathrm{tz}$ & - & - \\
\hline VCA & + & +++ \\
\hline VCP & +++ & ++++ \\
\hline \multicolumn{3}{|l|}{ Myelencephal on } \\
\hline 10 & ++++ & +++ \\
\hline $10 \mathrm{n}$ & - & - \\
\hline 12 & +++++ & + \\
\hline $12 n$ & - & - \\
\hline $\mathrm{A} 1$ & ++++ & ++ \\
\hline A2 & +++ & ++ \\
\hline A7 & ++ & ++++ \\
\hline Amb & +++++ & +++++ \\
\hline AP & - & +++ \\
\hline $\mathrm{C} 1$ & ++++ & ++ \\
\hline $\mathrm{C} 2$ & +++ & ++ \\
\hline $\mathrm{C} 3$ & - & - \\
\hline $\mathrm{Cl}$ & - & - \\
\hline $\mathrm{Cu}$ & +++ & +++ \\
\hline DMSp5 & +++ & +++ \\
\hline DPGi & + & + \\
\hline $\mathrm{ECu}$ & + & +++ \\
\hline $\mathrm{Gi}$ & ++ & ++ \\
\hline GiV & ++++ & +++ \\
\hline $\mathrm{Gr}$ & + & + \\
\hline In & - & - \\
\hline IOA & + & ++++ \\
\hline $\mathrm{IOB}$ & + & +++ \\
\hline IOD & +++ & +++ \\
\hline IODM & ++ & +++ \\
\hline IOM & ++ & +++++ \\
\hline IOPr & +++ & ++++ \\
\hline LRt & ++++ & ++ \\
\hline LVe & +++ & - \\
\hline $\mathrm{MdD}$ & ++ & ++++ \\
\hline $\mathrm{MdV}$ & ++ & ++ \\
\hline mif & - & - \\
\hline $\mathrm{MnA}$ & - & ++++ \\
\hline $\mathrm{MVeV}$ & +++ & ++ \\
\hline
\end{tabular}

TABLE 2. (continued)

\begin{tabular}{|c|c|c|}
\hline CNS Region & ORL 1 mRNA & $\begin{array}{c}\text { 125]-[14Tyr]-OFQ } \\
\text { Binding }\end{array}$ \\
\hline \multicolumn{3}{|c|}{ Myelencephalon (continued) } \\
\hline MVe & +++ & +++ \\
\hline $\mathrm{Pa} 5$ & +++ & +++ \\
\hline $\operatorname{Pr}$ & ++++ & ++++ \\
\hline py & - & - \\
\hline RAmb & ++++ & +++ \\
\hline $\mathrm{RMg}$ & +++++ & +++ \\
\hline ROb & +++ & ++ \\
\hline $\mathrm{RPa}$ & +++ & ++++ \\
\hline RVL & ++++ & ++ \\
\hline $\mathrm{SGe}$ & - & ++++ \\
\hline sol & - & - \\
\hline Sol & +++ & ++++ \\
\hline SolC & ++++ & ++++ \\
\hline Soll & +++ & ++ \\
\hline SolM & +++ & ++ \\
\hline sp5 & - & ++++ \\
\hline $\mathrm{Sp} 5 \mathrm{C}$ & +++ & ++++ \\
\hline Sp51 & ++++ & +++ \\
\hline SpVe & +++ & + \\
\hline \multicolumn{3}{|l|}{ Spinal cord } \\
\hline \multicolumn{3}{|l|}{ Cervical } \\
\hline I & - & - \\
\hline II & + & ++++ \\
\hline III & ++ & +++ \\
\hline IV & ++ & ++ \\
\hline $\mathrm{V}$ & +++ & + \\
\hline VI & +++ & +++ \\
\hline VII & ++ & ++ \\
\hline VIII & ++++ & ++ \\
\hline IX & ++++ & ++ \\
\hline$x$ & ++ & +++ \\
\hline \multicolumn{3}{|l|}{ Thoracic } \\
\hline 1 & - & - \\
\hline II & + & + \\
\hline III & + & +++ \\
\hline IV & +++ & ++++ \\
\hline V & + & + \\
\hline VII & +++ & ++ \\
\hline VIII & +++ & + \\
\hline IX & +++++ & - \\
\hline$x$ & +++ & ++++ \\
\hline $\mathrm{CeCv}$ & ++ & + \\
\hline $\mathrm{Cu}$ & - & - \\
\hline dcs & - & - \\
\hline DRG & +++++ & - \\
\hline gr & - & - \\
\hline IML & ++++ & ++ \\
\hline IMM & ++++ & +++ \\
\hline LatC & + & - \\
\hline $1 \mathrm{fu}$ & - & - \\
\hline LSp & + & - \\
\hline Sp5C & +++ & ++++ \\
\hline vfu & - & - \\
\hline
\end{tabular}

'Degree of mRNA expression and OFQ binding were arbitrarily graded, based on density and intensity of binding, and intensity of microscopic mRNA expression on emulsion-dipped sections. Gradations used for mRNA expression are as follows: highest signal intensity, +++++ ; high, ++++ ; moderate, +++ ; low to moderate, ++ ; low or sparse, + ; undetectable, - . Gradations used for OFQ binding are as follows: densest signal intensity,++++ ; dense, ++++ ; moderate, +++ ; low to moderate, ++ ; low or sparse, + ; undetectable, - . For abbreviations, see list.

though mRNA expression is diffusely located throughout the arcuate nucleus, ORL 1-containing neurons are most numerous ventromedially (Fig. 3D-F). The ventromedial nucleus is the most densely labeled structure in the hypothalamus, heavily labeled at all levels, with mRNA expression slightly higher in the dorsomedial part than in the ventrolateral part (Figs. 3D,E, 7D). At mid-caudal levels, mRNA expression in the dorsomedial part of the ventrolateral nucleus decreases laterally and is moderate in the medial tuberal nucleus and tuber cinereum.

In the dorsal part of the hypothalamus, mRNA expression in the posterior bed nudeus of the stria terminalis decreases and becomes low to moderate in the anterior and lateral hypothalamic areas. There is a decrease in mRNA levels in this transition area in the periventricular nucleus also, with mRNA expression low to moderate. The paraventricular nucleus demonstrates differential mRNA expres- 
sion, with moderate expression in the anterior parvicelluIar part, and high expression in the ventral and lateral magnocellular parts (Figs. 3C, 7B). Caudally in this nucleus, mRNA-expressing neurons are lightly scattered in the posterior part and dorsal cap. Caudal to the paraventricular nucleus, mRNA expression is sparse in the dorsal hypothalamic area and moderate in the dorsomedial hypothalamic nucleus (Figs. 3D, 7D). Lateral to the dorsal hypothalamic area, the perifornical nucleus contains sparse expression, with moderate expression into the posterior hypothalamus (Fig. 3E ). There is only sparse to low mRNA expression detected in the terete hypothalamic nucleus.

In the mammillary region, ORL1 mRNA expression in the ventral premammillary nucleus is high but diffuse. The adjacent dorsal premammillary and tuberal magnocellular nuclei contain sparse mRNA expression. In the rostral mammillary nuclear complex, the medial mammillary nucleus is devoid of mRNA expression in its lateral part. Lightly scattered mRNA-containing neurons are observed in the rostral supramammillary nucleus, becoming more moderate in number at caudal levels. The medial part of the medial mammillary nudeus contains low to moderate mRNA expression (Fig. 3F). The mammillary peduncle and supramammillary decussation are devoid of mRNA expression.

Orphanin FQ binding. Orphanin binding in the hypothalamus has an overall similar distribution pattern to that of ORL 1 mRNA expression. As with mRNA expression, no binding is seen in the median eminence, the anterior and intermediate pituitary, and the pineal gland. In the rostral part of the hypothalamus, the suprachiasmatic nucleus contains dense binding, filling the nucleus at all levels. Binding in the supraoptic nucleus is sparse to low. The retrochiasmatic supraoptic nucleus is devoid of binding. Binding in the retrochiasmatic area is diffuse and low, with increased intensity into the arcuate region. The rostral arcuate nucleus contains sparse orphanin binding in its lateral region and low to moderate binding medially. The density of binding sites increases slightly in more caudal regions, but generally moderate in the arcuate (Fig. 7B). The tuber cinereum, medial tuberal nucleus, and perifornical nucleus all contain moderate to dense OFQ binding at all levels. As with mRNA expression, the ventromedial nucleus shows the densest binding in the hypothalamus (Fig. 7C). Rostrally, the shell region of this structure shows moderate levels of binding that increases caudally to become dense throughout the shell and core regions, equally dense in the dorsomedial and ventrolateral parts.

In the dorsal part of the hypothalamus, orphanin binding in the anterior and lateral hypothalamic regions is low to moderate (Fig. 7A). Binding in the periventricular nucleus rostrally is very sparse. Further caudal, the paraventricular nucleus has low orphanin binding in the parvicellular region (Fig. 7A). In the rostral pole of the paraventricular nucleus, only sparse binding is observed the anterior parvicellular part. Signal intensity increases somewhat to become low to moderate in the lateral magnocellular and posterior parts, becoming moderate to dense in the ventral part and dorsal cap. Caudal to the paraventricular nucleus, the dorsal hypothalamic area is devoid of binding. Binding in the dorsomedial hypothalamus is low (F ig. 7C). Labeling in the posterior hypothalamus is low to moderate. Theteretehypothal amic nud eus contains dense OF Q binding throughout its extent.
In the caudal hypothalamus, the tuberal magnocellular nucleus is devoid of OFQ binding and binding in the ventral premammillary nucleus only consists of occasional sparse patches. The dorsal premammillary nucleus contains low to moderate labeling at all levels, increasing in density into the mammillary bodies. Orphanin FQ binding in the lateral mammillary nucleus and median part of the medial mammillary nucleus is negligible. This is in contrast to the supramammillary nucleus and lateral part of the medial mammillary nucleus, where binding is moderate to dense at all levels. No OFQ binding is observed in the mammillary peduncle and supramammillary decussation.

\section{Amygdala}

In situ hybridization. Rostrally, mRNA-expressing cells are sparsely scattered in the anterior amygdaloid area and anterior cortical amygdala. Orphanin receptor mRNA expression is low to moderate in the cortexamygdala transition zone. At the level of the paraventricular hypothalamus, Iow mRNA expression is observed in the rostral medial and anterior cortical nuclei, with low to moderate expression in the basolateral nucleus (Figs. 3C, 7A). The bed nucleus of the accessory olfactory tract contains moderate to dense mRNA expression at this level. The central nucleus contains an occasional mRNAcontaining neuron in its lateral part but is essentially devoid of mRNA expression (Fig. 7B,D).

Further caudal, the anterodorsal division of the medial nucleus contains low mRNA expression, with dense expression in the anteroventral division. At this level, the anterior part of the basomedial nucleus contains moderate mRNA expression, with low signal detected in the anterior basolateral nudeus (Fig. 3D). In the most caudal part of the medial nucleus, the posterodorsal division contains low to moderate expression, whereas the posteroventral division is filled with numerous densely labeled mRNAexpressing cells (Figs. 3D, 7D). Moderate mRNA expression is observed extending into the basolateral and posterolateral cortical nuclei at this level. The basomedial nucleus has moderate to dense mRNA expression, and only sparse expression is observed in the lateral nucleus, in both the ventral and dorsal divisions. The intercalated nuclei of the amygdala contain scattered, sparsemRNA-expressing cells.

In the caudal amygdala, the posterior basomedial nucleus and posterior basolateral nucleus contain low to moderate mRNA expression at all levels. Scattered neurons with low levels of mRNA expression are observed throughout the posteromedial and posterolateral cortical amygdala nuclei and the amygdal ohi ppocampal area (Fig. 3E,F). The intraamygdal oid bed nucleus of the stria terminalis is devoid of mRNA expression. Transitioning into the ventral hippocampal region, the amygdalopiriform transition area contains moderate mRNA expression.

Orphanin FQ binding. In the rostral pole of the amygdala, the ventral and dorsal parts of the anterior amygdaloid area contains only sparse binding. This binding increases somewhat into the anterior cortical nucleus, where low to moderate binding is observed. The cortexamygdala transition zone is devoid of orphanin binding. Low to moderate binding is observed in the anterior part of the medial and basolateral nudei (Fig. 7A), with moderate binding in the rostral bed nucleus of the accessory olfactory tract. F urther caudal, the anterodorsal division of the medial nudeus emerges with moderate to dense binding 
(Fig. 7C). At this level, binding in the bed nucleus of the accessory olfactory tract becomes dense. The anterior cortical nucleus and dorsal lateral part of lateral nucleus contain low to moderate binding, with sparse binding in the anterior part of the basomedial and basolateral nuclei. Only sparse binding is observed in the region of the intercalated nuclei, and the central nucleus is devoid of binding at all levels (Fig. 7C). The basolateral nucleus contains moderate to dense binding in its anterior part, sparse to low posteriorly.

In the caudal amygdala, no binding is observed in the posterolateral cortical nucleus and basomedial nucleus. The posteroventral division of the medial nucleus contains dense binding, while binding in the posterodorsal region is sparse to low. This pattern in the medial nucleus persists until the most caudal level of the amygdala, where binding is conspicuously absent in the caudal pole of the posterodorsal division of the medial nucleus. At this level, the posteromedial cortical nucleus has moderate to dense binding. Low to moderate binding is observed in the lateral nucleus, in both the dorsolateral and ventromedial parts. Binding in the intra-amygdaloid portion of the bed nucleus of the stria terminalis is sparse, and the posterior basomedial nucleus is devoid of binding. In transition to the ventral hippocampus, the amygdalohippocampal area contains moder ateto dense binding, whereas theamygdal opiriform transition shows no orphanin binding.

\section{Hippocampal formation and related structures}

In situ hybridization. In the rostral forebrain, at the level of the septal nuclei, the septohippocampal nucleus contains high ORL1 mRNA expression. Dorsal to the corpus callosum, only sparse mRNA expression is observed in the indusium griseum. The subfornical organ contains moderate to dense mRNA expression at all levels. The fornix is devoid of mRNA expression. In the caudal forebrain, the subiculum contains moderate to dense mRNA expression. These mRNA-expressing neurons are found in both the dorsal and ventral components of the subiculum, with message expression heaviest in deeper layers (Fig. 8D). Orphanin receptor mRNA expression is sparse in the presubiculum and parasubiculum, at all levels.

Orphanin receptor mRNA expression in the hippocampal formation is generally lower in rostral than in caudal levels, with particularly increased expression in the ventral part of the dentate gyrus and Ammon's horn ( $F$ igs. 3 , $4 A, B, 7 B, D, 8 B$ ). Rostrally, the hilus of the dentate gyrus contains scattered, sparsely labeled neurons, with no mRNA expression detected at more caudal levels. In the polymorph layer of the dentate gyrus (also referred to as area CA3C of Ammon's horn), no mRNA expression is observed rostrally, but low to moderate levels are observed scattered in this layer in the caudal ventral region. The molecular layer contains no mRNA expression at all levels. The granule cell layer of the dentate gyrus has moderate to high mRNA expression rostrally, with dense expression in caudal ventral levels. This dense mRNA pattern persists to its caudal extent.

In Ammon's horn, area CA1 has sparse to negligible mRNA expression rostrally, primarily in stratum pyramidal. Stratum radiatum and oriens are devoid of labeling at this level. Caudally, mRNA expression remains sparse to negligible in stratum pyramidal, with only an occasional scattered mRNA-expressing neuron observed in stratum oriens and radiatum. This mRNA expression is also evident in area CA1 in sense control sections, and this sparse labeling is most likely nonspecific. In area CA2, occasional mRNA-expressing neurons are observed rostrally in stratum pyramidal, with stratum radiatum and oriens devoid of labeling. In caudal area CA2, stratum pyramidal contains moderate to high mRNA expression, with lightly scattered cells observed in stratum oriens and radiatum. Area CA3 contains sparse mRNA expression in stratum lucidum, oriens, and radiatum at rostral levels, with high mRNA expression in stratum pyramidal. In caudal area CA3, mRNA expression in stratum pyramidal becomes dense, with no real change in stratum lucidum and radiatum. Stratum oriens in caudal area CA3 shows significant increase in signal intensity, with mRNA expression high at this level.

Orphanin $\mathbf{F Q}$ binding. At the level of the septal nudei, orphanin binding is low in both the subfornical organ and the septohippocampal nucleus, moderate to dense in the indusium griseum. The fornix is devoid of orphanin binding at all levels. In the caudal forebrain, the dorsal subiculum emerges with dense binding in all layers (Fig. 8A). This binding pattern persists throughout the dorsal and ventral subiculum (Fig. $8 \mathrm{C}$ ). In contrast to dense subiculum binding, orphanin binding in the presubiculum and parasubiculum is low.

In contrast to the rostral to caudal differences observed with ORL1 mRNA expression, orphanin binding in the hippocampal formation is generally unchanged from rostral to caudal levels (Figs. 7A,C, 8A). No orphanin FQ binding is observed in the dentate gyrus in the granule cell layer, hilus, or polymorph layer. The molecular layer is filled with moderate to dense binding, slightly denser in the caudal ventral region than at more rostral levels. In Ammon's horn, area CA1 contains almost no orphanin binding. Sparse, patchy binding is observed in caudal stratum oriens, but no binding is observed in stratum pyramidal or stratum oriens at all levels. Area CA2 of Ammon's horn has slightly more binding than area CA1. Rostrally, sparse receptor binding is observed in stratum oriens and stratum radiatum, with only a slight increase in caudal levels in stratum oriens. No binding is observed in stratum pyramidal at all levels. In area CA3, very dense binding is observed in stratum oriens, with low to moderate binding observed in stratum lucidum, primarily at rostral levels. Stratum pyramidal and radiatum are devoid of OF Q receptor binding at all levels in this region.

\section{Thalamus}

In situ hybridization. At the caudal extent of the posterior bed nucleus of the stria terminalis, the anterior part of the paraventricular thalamic nucl eus emerges with high mRNA expression. Low to moderate expression is observed in the adjacent paratenial nucleus (Fig. 3C). The rostral anteroventral nucleus, and the anterodorsal and dorsomedial parts of the anteroventral nucleus have no mRNA expression (Fig. 7A). Lateral to this midline thalamic group, the reticular nucleus and ventrolateral part of the anteroventral nucleus contain low to moderate mRNA expression. The rhomboid nucleus contains low mRNA expression, with the interanterodorsal, reunions, anteromedial, and paracentral thalamic nuclei devoid of mRNA expression rostrally. Further caudal, paratenial expression decreases slightly and sparse ORL1 mRNA 
expression is observed in the interanterodorsal and anterodorsal nuclei. Messenger RNA expression in the paraventricular nucleus decreases slightly in the posterior division, remaining moderate to high to its caudal pole.

At the emergence of the medial habenula, moderate to high mRNA expression is observed (Fig. 3D). At this level, the rostral zona incerta also emerges with scattered cells containing sparse mRNA expression (Fig. 7D). M essenger RNA expression in zona incerta increases to moderate levels caudally. Themediodorsal, ventromedial, and ventrolateral nuclei at this level are devoid of labeling, and only sparse mRNA labeling is observed in the caudal anteroventral nucleus, in its ventrolateral and dorsomedial parts, and the anterodorsal, centromedial, and paracentral nuclei. Ventral to the centromedial nucleus, the interanteromedial nucleus has no detectable mRNA and the reunions nucleus contains low to moderate mRNA levels.

Further caudal the lateral habenula emerges with, scattered, sparse mRNA-containing neurons, whereas expression in the medial habenula and paraventricular nucleus remain high. At this level, moderatemRNA expression is observed in the reunions and rhomboid nudei, with low expression in the interanteromedial, ventral posteromedial, and ventral posterolateral nuclei (Fig. 7C). Sparse expression is noted in the ventromedial, ventrolateral, reticular, and laterodorsal nuclei. The mediodorsal thalamic group, and the paracentral, centromedial, gelatinosus, and posterior thalamic nuclei are devoid of mRNA expression at this level. F urther caudal, at the emergence of the posterior paraventricular nucleus, mRNA expression decreases slightly from that of the anterior division but remains moderate to high. The lateroposterior, laterodorsal, ventral posterolateral, ventral posteromedial, ventromedial, and intermediodorsal nuclei all contain sparse mRNA expression at this level. The subincertal nucleus at this level has moderate to high expression.

In the mesencephalic thalamus, dense mRNA expression persists in the posterior paraventricular nucleus, with moderate to high expression emerging in the precommissural and perifornical nuclei (Fig. 3E). The rostral interstitial nucleus of the medial Iongitudinal fasciculus and prerubral field contain moderate mRNA expression, extending laterally to scattered, sparse labeling in the fields of Forel, medial geniculate nucleus, and dorsal geniculate region ( $\mathrm{Figs}$. 3F, 4A). The lateral geniculate nucleus has moderate mRNA expression. The lateroposterior thalamic nudeus contains sparse mRNA expression, but this increases caudal into the level of the pretectum, where mRNA expression is more moderate. At the caudal boundaries of thethalamus, the parvicellular part of thesubparafascicular thalamic nucleus contains scattered, moderately labeled neurons, adjacent to large moderately expressing cells in the caudal zona incerta. The posterior, ethmoid, posterior limitans, and suprageniculatethalamic nuclei at this level contain sparse mRNA expression.

Orphanin FQ binding The rostral thalamus emerges with dense binding filling the anterior part of the paraventricular nucleus and the anteroventral nucleus, persisting throughout these nuclei (Fig. 7A,C). Binding in the paratenial nucleus rostrally is moderate to dense, decreasing slightly at the emergence of the stria medullaris. The rostral anterodorsal nucleus is conspicuously devoid of binding. Laterally, the dorsomedial part of the anteroventral thalamic nucleus contains low to moderate OFQ binding. Binding in the ventrolateral part is moderate to dense, particularly adjacent to the lateral ventride. The reticular nucleus contains moderate binding in a patchy distribution. Binding is sparse in the anteromedial and rhomboid nuclei.

In the mid-thalamus, the paracentral nucleus contains moderate to dense binding in a circumferential distribution around the paratenial nucleus. At this level, the interanterodorsal and reunions nuclei contain low levels of binding. The medial habenula emerges with moderate binding filling the nucleus. At this level, the mediodorsal nuclear group is devoid of binding, and the anterodorsal nucleus contains moderateto denselabeling. The centromedial nucleus contains low levels of binding. The rostral zona incerta contains low to moderate binding. In the dorsal thalamus, the ventrolateral part of the laterodorsal nucleus contains moderate binding, as do the ventrol ateral and ventromedial nuclei (Fig. 7A). Binding is low and diffuse in the interanteromedial nucleus, negligible in the anteromedial nucleus, and sparse in therhomboid nucleus. The gelatinosus nucleus is conspicuously devoid of orphanin binding at all levels.

At the emergence of the lateral habenula, binding in the medial habenula intensifies, and dense labeling persists in the paraventricular nucleus (Fig. 7C). The laterodorsal nuclei maintain moderate to dense binding. Moderate levels of receptor binding are seen in the reunions, with moderate to dense labeling in the adjacent zona incerta. Low levels of receptor binding seen in the reticular nucleus spread diffusely through the ventromedial, ventrolateral, ventral posterolateral, ventral posteromedial (Fig. 7C), and subincertal nuclei. Moderate binding is observed in the centrolateral nudeus. The mediodorsal thalamic nuclei remain devoid of binding throughout their extent.

In the caudal thalamus, the posterior part of the paraventricular nucleus emerges with lower levels of binding than in the anterior part, with overall levels remaining moderate to dense. The lateroposterior thalamic nuclei contain low to moderate binding, as do the posterior and perifornical nuclei throughout their extent. The ventral posteromedial nucleus is devoid of binding. The zona incerta at this level maintains low to moderate binding in its ventral and dorsal parts, with patchy, sparse binding observed in the fields of Forel. The adjacent prerubral field and rostral interstitial nucleus of the medial longitudinal fasciculus contain diffuse low to moderate OF Q binding. The parvicellular part of the subparafascicular thalamic nucleus is devoid of binding. The acoustic radiation is conspicuously devoid of orphanin binding, distinguishing themoderateto dense binding observed in the lateral geniculate nucleus from the sparse, diffuse label observed in the medial geniculate body (Fig. 8A). The adjacent suprageniculate nud eus al so contains sparse binding. The precommissural and posterior limitans nudei contain no OF Q binding.

\section{Mesencephalon}

In situ hybridization. In the mesencephalon ORLI mRNA expression is diffuse. However, no mRNA expression is noted in any of the major fiber bundles, including the brachium of the inferior or superior colliculus, the commissure of the inferior or superior colliculus, the cerebral pedunde, central tegmental tract, dorsal longitudinal fasciculus, fasciculus retroflexus, Iongitudinal fasciculus, lateral or medial lemniscus, mammillary peduncle, posterior commissure, rubrospinal tract, superior cerebellar peduncle, or spinal trigeminal tract. 
In the rostral dorsal midbrain, sparse mRNA expression is observed in the nucleus of the optic tract, the posterior pretectal nucleus, and olivary pretectal nucleus. Low to moderate mRNA expression is observed in the dorsal and ventral parts of the anterior pretectal nucleus, the medial pretectal nucleus and the nucleus of the posterior commissure. The magnocellular nucleus of the posterior commissure contains moderate to high mRNA expression. Caudal to the pretectal nuclei, orphanin receptor mRNA expression in the tectum is generally low. The superior colliculus emerges with low to moderate mRNA expression at all levels (Figs. 4A, 8B). The zonal and superficial granular layers are devoid of mRNA expression, and sparse expression is observed in the deep gray and deep white layers. In the intermediate gray, intermediate white and optic nerve layers, mRNA expression increases slightly and is low to moderate. At the level of the inferior colliculus, low to moderate expression is observed in the recess of the inferior colliculus, increasing slightly into the dorsal cortex where mRNA expression is moderate (Figs. 4C, 8D). The external cortex and central nucleus of the inferior colliculus contain only sparse mRNA expression. The intercollicular nucleus contains sparse to low expression. Ventral to the tectum, a moderate number of large mRNAcontaining neurons are scattered throughout the deep mesencephalic nudeus, seen at its emergence in the rostral midbrain and persisting in this reticular structure at all levels. In the caudal mesencephal on, the oral part of the pontine reticular nucleus contains scattered, sparse mRNA expression throughout.

Laterally, Iow mRNA expression in the lateral geniculate nucleus and sparse expression in the medial geniculate nucleus persist to their caudal poles (Figs. 4A, 8B). At this level, the peripeduncular nucleus contains only sparse to low mRNA expression, with signal intensifying to become moderate in the substantia nigra, pars reticulata, and high in pars compacta ( $F$ igs. 4A,B, 8B,D). Messenger RNA expression in pars lateralis is low at all levels. Caudal to the substantia nigra, sparse to low mRNA expression is observed in the nucleus of the brachium of the inferior colliculus, and the paralemniscal nucleus contains moderate to high expression. The brachium and commissure of the inferior colliculus contain no mRNA expression. Caudally, sparse expression is observed in the ventral and intermediate nuclei of the lateral lemniscus. The dorsal nucleus of the lateral lemniscus contains low mRNA expression, and the lateral lemniscus is devoid of mRNA expression.

Several mesencephalic tegmental nuclei contain ORL 1 mRNA-expressing cells. Adjacent to the retrorubral field, the pedunculopontine tegmental nucleus contains low mRNA expression. Caudally, mRNA expression is sparse in the microcellular tegmental nucleus and moderate in the reticulotegmental nucleus. The anterior tegmental nudeus contains low to moderate mRNA expression in small-size neurons, and the adjacent subpeduncular tegmental nucleus contains a moderate number of slightly larger-sized mRNA-containing neurons. The rhabdoid nudleus contains moderate to high mRNA expression. Numerous large cells in the ventrolateral tegmental nudeus contain moderate mRNA expression, whereas the ventral tegmental nucleus only contains sparse expression. Moderate to high expression is observed in the laterodorsal tegmental nudeus, adjacent to the dorsal raphe. The dorsal tegmental nucleus is devoid of mRNA expression.

At the midline, the central gray contains moderate mRNA expression ventrally and its dorsal part is filled with ORL 1-containing neurons. High mRNA expression persists through the entire extent of the central gray (Figs. 3F, 4, 8B,D). Dorsolateral to the central gray, the cuneiform nucleus is devoid of mRNA expression. Ventral to the central gray, the nucleus of Darkschewitsch contains low mRNA expression, with mRNA-containing neurons also lightly scattered throughout the interstitial nucleus of the medial longitudinal fasciculus. Themedial accessory oculomotor nucleus contains moderate to high mRNA expression. From its emergence rostrally, the Edinger-Westphal nucleus is filled with densely labeled mRNA-containing neurons (Fig. 4A). In the caudal mesencephalon, mRNA expression remains high in the central gray and the supraoculomotor central gray. The oculomotor nucleus contains moderate mRNA expression (Fig. 4B). The paratrochlear nucleus is devoid of mRNA expression, whereas the trochlear nucleus is filled with densely label ed mRNA-expressing cells. The dorsal rapheemerges in the caudal midbrain with high mRNA expression, filling the nucleus (Figs. 4C, 8D). This signal intensity extends ventrally into the caudal linear nucleus of the raphe, where mRNA expression is slightly decreased but still high (Fig. 4C). The paramedian raphe contains only sparse, scattered mRNA-containing neurons, and the median raphe contains moderate to high mRNA expression.

In the ventral midbrain, the rostral interpeduncular nucleus contains scattered cells expressing low levels of mRNA. The rostral division contains only sparse mRNA expression, and the dorsal division is devoid of labeling. In the caudal interpeduncular nucleus, mRNA expression in the caudal division is moderate to high (Figs. 4C, 8B) and rostral division expression remains sparse. The retrorubral field and retrorubral nucleus contain low to moderate mRNA expression rostrally. At the emergence of the red nucleus, the magnocellular division contains the highest mRNA expression in the mesencephalon, with numerous, large, densely labeled neurons filling this structure (Fig. $4 B$ ). This level of signal intensity remains throughout the extent of this nucleus. The parvicellular division of the red nucleus contains sparse mRNA expression rostrally, becoming denser at mid-caudal levels, but still much less than that seen in the magnocellular division. In the adjacent ventral tegmental region, moderate to high expression is observed in the ventral tegmental area proper, with high expression observed in the paranigral nucleus (Figs. 4A, 8B). At the midline, mRNA expression is low in the interfascicular nucleus, moderate to high in the rostral linear nucleus of the raphe and parabrachial pigmented nucleus, and high in the medial terminal nucleus of the accessory olfactory tract. This pattern persists to the caudal extent of the ventral midbrain, with the emergence of the pontine nuclei, which demonstrate high levels of diffuse mRNA expression (Figs. 5A, 9B).

Orphanin FQ binding. Orphanin binding in the mesencephalon, like ORL1 mRNA expression, is diffuse. No binding is noted in the brachium of the inferior or superior colliculus, the commissure of the inferior or superior colliculus, the cerebral peduncle, central tegmental tract, dorsal longitudinal fasciculus, fasciculus retroflexus, longitudinal fasciculus, lateral or medial lemniscus, mammillary peduncle, posterior commissure, 
rubrospinal tract, superior cerebellar peduncle, or spinal trigeminal tract.

In the rostral dorsal midbrain, the nucleus of the posterior commissure contains low levels of binding, and the magnocellular nucleus of the posterior commissure is devoid of OFQ binding. At this level, the perifornical nucleus contains moderate to dense binding, which persists throughout its extent. The olivary pretectal nucleus contains dense binding. A low level of binding is observed in the posterior and medial pretectal nuclei, and sparse signal is observed in the dorsal and ventral anterior pretectal nucleus. Thenucleus of the optic tract is devoid of orphanin binding. Caudal to the pretectal nuclei, the superior colliculus emerges with denselabeling in its zonal and superficial gray layers (Fig. 8A). Dense binding remains within these layers to its caudal extent. Binding in the intermediate gray layer is sparse, and in the deep gray layer low to moderate. The optic nerve, intermediate white and deep white layers are devoid of binding. Caudally, the nucleus of the brachium of the inferior colliculus contains sparse binding. The inferior colliculus emerges with low levels of binding in the central and intercollicular nuclei, and low binding in its dorsal and external cortices (Fig. 8C). The recess of the inferior colliculus is devoid of OFQ binding. The deep mesencephalic nucleus contains only sparse binding, and the oral part of the pontine reticular formation contains patches of low to moderate labeling.

In the lateral midbrain, moderate binding is seen in the lateral geniculate nucleus, and sparse binding in the medial geniculate nucleus that persists to their caudal extent (Fig. 8A). The peripeduncular nucleus at this level contains moderate to high levels of OFQ binding, with density of binding sites decreasing slightly intothe substantia nigra, pars compacta, and pars reticulata, where a moderate density of binding sites is observed at all levels (Fig. 8A,C). Binding in pars lateralis is low. The dorsal nudeus of the lateral lemniscus contains sparse to low binding. In the paralemniscal nucleus, and the lateral and ventral nuclei of the lateral lemniscus, no detectable orphanin binding is observed.

The tegmental nuclei of the basal mesencephalon contain little OFQ binding. Adjacent to the retrorubral field, the pedunculopontine tegmental nucleus contains only sparse binding. Caudal and laterally, the microcellular tegmental nucleus has no detectable orphanin binding, with negligible to sparse binding in the reticulotegmental nudeus. The anterior tegmental nucleus contains low to moderate binding, and the adjacent rhabdoid nucleus shows no binding. J ust ventral to the decussation of the superior cerebellar peduncle, the subpeduncular tegmental nucleus is devoid of OFQ binding. In the caudal mesencephalon, the ventrolateral, dorsal, and ventral tegmental nudei contain no detectable orphanin binding. The laterodorsal tegmental nudeus stands out at this level with moderate to dense binding at the level of the caudal dorsal raphe.

At the midline, the central gray emerges with moderate to dense binding rostrally, becoming more dense caudally, in its dorsal division. This dense central gray binding persists to its caudal extent (Fig. 8A). Dorsal to the central gray, the cuneiform nucleus has no binding. Ventrally, the nudleus of Darkschewitsch contains sparse, patchy binding, and the interstitial nucleus of the medial Iongitudinal fasciculus has no detectableorphanin binding. TheE dingerWestphal nucleus at this level is filled with a dense number of orphanin binding sites, which persists to its caudal pole (Fig. 8A). Binding extends ventrally from this nucleus onto the rostral linear nucleus of the raphe, decreasing in intensity, but still moderate to dense. The medial accessory oculomotor nucleus contains low to moderate binding, with signal intensity in the supraoculomotor central gray very dense throughout. In contrast to ORL 1 mRNA expression, no binding is observed in the paratrochlear, oculomotor, or trochlear nuclei. At the emergence of the dorsal raphe, dense binding is noted filling this nucleus. Binding remains high in this structure throughout the mesencephalon (Fig. 8C). Ventral to the dorsal raphe, receptor binding diminishes slightly into the caudal linear raphe, where it remains moderate to high. The paramedian and median raphe also contain moderate to high levels of binding throughout their rostral to caudal extent.

In the ventral mesencephalon, the interpeduncular nucleus contains dense OFQ binding in the caudal and lateral divisions (Fig. 8A). The dorsal and rostral divisions of this nucleus, however, are devoid of orphanin binding. The retrorubral field and retrorubral nucleus have no detectable orphanin binding. In contrast to the high levels of ORL 1 mRNA expression observed in the red nucleus, orphanin binding in this structure is sparse to negligible in both the parvicellular and magnocellular divisions. The adjacent ventral tegmental region contains generally low orphanin binding. Receptor binding levels are low in the ventral tegmental area proper, sparse in the adjacent paranigral nucleus, and sparse in the parabrachial pigmented nucleus (Fig. 8A). At the midline, the interfascicular nucleus contains moderate binding, becoming moderate to dense in the rostral linear raphe and medial terminal nucleus of the accessory olfactory tract. At the caudal extent of the ventral mesencephalon, the pontine nuclei emerge filled with dense binding that extends into the metencephal on (Fig. 9A).

\section{Cerebellum}

In situ hybridization. Cerebellar ORL 1 mRNA expression is confined to the deep cerebellar nuclei. Messenger RNA expression detected within the granular, molecular, or Purkinje cell layer of the cerebellar lobules at all levels was nonspecific and did not differ with sense or antisense probes. Within the deep cerebellar nuclei, the lateral (dentate) nucleus is filled with numerous, large mRNAexpressing cells. Unlike that observed in the cerebellar lobules, mRNA expression in these cells is specific and persists to its caudal boundaries. In the parvicellular part of the dentatenucleus, mRNA expression decreases slightly and remains moderate to its caudal extent. The anterior part of the interposed cerebellar nucleus contains minimal expression rostrally, with expression becoming moderate to high from mid to caudal levels. The posterior part of the inter posed nucleus contains low to moderatemRNA expression at all levels, with similar expression in the dorsolateral and dorsomedial divisions. The medial (fastigial) cerebellar nucl eus contains moderate to high mRNA expression at all levels, extending into its dorsolateral protuberance.

Orphanin FQ binding. No specific orphanin binding is observed in the cerebellar lobules, with the granular, molecular, and Purkinje cell layers devoid of specific labeling. Specific orphanin binding in the deep cerebellar nuclei is present but minimal. The interposed nucleus of 
the cerebellum is devoid of OFQ binding, in its anterior, dorsomedial, dorsolateral, and posterior parts. The lateral (dentate) nucleus contains low to moderate binding at all levels, but no binding is observed in its parvicellular part. Sparse, patchy binding is observed in the medial (fastigial) nudeus, mostly in its lateral boundary. The dorsolateral protuberance of the fastigial nucleus, has no detectable orphanin binding.

\section{Metencephalon}

In situ hybridization. Orphanin receptor mRNA expression is high throughout the pons. No expression was observed in major fiber bundles, including the superior cerebellar pedunde, inferior cerebellar peduncle, pyramidal tract, abducens nerve, facial nerve, vestibulocochlear nerve, sensory root of the trigeminal nerve, medial longitudinal fasciculus, and trapezoid body. Rostrally in the pons, the motor trigeminal nucleus emerges with high mRNA expression (Fig. 9B). The nucleus is filled with numerous large, densely labeled neurons. Lateral to the motor trigeminal nudeus, the principal sensory trigeminal nucleus also contains numerous, large ORL 1-expressing neurons, diffusely filling the dorsomedial division. The ventrolateral division of the principal sensory trigeminal nucleus has no detectable mRNA expression. Adjacent to the principal trigeminal nucleus, the $A 7$ cell region contains low to moderate mRNA expression and the Kolliker-F use nudleus contains sparse mRNA expression. The tegmental nuclei in the metencephal on show very little mRNA expression. The posterodorsal tegmental nucleus contains sparse, scattered mRNA expression, and the dorsal and dorsomedial tegmental nuclei have no detectable mRNA expression.

In the rostral dorsal pons, mRNA expression in the dorsal raphe is significantly less than that observed in the mesencephalon. The metencephalic portion of this nucleus contains moderate to high mRNA expression to its caudal extent (Figs. 5A, 9B). The pontine central gray at this level contains low to moderate mRNA expression. F urther caudal, the mesencephalic trigeminal nucleus emerges with high mRNA expression. Numerous, large mRNA-expressing neurons are observed filling this nucleus at all levels. The locus coeruleus is filled with numerous, densely labeled neurons and is one of the highest mRNA-expressing regions in the metencephalon (Figs. 5A, 9B). High mRNA expression in this structure persists to its caudal extent at the genu of the facial nerve. Laterally, the medial parabrachial nucleus contains only scattered neurons with sparse mRNA expression, whereas the lateral parabrachial nucleus contains high levels of mRNA expression (Figs. 5A, 9B). The $\alpha$ division of the subcoeruleus nucleus contains low to moderate mRNA expression, and Barrington's nucleus has no detectable mRNA expression. Laterally, the anterior ventral cochlear nucleus contains sparse mRNA expression.

In the caudal dorsal pons, the abducens nud eus emerges filled with numerous, large mRNA-expressing neurons. The adjacent para-abducens nudeus contains less mRNA expression but still is moderately to densely labeled. Laterally, the posterior ventral cochlear nucleus contains moderate to high mRNA expression, with expression in the adjacent dorsal cochlear nucleus low to moderate. At the level of the genu of the facial nerve, the supragenual nudeus contains no mRNA expression. Laterally, the vestibular nudear complex emerges with low to moderate
mRNA expression in the superior vestibular nucleus. At this level, the medial vestibular nucleus contains high mRNA expression diffusely distributed throughout the nucleus, extending into its ventral division (Fig. 5B). The lateral vestibular nucleus contains moderate mRNA expression. Moderate mRNA expression is also observed in the spinal vestibular nucleus in the caudal pons. Ventral to the vestibular complex, numerous large, densely label ed neurons are observed in the dorsomedial spinal trigeminal nucleus. Pars oralis of the spinal trigeminal nucleus is also filled with high expressing cells at this level (Fig. 5B).

In the ventral pons just caudal to the pontine nuclei, the nucleus of the trapezoid body emerges with moderate mRNA expression persisting throughout its extent. J ust lateral to the nucleus of the trapezoid body, the rostral periolivary region contains low to moderate mRNA expression. Further caudal, the medioventral and lateroventral periolivary nuclei of the superior olive contain moderate mRNA expression. The adjacent superior paraolivary nucleus and dorsal periolivary nudeus contain moderate to high mRNA expression. The lateral superior olive contains the highest mRNA expression of the superior ol ivary complex, with numerous ORL 1-containing neurons filling the nucleus at all levels. The caudal periolivary nucleus contains low to moderate mRNA expression and the medial superior olive has no detectable mRNA expression. Lateral to the olivary complex the $A 5$ cell region contains moderate mRNA expression (Figs. 5B, 9D). In the caudal pons, mRNA expression is high, filling the region of the $A 5$ cell group. Caudal to the superior olive, the nucleus of the facial nerve emerges with high mRNA expression. Large, densely labeled neurons fill this nucleus at all levels, making it the most densely labeled structure in the metencephal on. Densely label ed ORL 1-containing cells fill this nucleus to its caudal extent into the medulla (Figs. 5B, 9D).

At the midline, the raphe magnus emerges with high mRNA expression. Large, densely labeled neurons fill this structure and persist to its caudal extent. Caudally, mRNA expression extends from raphe magnus into the raphe pallidus nucleus, where high mRNA expression is also observed (Figs. 5B, 9D,F). The pontine raphe nucleus contains moderate to high mRNA expression at all levels. Message expression within this ventral raphe complex persists into the medulla. Within the reticular formation, the pontine reticular nucleus contains low to moderate mRNA expression rostrally, with large mRNA-containing cells scattered throughout the ventral and caudal parts (Fig. 5A). Further caudal, at the level of the facial nucleus, mRNA expression increases dramatically in this region. The caudal pontine reticular nucleus is filled with densely labeled, large neurons. Messenger RNA expression in the ventral nucleus is moderate to high. Laterally, the intermediate reticular nucleus contains low mRNA expression and the parvicellular reticular nucleus contains only sparse mRNA expression at all levels. In the caudal ventral pons, the gigantocellular reticular nucleus emerges with low to moderate mRNA expression, slightly increased in its al pha division (Figs. 5B, 9D). The lateral paragigantocellular reticular nucleus has sparse mRNA expression.

Orphanin FQ binding. Although less widespread than ORL 1 mRNA expression, orphanin binding is still quite extensive in the metencephalon. No OFQ binding was observed in major fiber bundles, induding the superior cerebellar peduncle, inferior cerebellar pedunde, pyra- 
midal tract, abducens nerve, facial nerve, vestibulocochlear nerve, medial Iongitudinal fasciculus, sensory root of the trigeminal nerve and trapezoid body. Rostrally, the motor trigeminal nucleus contains low to moderate binding (Fig. 9A), with binding in the adjacent principal sensory trigeminal nucleus high in its dorsomedial division and only low to moderate in the ventrolateral part. J ust dorsal to the rostral principal sensory nucleus, the A7 cell region and Kolliker-F use nucleus contain low to moderate binding. The dorsal, dorsomedial, and posterodorsal tegmental nuclei in the pons have no detectable orphanin binding.

In the rostral dorsal pons, the dorsal raphe demonstrates high levels of orphanin binding. This binding pattern persists to the caudal extent of this structure (Figs. 8C, 9A). The adjacent pontine central gray contains moderate to high OFQ binding at all levels. The mesencephalic trigeminal nucleus, in contrast to ORL 1 mRNA expression, has no detectable orphanin binding at all levels. Adjacent to this nucleus, the locus coeruleus is diffusely filled with dense OFQ binding. This binding pattern persists in the locus coeruleus to its caudal extent (Fig. 9A). Laterally, the medial parabrachial nucleus contains sparse binding, whereas binding in the lateral parabrachial nucleus is moderate to dense (Fig. 9A). Binding in the $\alpha$ division of the subcoeruleus nudeus is low and in Barrington's nucleus is sparse. Laterally, the granular layer of the anterior ventral cochlear nucleus is filled with moderate to dense OF Q binding.

In the caudal dorsal pons, the abducens nudeus contains low levels of binding, in marked contrast to the high ORL 1 mRNA expression observed in this nucleus. The adjacent para-abducens nucleus has no detectable OFQ binding. Laterally, the posterior ventral cochlear nucleus and dorsal cochlear nucleus are densely labeled with OFQ binding. At the genu of the facial nerve, in contrast to the paucity of orphanin receptor mRNA expression in this structure, the supragenual nucleus shows high levels of orphanin binding. Binding in the vestibular nuclear complex is generally moderate. Thesuperior vestibular nucleus emerges rostrally with low to moderate binding. The adjacent medial vestibular nucleus contains moderate to dense binding, with low levels of binding observed in its ventral subdivision (Fig. 9C). The lateral vestibular nucleus shows no detectable orphanin binding, and binding in the spinal vestibular nucleus is sparse to negligible. Ventral to the vestibular complex in the caudal metencephalon, the dorsomedial spinal trigeminal nucleus and the pars oralis of the spinal trigeminal nucleus contain moderate orphanin binding (Fig. 9C).

In the ventral pons, the nucleus of the trapezoid body emerges with moderate OF Q binding, the intensity persisting to the caudal extent of this nucleus. Lateral to the nucleus of the trapezoid body, the superior olivary nudear complex generally contains minimal binding. Rostrally, moderate binding is observed in the rostral periolivary area. Caudal to this structure, the medioventral and lateroventral periolivary nuclei show no OFQ binding. Binding in the superior paraolivary nucleus and dorsal periolivary nucleus is sparse. The lateral superior olive and medial superior olive have no detectable orphanin binding. The caudal periolivary nudeus contains low to moderate binding. Lateral to the olivary complex, the region of the $A 5$ cell group contains low to moderate orphanin binding. Caudal to the superior olive, binding in the facial nucleus is moderate (Fig. 9C). Although much decreased in intensity to that observed for ORL1 mRNA expression, binding in this nucleus remains dense to its caudal extent into the rostral medulla.

At the pontine midline, the raphe magnus emerges with negl igible binding. Theraphe pallidus nudeus and pontine raphe nucleus show no detectable OFQ binding at this level. F urther caudally, the pontine raphe nucleus remains devoid of binding, but orphanin binding intensity increases dramatically in the other ventral raphe nuclei. At the level of the facial nucleus, binding in the raphe pallidus nucleus is moderate and in the raphe magnus is low to moderate (Fig. 9C,E). This binding pattern becomes slightly more dense into the medulla. Within the reticular formation, the pontine reticular nucleus contains only sparse binding in its caudal division (Fig. 9A) and low to moderate in the ventral division. Further caudal, the intermediate reticular nucleus contains only sparse binding and the parvicellular reticular nucleus shows low to moderate binding. In the caudal pons, binding in the gigantocellular reticular nudeus is low to moderate. The lateral paragigantocellular reticular nucleus and the alpha division of the gigantocellular reticular nucleus show no detectable OF Q binding.

\section{Myelencephalon}

In situ hybridization. As seen in the metencephalon, orphanin receptor mRNA expression is high and widespread in the medulla. No mRNA expression is observed in major fiber bundles in this region, including the inferior cerebellar peduncle, vagal nerve, hypoglossal nerve, medial longitudinal fasciculus, pyramidal tract, solitary tract, and spinal trigeminal tract. In the rostral dorsal medulla, the region of the C3 cell group contains no mRNAexpressing cells. Further caudal, in the region of the C2 cell group, moderate to high mRNA expression is noted, medial to the nucleus of the solitary tract. The prepositus hypoglossus contains sparse mRNA expression rostrally and, at caudal levels, numerous large mRNA-expressing neurons fill this structure (Fig. 9D). The caudal interstitial nucleus of the medial Iongitudinal fasciculus has no detectable mRNA expression. Caudal to the prepositus hypoglossus, the dorsal motor nucleus of the vagal nerve contains high mRNA expression. The hypoglossal nucleus is packed with cells expressing high levels of mRNA, filling the nucleus to its caudal extent (Figs. 9F, 10B). The intercalated nucleus of the medulla has no mRNA expression.

In the medullary vestibular nuclear complex, mRNA expression remains unchanged, with moderate expression in the medial vestibular nudeus, low expression in the ventral part of the medial nucleus, sparse expression in the spinal vestibular nucleus and moderate expression in the lateral vestibular nucleus (Fig. 9D). This pattern persists to the caudal extent of the vestibular complex. Lateral to the spinal vestibular nucleus, the external cuneate nucleus contains sparse, scattered ORL 1-containing neurons. The nucleus of the solitary tract emerges in the rostral medulla with moderate mRNA expression. This pattern of expression persists caudally, where mRNA expression in the lateral and medial divisions is moderate, and the central division demonstrates high levels of mRNA expression (Figs. 9F, 10B). The high levels of mRNA expression in the central part of the solitary nudeus is in contrast to the paucity of mRNA expression observed in the area postrema and, further caudal, the median acces- 
sory nucleus of the medulla (Fig. 9F). At the lateral border of the central solitary nucleus, the region of the A2 cell group contains moderate mRNA expression. The solitary tract has no detectable mRNA expression. In the caudal dorsal medulla, the cuneate nucleus contains moderate mRNA expression, and the gracile nucleus has only sparse expression (Fig. 10B). Laterally, the paratrigeminal nucleus contains moderate mRNA expression.

Laterally, the spinal trigeminal nudeus in the rostral medulla contains high mRNA expression in its oral part and moderate in the dorsomedial part (Figs. 5B, 9C). The interpolar division of this nucleus emerges with high mRNA expression, persisting into the caudal myelencephaIon where the pars caudalis of the spinal trigeminal nudeus contains moderate to high mRNA expression (Figs. 9E, 10B). In the medullary reticular formation, mRNA expression is sparse to negligible in the parvicellular reticular nucleus and intermediate reticular nucleus. Medially in the rostral medulla, the gigantocellular reticular nucleus contains low to moderate mRNA expression, with moderate to high expression in its ventral division. The lateral paragigantocellular reticular nucleus contains negligible mRNA expression, and the adjacent rostroventriculolateral reticular nucleus contains very high mRNA expression. Caudal to the paragigantocellular reticular nucleus, the lateral reticular nucleus emerges with high mRNA expression, filling this region with large-sized cells (Fig. 10B). High mRNA expression persists in the rostroventriculolateral reticular nucleus at this level, in its lateral and medial components. Posterior to the gigantocelIular reticular nucleus, mRNA expression falls off in the caudal medullary reticular region, with moderate mRNA expression observed in the dorsal and ventral medullary reticular nuclei, and negligible expression in the intermediate reticular nudeus. This pattern persists to the caudal extent of the myelencephal on.

In the rostral ventral medulla, just caudal to the facial motor nucleus, high mRNA expression is observed the region of the $\mathrm{C} 1$ cell group and the rostroventriculolateral reticular nucleus. This persists caudally into the region of theAl cell group, where mRNA expression remains high to its caudal extent. At this level, the nucleus ambiguous emerges with high mRNA expression, providing some of the highest mRNA expression in the medulla (Fig. 9F). Further caudal, intensity of mRNA expression decreases slightly into the retroambiguous nucleus. At the emergence of the inferior olivary complex, the principal and dorsal nuclei contain moderate to high mRNA expression, with low to moderate expression in the medial nucleus and dorsomedial cell group (Fig. 10B). Caudal to the principal olivary nucleus, mRNA expression falls off in the inferior olivary complex, with sparse mRNA expression in subnudeus $A$ and subnucleus $B$, low to moderate expression in the medial nucleus, and persistent moderate expression in the dorsal nucleus. At the ventral midline, the raphe magnus is filled with dense mRNA expression in the rostral medulla and persists throughout the myelencephaIon (Fig. 9F ). Adjacent to raphe magnus, the raphe pallidus nucleus contains high mRNA expression, and the raphe obscurus nucleus contains moderate mRNA expression, which persists to its caudal extent, at the pyramidal decussation (Fig. 10B).

Orphanin FQ binding. Similar to ORL 1 mRNA expression, OFQ binding in the myelencephalon is widespread and not observed within major medullary fiber bundles. One exception is the caudal spinal trigeminal tract, which contains some OF Q binding (discussed bel ow). In the rostral dorsal medulla, the region of the C3 cell groups is devoid of orphanin binding and binding in the $\mathrm{C} 2$ cell region is low to moderate. J ust caudal to the supragenual nucleus of the pons, dense orphanin binding is observed in the prepositus hypoglossus, persisting to its caudal pole (Fig. 9C). Caudal to the prepositus hypoglossus, the dorsal motor vagal nucleus contains moderate binding. Binding in the hypoglossal nudeus is sparse (Fig. 9E ). Adjacent to the hypoglossal nucleus, the intercalated nucleus of the medulla and the caudal interstitial nucleus of the medial longitudinal fasciculus have no detectable orphanin binding.

In the medullary vestibular nuclear complex, the medial vestibular nucleus and ventral medial vestibular nucleus have moderate OFQ binding. Binding is sparse in the spinal vestibular nucleus and negligible in the lateral vestibular nucleus (Fig. 9C). Laterally, the external cuneate nucleus contains moderate to dense binding. At this level, the nucleus of the solitary tract emerges with sparse binding initially, increasing to become low to moderate in the lateral and medial divisions more caudally. This pattern persists into the caudal part of this structure, where binding intensifies and becomes dense in the central division (Figs. 9E, 10A). The adjacent area postrema at this level contains moderate to high levels of binding (Fig. $9 \mathrm{E}$ ), and binding in the region of the A2 cell group is low to moderate. At the caudal pole of the nucleus of the solitary tract, the median accessory nucleus of the amygdala is filled with cells expressing high levels of orphanin binding. In the caudal dorsal medulla, binding is modest in the paratrigeminal and cuneate nuclei, and sparse to negligible in the gracile nucleus (Fig. 10A).

In the rostral lateral medulla, the spinal trigeminal nudleus, pars oralis contains moderate binding. This binding intensity persists into the interpolar and dorsomedial parts of the medullary spinal trigeminal nucleus, increasing dramatically into the caudal medullary region (Fig. 9E). At this level, OFQ binding is dense throughout the pars caudalis of the spinal trigeminal nucleus, making it one of the most densely labeled structures in the medulla. Orphanin binding extends from the spinal trigeminal nucleus into the caudal spinal trigeminal tract, making this the only major fiber bundle in the CNS with OFQ binding (Fig. 10A). This binding pattern persists into the spinal cord.

Orphanin binding in the medullary reticular formation is generally low. Binding in the parvicellular reticular nucleus is low to its caudal extent. The intermediate reticular nucleus contains only sparse orphanin binding. Medially, the gigantocellular reticular nucleus contains low to moderate orphanin binding, more moderate in its ventral division. At this level, the lateral paragigantocellular reticular nucleus has no detectable OF Q binding, and the dorsomedial paragigantocellular reticular nucleus contains only sparse to low levels of binding. Laterally, the rostroventriculolateral reticular nucleus contains low to moderate binding, and binding in the lateral reticular nudeus is low (Fig. 10A). The ventral medullary reticular nucleus contains low to moderate binding at all levels, whereas the dorsal medullary reticular nucleus contains low levels of binding rostrally and dense labeling at the level of the pyramidal decussation (Fig. 10A). 
In the ventral medulla, low to moderate binding is observed in the region of the $\mathrm{Cl}$ cell group within the rostroventriculolateral reticular nucleus. This binding pattern persists to the Al cell group caudally. At this anatomic level, the nucleus ambiguous emerges with dense OFQ binding. Orphanin binding decreases to some degree into the retroambiguous nucleus where it is only moderate. Dense binding is observed throughout the inferior olive, persisting throughout the entire ventral medulla (Fig. 10A). Rostrally, moderate binding is observed in the dorsal nudeus of the inferior olive and dense binding in the principal nucleus. The dorsomedial cell group contains moderate binding, and the medial nucleus of the inferior olive emerges with dense binding. This pattern persists caudally, with moderate binding noted in subnucleus B of the olivary complex. Subnucleus $A$ of the inferior olive emerges with dense OFQ binding, persisting to the caudal medulla with some of the most dense orphanin binding seen in this region. At the caudal pole of the inferior olive, the medial nucleus is filled with dense OFQ binding. Adjacent to the inferior olivary complex, the raphe magnus contains moderate binding (Fig. 9E). This level persists to its caudal extent. The adjacent raphe pallidus nucleus contains dense binding throughout. This dense binding persists to the caudal extent of the medulla. The raphe obscurus contains only low to moderate binding (Fig. 10A).

\section{Spinal cord}

In situ hybridization. In the cervical spinal cord, ORL 1 mRNA expression is higher in the ventral horn than the dorsal horn (Fig. 10D). Messenger RNA-containing cells in the dorsal horn are confined mostly to the deeper laminae. No orphanin receptor mRNA expression is observed in lamina I, and only scattered mRNA-containing cells are noted in Iamina II. Messenger RNA expression becomes slightly stronger in laminae III and IV, where low to moderate expression is observed. Laminae $\mathrm{V}$ and $\mathrm{VI}$ contain moderate to high mRNA expression, extending medially to lamina $X$, where scattered neurons with only Iow mRNA expression are observed. The highest ORL 1 mRNA expression in the cervical spinal cord is in laminae VIII and IX of the ventral horn. In this region, numerous, large ventral horn cells containing abundant mRNA expression are widely distributed, slightly more concentrated in Iamina IX.

In the thoracic spinal cord, the ORL 1 mRNA expression pattern is very similar to that of the cervical cord. No mRNA expression is observed in Iamina I, and laminae II and III contain only scattered mRNA-expressing cells. Layer $\mathrm{V}$ in the thoracic region has very sparse mRNA expression, and lamina IV contains moderate expression. Laminae VII and VIII contain scattered, large neurons with moderate mRNA expression, spreading medial to lamina X, where expression is also moderate. The ventral horn, similar to that seen in the cervical region, contains numerous large, densely labeled neurons, with most mRNA-expressing neurons within Iamina IX. High mRNA expression is observed in the intermediomedial cell column and in the intermediolateral column.

The dorsal root ganglion is filled with numerous, large mRNA-expressing neurons. These neurons are located widely throughout the ganglion and contain high mRNA expression (Fig. 10D). I n other areas of the spinal cord, the central cervical nucleus contains low to moderate mRNA expression, and the lateral cervical and lateral spinal nud ei contain sparse mRNA expression. NomRNA expression is observed in the cuneate fasciculus, the dorsal corticospinal tract, lateral funiculus, or ventral funiculus.

Orphanin FQ binding. In contrast to ORL 1 mRNA distribution in the spinal cord, orphanin binding is higher in the dorsal horn than in the ventral horn (Fig. 10A). In the cervical spinal cord, lamina I contains no OF Q binding. Binding then increases significantly, becoming dense in Iamina II and remaining moderate to dense in lamina III. Binding intensity decreases significantly into the deeper laminae of the dorsal horn, becoming low in lamina IV and V. M ore moderate binding is observed in lamina VI, but the density of binding sites falls off into the ventral horn, with only Iow levels of binding observed in laminae VII, VIII, and IX. Lamina X contains moderate binding, diffusely localized.

In the thoracic spinal cord, no binding is noted in lamina I and only low binding is noted in lamina II. The density of binding sites increases significantly, with moderate binding in lamina III and high levels of binding noted in Iamina IV. This level of binding extends medially into lamina $X$, where very dense orphanin binding is noted. Into the ventral horn, Iow levels of binding are noted in laminae VII and VIII.

In marked contrast to ORL1 mRNA expression, no orphanin binding is observed in the dorsal root ganglia (Fig. 10A). In the remaining areas of the spinal cord, low to moderate binding is observed in the intermediomedial cell col umn, with moderate to dense binding in the intermediolateral cell column. Other than sparse labeling noted in the central cervical nucleus, the remainder of the spinal cord has no detectable orphanin binding, including the lateral cervical and lateral spinal nuclei, cuneate fasciculus, dorsal corticospinal tract, lateral funiculus, and ventral funiculus.

\section{DISCUSSION \\ ORL1 mRNA expression and OFQ binding}

Both in situ hybridization and ${ }^{125}$-[14Tyr]-OF Q peptide binding demonstrate a wide-spread distribution of ORL 1 receptor in the adult male rat brain. Our in situ hybridization findings are in good agreement with earlier studies of ORL 1 mRN A distribution in the rat and mouse (Bunzow et al., 1994; Fukuda et al., 1994; Mollereau et al., 1994; Wick et al., 1994; Lachowicz et al., 1994). In addition, the 125/-[14Tyr]-OFQ peptide, in our hands, demonstrates a high affinity for the ORL 1 receptor, similar to that previously observed for [14Tyr]-OF Q (Ardati et al., 1997).

In the present study, distribution of ORL 1 mRNA expression correlated closely with that of ${ }^{125}$-[ ${ }^{14} \mathrm{Ty}$ r]-OF Q binding in most CNS regions. In general, most areas that contained mRNA expression also demonstrated some degree of receptor binding. Additionally, almost every region with dense OF Q binding al so contained mRNA-expressing cells. This close correlation was observed in all cortical regions, including the neocortex, orbital cortex, insular cortex, cingulate cortex, entorhinal cortex, piriform cortex and retrosplenial cortex. It was also observed in the anterior olfactory nucleus, diagonal band, lateral septum, claustrum, endopiriform nuclei, globus pallidus, substantia nigra, most divisions of the medial preoptic area and bed nucleus of the stria terminalis, multiple hypothalamic nuclei, including the anterior hypothalamus, arcuate nucleus, mammillary region, paraventricular nucleus, posterior hypothalamus and ventromedial nucleus, the ante- 
rior cortical, basolateral, medial and posterior cortical amygdaloid nuclei, the stratum oriens of Ammon's horn, the subiculum and multiple thalamic nuclei, including the anteroventral nucleus, habenula, Iateral geniculate nucleus, paratenial nucleus, paraventricular nucleus, reunions, rhomboid nucleus, reticular nucleus, and zona incerta. In the brainstem, close correlation was observed in the central gray, raphe nuclei, inferior colliculus, Edinger-Westphal nucleus, interpeduncular nucleus, precommissural nucleus, perifornical nucleus, pontine nuclei, peripeduncular nucleus, motor nuclei of the abducens and facial nerves, A5 cell region, superior olivary region, locus coeruleus, lateral parabrachial nucleus, several vestibular nuclei, the principal and sensory nuclei of the trigeminal nerve, the nucleus of the trapezoid body, ventral cochlear nucleus, motor nucleus of the vagal nerve, $A 1, A 2$, and $A 7$ cell regions, nucleus ambiguous, multiple nuclei of the brainstem reticular system, several divisions of the inferior olive, the rostral ventrolateral medulla, the retroambiguous nucleus, and nucleus of the solitary tract. In the spinal cord, each of laminae II-X contained varying levels of both mRNA expression and OF Q binding.

Despite the immense number of structures that contained both ORL1 mRNA expression and OFQ binding, there were some notable exceptions where mismatch occurred between ORL1 mRNA expression and orphanin receptor binding. High ORL1 mRNA expression was observed in several regions in which no detectable ${ }^{125}$-[14Tyr]OFQ binding was observed. This was noted in several forebrain structures, including the basal nucleus of Meynert, posterolateral and medial posteromedial divisions of the bed nudeus of the stria terminalis, medial preoptic nucleus, periventricular and supraoptic nuclei of the hypothalamus, amygdalopiriform transition area, basomedial amygdala, the pyramidal layer of area CA3, the dentate gyrus granule cell and polymorph layers, the precommissural, and ventral posteromedial nuclei of the thalamus. In the midbrain, this pattern was observed in the oculomotor and trochlear motor nudei, parabigeminal nucleus, parabrachial pigmented nucleus, magnocellular nucleus of the posterior commissure, red nucleus, retrorubral field, and the optic and intermediate layers of the superior colliculus. In the cerebellum, the interposed, lateral and medial deep nudei all contain abundant ORL1 mRNA expression, with only slight binding in the lateral nucleus. In the metencephalon, the abducens and facial motor nuclei contain high mRNA expression. Both cranial nerve nudei contain ${ }^{125}$-[14Tyr]-OFQ binding, but markedly lower density of receptor sites. In addition, high mRNA expression is observed in the alpha subdivision of the gigantocellular and caudal pontine reticular nuclei, lateral superior olive, lateral vestibular nucleus, lateroventral and medioventral preol ivary nudei, mesencephalic trigeminal nucleus, para-abducens nudeus, and pontine raphe nucleus. In all of these structures, OFQ binding is negligible. In the myelencephalon, dense mRNA expression is observed in the hypoglossal nucleus and dorsal motor nucleus of the vagal nerve, whereas orphanin binding is negligible in the hypoglossal nucleus and significantly decreased in the dorsal motor vagal nucleus. No other medullary region exhibits such dissimilarity. The disparity of ORL 1 expression and OF Q binding is also marked in the spinal cord. In the cervical spinal cord, ORL 1 mRNA expression is high in laminae VIII and IX of the ventral horn, where ${ }^{125}$-[14Tyr]-OFQ binding is low. Moderate to high mRNA expression is also observed in lamina $\mathrm{V}$, another area where OFQ binding is negligible. In the thoracic spinal cord, this disparity is most pronounced in laminae VIII and IX. The dorsal root ganglion is densely filled with cell bodies containing high mRNA expression, but is devoid of OF Q binding.

There were very few notable CNS regions where ${ }^{125}$ [14Tyr]-OF Q binding is dense, whereas ORL 1 mRNA expression is negligible or absent. These regions of disparity include the glomerular layer of the olfactory bulb, the medial mammillary nucleus, suprachiasmatic nucleus, tuber cinereum, molecular layer of the dentate gyrus and multiplethalamic nuclei (anteroventral, laterodorsal, paracentral, and ventromedial), the olivary pretectal nucleus, the zonal and superficial gray layers of the superior colliculus, supragenual nucleus, anterior ventral cochlear nucleus, external cuneate nucleus, medial subnucleus $A$ and $\mathrm{B}$ of the inferior olive, dorsal medullary reticular nucleus, and median accessory nucleus of the medulla. All of these structures contain abundant OFQ binding with negligible ORL1 mRNA expression. In the spinal cord, lamina II in the cervical region and lamina III in the thoracic region also demonstrate this disparity. The spinal trigeminal tract, the only fiber bundle in the CNS that demonstrates OF Q binding, is also devoid of ORL 1 mRNA expression.

For the numerous CNS structures containing robust ORL 1 mRNA expression, while having minimal or no OF Q binding, several possible explanations for this disparity exist. Although ORL 1 mRNA is transcribed in cell bodies within these structures, the ORL 1 receptor may not be translated, and therefore not available for binding. These could also be regions where inactive orphanin receptor is made, and unavailable for binding. Most likely however, these are regions where ORL 1 is produced in neuronal cell bodies, transported, and incorporated into the cell membrane at a site distal from the cell bodies containing orphanin receptor $\mathrm{mRNA}$. Although there are many fewer structures in which OFQ binding is robust while ORL 1 mRNA expression is absent, these too are most likely regions where ORL 1 receptor has been transported.

This mismatch in receptor mRNA and agonist binding also has been observed in the opioid receptor system (Mansour et al., 1993, 1994a,b, 1995b), where it is also thought that such a mismatch provides evidence for opioid receptor trafficking (Mansour et al., 1995b). In the orphanin system, this explanation also likely holds true. Regions where there is a strong correlation between OFQ binding and ORL 1 mRNA expression likely represent areas of Iocal receptor synthesis. In regions of poor correlation, receptor transport is most likely. For example, several cranial nerve nuclei contain robust ORL1 mRNA expression, with negligible or no receptor binding sites. This suggests that the ORL 1 receptors are synthesized in cells of the red and facial nuclei, for example, and transported to their terminals where they are localized presynaptically. Similar to what has been observed in the $\mu, \kappa$, and $\delta$ opioid receptor system (Mansour et al., 1995b), ORL 1 receptor mRNA expression is low in superficial and moderate in deeper layers of the dorsal horn of the spinal cord. This expression is robust in the ventral laminae, and high in the dorsal root ganglia. In contrast, OF Q binding is densest in the superficial and deep dorsal horn layers, low in the ventral horn, and absent in the dorsal root ganglia. A likely explanation for these findings is that receptors expressed in the deeper 
layers of the dorsal horn are probably postsynaptic, and those in the superficial laminae probably reside on presynaptic fibers originating from the dorsal root. Orphanin receptor-containing cells in the ventral horn most likely transport ORL1 receptor to a distal site where they act presynaptically.

\section{Comparisons with ORL1-like immunolabeling}

Anton et al. (1996) has reported a detailed distribution of the immunohistochemical localization of the ORL1 receptor. This study did not include an analysis of ORL 1 mRNA distribution or OF Q binding, but rather focused on the distribution of the receptor protein. The ORL 1 receptor monoclonal antibody used by Anton et al. was also used in a recent report comparing ORL 1 and $\mu$ opioid receptor distributions in pain processing regions of the brain (Monteillet-Agius et al., 1998). We have spoken with the senior author of the Anton study (Chris Evans, PhD). He has informed us that recent studies that used his ORL 1 monoclonal antibody in ORL 1 knockout mice have raised doubts concerning the specificity of this antiserum and he encouraged us to present these concerns as part of this discussion. It appears that this antibody still generates significant immunoreactivity in ORL1 knockout mice, suggesting the presence of at least two epitopes in the CNS that this antiserum is recognizing, one epitope being ORL 1 and the other(s) unknown (Chris J . Evans, personal communication). Although these recent findings raise questions concerning the specificity of the antiserum used by Anton et al. (1996), the pattern of distribution observed by this group is in much agreement with ORL1 mRNA distribution reported previously (Bunzow et al., 1994; Fukuda et al., 1994; Lachowicz et al., 1994; Mollereau et al., 1994; Wick et al., 1994) and with the findings of the present study. Taking intoaccount theseconcerns, comparisons made between our findings and those of the Anton study should be made with caution. However, due to the similarity in ORL 1 distribution observed in our study and that of Anton et al. (1996), brief comment will be made regarding mismatch of receptor mRNA, protein, and binding distributions.

In concordance with our findings the authors found the orphanin receptor to be distributed throughout a wide range of the rat CNS, with most staining confined to fibers and puncta. Orphanin receptor immunoreactivity in neuronal cell bodies was observed only in the hilus of the dentate gyrus in the forebrain, in the red nucleus, pontine reticular nucleus, gigantocellular reticular nucleus and paragigantocellular reticular nucleus in the brainstem, and in Iaminae VIII and IX, the intermediolateral cell column, dorsal nucleus, and lateral cervical nucleus of the spinal cord. All of the above structures contain variable ORL 1 mRNA expression, ranging from sparse in the dentate hilum, paragigantocellular reticular nucleus, and lateral cervical nucleus, to high in thered nucleus, caudal pontine reticular nucleus, Iaminae VIII and IX of the ventral horn, and intermediolateral cell column. However, in all of these structures, OFQ binding is very sparse to undetectable. These regions most likely represent areas where abundant mRNA is translated into ORL 1 receptor protein that is transported distally, rather than being incorporated in the cell body as a postsynaptic receptor. Interestingly, in no region where ORL1 receptor immunoreactivity was detected with cell bodies was significant ${ }^{125}$ I-[14Tyr]-OFQ binding also observed. However, mRNA expression was present in all these congruent structures. Colchicine was not used in the study by Anton et al. (1996), and had axonal transport been inhibited, it is possible that many more regions with ORL 1-containing cells expressing both mRNA and receptor protein would be observed.

Assuming that most ORL 1 receptor protein observed by immunohistochemistry is specific (see above) and represents regions where active receptor is incorporated into neuronal cell membranes, we expect that the distribution of ${ }^{125} \mathrm{I}-\left[{ }^{14} \mathrm{Tyr}\right]-O F Q$ binding should correlate well with the distribution of ORL 1-like immunoreactivity (Anton et al., 1996). Indeed, this is generally the case, as ${ }^{125}$-[ ${ }^{14} \mathrm{Ty}$ r]OFQ binding analyzed in the present study correlates extremely well with previously reported ORL 1-like immunoreactivity. Orphanin receptor protein and binding are both widely distributed throughout the CNS, with only few areas of mismatch in our findings.

In the indusium griseum, subfornical organ, several thalamic nuclei (ventrolateral, ventral posteromedial, ventral posterolateral, interanteromedial, Iaterodorsal, lateral geniculate, and paraventricular), and the tuber cinereum, no ORL 1-like immunoreactivity was observed but significant OFQ binding was present. No such regions of mismatch were observed in the brainstem or spinal cord. This finding was especially evident in the thalamus, where moderate to dense OF Q binding was observed in multiple nuclei, whereas ORL 1-like immunoreactivity was absent in many regions and low in most others. There are several CNS structures where ORL1-like immunoreactivity is light, whereas $\left.{ }^{125} \mathrm{I}-{ }^{14} \mathrm{~T} y \mathrm{r}\right]-O F Q$ binding is dense. These may represent regions where receptor protein is not as detectable as OFQ binding by the methods used. Regions where no receptor protein is detected but binding is detectable are very few. Other than several thalamic nuclei, only three other structures in the CNS that contain OFQ binding also lack ORL1 immunoreactivity. Given that ORL 1 immunoreactivity is very weak throughout the thalamus, whereas OF Q binding is high, it is possible that this particular region may have mismatch solely due to limits of sensitivity in detecting ORL 1 immunoreactivity in this region, even when considering probable lack of specificity of the ORL 1 antiserum. Orphanin FQ binding is robust and specific in this region, and ORL 1 mRNA expression is present and high in many thalamic nuclei as well. Although Anton et al. (1996) did not find ORL 1-like immunoreactivity in high quantities in the thalamus, most likely the receptor protein is present. Alternatively, the presence of binding and no protein may suggest the existence of multiple receptor subtypes that have yet to be cloned. Further studies are needed to more closely examine this possibility.

Finally, there are some structures for which ${ }^{125} \mathrm{I}-\left[{ }^{14} \mathrm{Tyr}\right]-$ OFQ binding is not detectable, but ORL1-likeimmunoreactivity is present in significant amounts. These structures include the islands of Calleja, basal nucleus of Meynert, endopiriform nucleus, basomedial, central and posterolateral cortical amygdaloid nuclei, stratum radiatum and stratum pyramidal of areas CA1-CA3 of Ammon's horn, the granular layer of the dentate gyrus, trochlear nucleus, rostral interpeduncular nucleus, deep mesencephalic nucleus, retrorubral field, Kolliker-Fuse nucleus, posterodorsal tegmental nucleus, laminae I and IX of the spinal cord, and the lateral cervical nucleus. Again, this may represent areas of nonspecific ORL 1 immunoreactivity (see above). However, these regions may also represent 
areas where the ORL 1 protein is present but being transported and not yet incorporated into cell membranes as active receptor. These may also be regions of inactive ORL1 receptor in the CNS. In general, despite the recent evidence questioning the specificity of the ORL 1 monoclonal antiserum (Chris J . Evans, personal communication), structures where mismatches were observed were only a small proportion, accounting for less than $8 \%$ of thetotal structures analyzed.

\section{Comparisons with endogenous opioid systems}

The orphanin FQ receptor is known to differ from known opioid receptors in its structure and distribution (Chen et al., 1994; Fukuda et al., 1994; Lachowicz et al., 1994) and its interactions with known opioid agonists (Meng et al., 1996; Sim et al., 1996; Ma et al., 1997). As reported in the present study, the distribution of the ORL 1 receptor is distinct from that of other opioid receptors. The distribution of the endogenous opioid peptide precursors, proopiomelanocortin, proenkephalin, and prodynorphin, has been studied in detail (Kachaturian et al., 1985), as has the distribution of corresponding $\mu, \kappa$, and $\delta$ receptors (Mansour et al., 1987, 1993, 1994a-d, 1995a,b, 1996). Correlations between the distribution of the endogenous opioid systems and orphanin FQ (mRNA and peptide) has been discussed previously (Neal et al., 1999). In the present discussion, we will focus on the relationship of ${ }^{125}$ - [14Tyr]OFQ binding and opioid peptide and receptor systems as possible sites of opioid modulation by ORL 1 activation. It is important to emphasize at this point that the possible modulation of opi oid and orphanin systems by one another is not direct, because opioid peptides have essentially no affinity for the orphanin receptor (Bunzow et al., 1994; Chen et al., 1994; Fukuda et al., 1994; Lachowicz et al., 1994; Wick et al., 1994; Ma et al., 1997; Nicholson et al., 1998), and orphanin FQ has no affinity for the known opioid receptors (Reinscheid et al., 1995). There may be some physiologic interactions, however, due to their possible localization in or interactions with the sameneuronal cell body or process.

Pro-opiomelanocortin and the $\mu$ receptor. Proopiomelanocortin gives rise to the endogenous opioid $\beta$-endorphin. Although this neuropeptide has a very limited CNS neuronal distribution, $\beta$-endorphin-containing fibers are widely distributed (Kachaturian et al., 1985). The $\mu$ opioid receptor, like $\beta$-endorphin, is widely distributed within fibers in the CNS, but it also has a much broader distribution within cell bodies (Mansour et al., 1987, 1994a, 1995a,b).

Moderate 125]-[14Tyr]-OFQ binding is observed in the arcuate nucleus, and dense binding is observed in the nucleus of the solitary tract, both structures with $\beta$-endorphin-containing cell bodies. In the bed nucleus of the stria terminalis, medial amygdala, dorsomedial hypothalamus, paraventricular thalamic nucleus, central gray, raphe system, lateral parabrachial nucleus, and nucleus of the solitary tract, orphanin binding is dense and may play a modulatory role on neurotransmitter rel ease from $\beta$-endorphin-containing fibers.

Similarly, $\mu$ and ORL 1 receptor binding are both dense in the neocortex, medial amygdala, dentate gyrus, thalamus, substantia nigra, pars compacta, superior colliculus, parabrachial nucleus, nucleus ambiguous, solitary nucleus, spinal trigeminal nucleus, and lamina II of the spinal dorsal horn. Similar to possible modulatory effects on the $\beta$-endorphin system, the orphanin system may modulate $\mu$ receptor effects in these regions. In addition, activation of the $\mu$ receptor could modulate ORL 1 receptor effects in these regions as well. In support of a possible inhibitory rolefor OF Q on this system, it has been demonstrated that orphanin FQ can inhibit $\beta$-endorphin neurons and secretory cells in the arcuate by means of activation of inward K+ currents (Wagner et al., 1998). Orphanin FQ has also been shown to inhibit dorsal raphe and central gray neurons by a similar mechanism (Vaughan and Christie, 1996; Vaughan et al., 1997).

Prodynorphin and the $\kappa$ receptor. Prodynorphincontaining cell bodies and fibers are widely distributed throughout the CNS (Kachaturian et al., 1985; Mansour et al., 1994b), and $\kappa$ receptor localization and binding is also quite widespread (Mansour et al., 1987, 1994b,c, 1995b, 1996). There are several regions where moderate to dense 125I-[14Tyr]-OFQ binding could coexist with dynorphincontaining cell bodies, including the dentate gyrus, the arcuate and ventromedial hypothalamic nuclei, central gray, parabrachial nucleus, nucleus of the solitary tract, caudal spinal trigeminal nucleus, and dorsal horn of the spinal cord. Within the CA3 region of Ammon's horn, the central gray, lateral parabrachial nucleus, caudal spinal trigeminal nucleus, nucleus of the solitary tract, and dorsal horn of the spinal cord, dynorphin fiber labeling and ORL 1 receptor binding are high. In these regions, ORL 1 receptor activation may directly influence the dynorphin system. Within the medial preoptic area, bed nucleus of the stria terminalis, paraventricular thalamic nucleus, medial nucleus of the amygdala, ventromedial hypothalamus, superficial gray layer of the superior colliculus, central gray, dorsal raphe, parabrachial nucleus, nucleus of the solitary tract, and spinal trigeminal nucleus, dense 125I -[14Tyr]-OFQ binding and robust $\kappa$ receptor localization and binding is observed. These areas provide sites for possible cross-modulation of ORL 1 and $\kappa$ activation within these structures. To date, a direct effect of orphanin FQ on dynorphin production or rel ease or on $\kappa$ receptor activation has not been demonstrated.

Proenkephalin and the $\delta$ receptor. Proenkephalin is the most widely distributed of the endogenous opioid peptides, but with a limited distribution in the brainstem (Kachaturian et al., 1985). In contrast, the $\delta$ receptor is less widely distributed than the other opioid receptors (Mansour et al., 1987, 1993, 1995b).

The function of enkephalin-containing neurons could be influenced by OFQ activation of the ORL 1 receptor in many regions where both are expressed. Such regions include the cingulate and piriform cortices, paraventricular and arcuate nuclei of the hypothalamus, hippocampal formation, central gray, paramedian raphe and raphe magnus, solitary nucleus, spinal trigeminal nucleus, and dorsal horn of the spinal cord. Enkephalin-containing fibers in the ventromedial nucleus of the hypothalamus, hippocampal formation, central gray, interpeduncular nudeus, solitary nudeus, and dorsal horn of the spinal cord are also within regions where OF Q binding is present, providing another milieu where orphanin modulation of enkephalin peptide may occur by means of ORL 1 activation. Interestingly, orphanin FQ has been shown to modulate enkephalin release in myenteric plexus preparations (Gintzler et al., 1997), providing evidence that such an interaction could occur in the CNS as well. The ventromedial nudeus of the hypothalamus, medial nudeus of the 
amygdala, interpeduncular nucleus, spinal trigeminal nucleus, and substantia gelatinosa of the dorsal horn contain dense ORL 1 and $\delta$ receptor binding. This codistribution of ORL 1 and $\delta$ receptor binding provides sites for possible cross-modulation of $\delta$ and ORL 1 receptor activation in these regions.

\section{Orphanin $F \mathbf{Q}$ and $O R L 1$ receptor circuitry}

Although ORL1 receptor MRNA and ${ }^{125}$-[14Tyr]-OFQ binding distribution differs markedly from that of the OFQ peptide, on closer analysis, multiple anatomic circuits become evident where peptide-receptor interactions may provide insights into functional roles for this new orphanin system. A detailed discussion of these functional implications with respect to the distribution of OF Q and the ORL 1 receptor has been published recently (Neal et al., 1999). Therefore, this discussion will not attempt to repeat the previous exhaustive review but will instead discuss possible roles of orphanin F Q in sel ected anatomic systems.

Cortical systems. Within the cerebral cortex, dense ORL 1 receptor binding is observed, particularly in layers IV-VI. In addition, OFQ peptide and mRNA are also heavily distributed in the neocortex in layers II I II , V, and VI (Neal et al., 1999). This diffuse pattern of OFQ and ORL 1 distribution provides evidence of involvement of the orphanin system in cortical input and output circuits. One example of such an influence is on cortical noradrenergic input. It has been demonstrated recently that orphanin may inhibit noradrenaline release in the cortex by means of presynaptic ORL 1 receptors (Schlicker et al., 1998).

Thalamic input into the cortex may also be a source of orphanin modulation. However, OFQ levels observed in the thalamus are very low, and orphanin-containing neurons that are identified in the thalamus reside in structures that tend to have limbic connections, such as the anteroventral, paratenial, and paraventricular nudei (Neal et al., 1999). One notable exception to this trend is the OF Q mRNA expression observed in the posterior thalamic group and suprageniculate nucleus. This region of the thalamus receives spinothalamic fibers and has been shown to be involved in the perception of painful stimuli in the monkey. Neurons within this region are known to project directly to somatosensory cortical areas (Bowsher, 1961; Kerr, 1975; Boivie, 1979), making this one of several areas where OF Q may play a role in pain modulation.

It is of interest to note that the claustrum contains strong OF Q immunoreactivity and mRNA expression and dense ORL 1 binding. Although, traditionally thought of as a basal ganglia structure, this telencephalic cell group has widespread reciprocal connections with the neocortex (Norita, 1977), bearing more resemblance with the thalamus than with the basal ganglia. Corticoclaustral projections arise from pyramidal cells in layer VI of the neocortex, and projections from the claustrum terminate mostly in layer IV of the neocortex (Olson and Graybiel, 1980; Sherk and Levay, 1981a,b). Cortical layer VI contains abundant OF Q binding, and OF Q peptide is in abundance in cell bodies in the claustrum, providing the framework for reciprocal cortical and claustral circuitry.

Mesolimbic systems Although OF Q expression within cell bodies in the nucleus accumbens is negligible, it is important to note that fiber labeling within this structure is quite dense, particularly in the rostral pole and core. Although the shell and core have been reported to contain a moderate amount of ORL1 immunoreactivity in fiber processes (Anton et al., 1996), 125I-[14Tyr]-OFQ binding observed in the accumbens core and shell is light. Afferents into the accumbens core differ markedly from those into the shell, which had much less OF Q fiber immunolabeling (Zahm and Brog, 1992; Brog et al., 1993). Major afferents to this region include the basolateral amygdala, entorhinal cortex, intralaminar thalamic nuclei, ventral tegmental area and dorsal raphe, regions with prominent OFQ immunoreactivity, and mRNA content (Neal et al., 1999). Little is known concerning the behavioral effects of OF Q in relation to these regions, but it may play a role in modulation of both motivational and motor-related behaviors. In support of a functional role for the orphanin system in this circuitry, injections of orphanin FQ into the lateral ventricle of the rat has been shown to suppress dopamine release in the nucleus accumbens (Murphy et al., 1996). Interestingly, although rats have been shown to develop tolerance to locomotor effects induced by orphanin (Devine et al., 1996a), they fail to demonstrate conditioned place preference when given intraventricular injections of this peptide (Devine et al., 1996b). However, the inability to generate conditioned place preference or aversion in earlier studies in the rat may have been limited again by locomotor effects of this peptide. The presence of OFQ within this ventral tegmental-accumbens circuitry may point to a modulatory role for this peptide in behavioral reinforcement.

Extended amygdala. It has been proposed that the bed nucleus of the stria terminalis provides a major output point for the extended amygdala complex (Alheid et al., 1995). In this model, the medial nudeus of the amygdala is intimately related with the medial division of the stria terminalis and the central nucleus is reciprocally connected with the lateral division of the bed nucleus of the stria terminalis and the shell of nucleus accumbens. Orphanin FQ peptide immunoreactivity is high in the medial and central amygdaloid nuclei, and both the medial and lateral divisions of the bed nucleus of the stria terminalis ( $\mathrm{Neal}$ et al., 1999). Orphanin receptor binding is negligible in the central amygdaloid nucleus but is dense in the medial and lateral divisions of the bed nucleus of the stria terminalis and the medial nucleus of the amygdala. The presence of OFQ within these structures provides a source of orphanin influence in many functional systems. For example, the medial extended amygdala with the medial division of the bed nucleus of the stria terminalis are known to have efferents to the medial preoptic area and anterior hypothalamus, medial thalamic nud ear group, and multiple hypothalamic nuclei. Orphanin receptor binding is robust within these regions, providing support for a broad range of orphanin influence in motor control, autonomic responses, and specific behavioral patterns (motivational, sexual, feeding, and defensive behaviors).

Preoptic and hypothalamic circuits. The medial preoptic-anterior hypothalamic area and ventromedial nucleus of the hypothal amus receive strong input from the extended amygdala, and both demonstrate dense ORL 1 binding. In addition, the medial preoptic area contains moderate OFQ neuronal, fiber, and terminal labeling (Neal et al., 1999). The ventromedial hypothalamus is devoid of OFQ-containing neurons but has a moderate plexus of orphanin FQ fibers and terminals and demonstrates high levels of OFQ binding. The medial preoptic area receives inputs from the medial nucleus of the 
amygdala and medial bed nucleus of the stria terminalis (medial extended amygdala), arcuate nucleus, lateral septum, ventral tegmental area, parabrachial nucleus, and nucleus of the solitary tract, all regions with OFQcontaining neurons. Output of the medial preoptic area is extensive and plays a major role in neuroendocrine, autonomic, and somatosensory responses responsiblefor highly integrated maternal and mating behaviors (Simerly, 1995). The ventromedial nucleus of the hypothalamus contains some of the most dense ORL 1 mRNA expression and OF Q binding in the CNS. It receives strong inputs from the ventral subiculum and medial amygdala, both of which contain abundant orphanin FQ immunoreactivity. It also receives multiple afferents from the hypothalamus and parabrachial nucleus. Most afferents to the ventromedial nucleus originate in structures with OFQ-containing neurons. Efferents from this nucleus project to the lateral septum, bed nucleus of thestria terminalis, medial nucleus of the amygdala, and medial preoptic area. There is an extensive representation of OFQ and ORL 1 receptor binding in nuclei involved with the medial preoptic areaanterior hypothalamus and the ventromedial nucleus of the hypothalamus. This organization makes it likely that OFQ may play a role in modulation of ingestive, affective, and sexual behavior. In support of this notion, several of these regions contain neurons expressing estrogen receptors and are highly involved in sexual behavior (Canteras et al., 1994). I n addition, orphanin FQ has been shown to stimulate feeding and ingestive behavior in rats (Pomonis et al., 1996; Stratford et al., 1997), and orphanin injections into the ventromedial hypothalamus induces Iordosis in female rats (Sinchak et al., 1997).

The paraventricular hypothalamic nucleus has only light to moderate orphanin-like immunoreactivity, but it does contain high ORL1 mRNA expression and binding. This nucleus is critical in the hypothalamo-pituitaryadrenocortical axis, and it receives afferent input from several structures with orphanin-like immunoreactivity (Herman and Cullinan, 1997). Brainstem afferents, providing input related to autonomic function, include the 1 cell group in the ventrolateral medulla, the A2 cell group and the locus coeruleus (A6 cell group), which projects to the more medial part of the parvicellular paraventricular nudeus, where orphanin fiber labeling is heaviest. The nudeus of the solitary tract also has nonadrenergic input into this structure. Forebrain regions with projections to the paraventricular nucleus include the subfornical organ, median preoptic nucleus, anteroventral periventricular nudeus, arcuate nucleus, dorsomedial nucleus lateral hypothalamus, medial preoptic area, bed nucleus of the stria terminalis, medial nucleus of the amygdala, and central nucleus of the amygdala (Herman and Cullinan, 1997). These paraventricular inputs are extensive, and OFQ is prominent in most of the regions that give rise to these afferents. Given the presence of ORL1 binding throughout the paraventricular nucleus, the orphanin system most likely plays a modulatory role in this structure. Little evidence to date supports a role for orphanin in the stress response, but it has been shown to have an anxiolytic effect in rat (J enck et al., 1997).

Hippocampal formation. The lateral septum contains robust orphanin peptide mRNA expression and neuronal immunoreactivity. The efferent and afferent connections of the lateral septum are confined to very discreet forebrain regions (Swanson and Cowan, 1979; J akab and
Leranth, 1995). All parts of the lateral septal nucleus receive heavy input from the hippocampal formation. Additional afferents arise from the bed nucleus of the stria terminalis, medial amygdaloid nucleus, and pontine tegmentum. Orphanin FQ immunoreactivity is very intense in these regions, and ORL 1 receptor binding is present in the lateral septal region. More importantly, the lateral septal region, with its high OFQ content, has efferent projections to several regions where ORL1 binding is present. These structures include the medial preoptic area, anterior and lateral hypothalamic areas, dorsomedial hypothalamus, supramammillary region, and medial nucleus of the amygdala. This ORL 1 and OF Q distribution pattern provides support for a role of OFQ in the function of this limbic structure and interactions with the hippocampus.

Orphanin binding and ORL1 mRNA expression, and OF Q expression in the hippocampal formation are widely distributed (Neal et al., 1999). Strongest OF Q immunolabeling and mRNA expression is observed in the pyramidal layer of area CA1 of Ammon's horn, stratum lucidum of area CA3, the granule cell layer of the dentate gyrus, and the subiculum. The overall intrinsic and extrinsic connections and efferent projections of the hippocampal formation have been studied in detail (Swanson and Cowan, 1977; Amaral and Witter, 1995). The dentate gyrus receives afferent input from the medial septum, diagonal band, supramammillary nucleus, lateral hypothalamus, locus coeruleus, and raphe nuclei. With the exception of the medial septum, these structures contain abundant OFQ peptide. Numerous neurons expressing mRNA for the ORL 1 receptor are localized within the granule layer of the dentate gyrus, whereas binding is confined to the molecular layer. Orphanin FQ immunolabeling and mRNA expression within the dentate gyrus is confined mostly to the granule cell layer. Basket cells within this layer provide dendritic fibers that form contacts with cells within the molecular layer where this OFQ binding is robust.

Ammon's horn contains dense ORL 1 binding, primarily in stratum oriens of CA2 and CA3, with lower levels of binding in stratum lucidum and radiatum. Area CA3 receives major input from the medial septum and diagonal band, primarily into stratum oriens, where OF Q binding is dense. The intrinsic connections of area CA2 are very similar to that of CA3, except that this region also receives prominent input from the tuberomammillary nucleus and supramammillary area, regi ons with several OFQ-containing neurons present. The subiculum has robust orphaninlike immunoreactivity. I ts extrinsic efferents are extensive and this structure contains dense ORL 1 receptor binding. Its primary afferents originate in the medial septumdiagonal band complex, posterior cortical and basal amygdaloid nuclei, reuniens thalamic nucleus, supramammillary region, ventral tegmental area, locus coeruleus, and raphe complex. Many of these structures express OF Q in perikarya, and orphanin may be providing modulatory input to the subiculum through many of these structures. Orphanin-containing cell bodies in the subiculum could influence many structures, as the subiculum is one of the major output regions of the hippocampal formation, and most of the regions to which it projects are rich in orphanin binding.

The role of orphanin in the hippocampus is presently not clear. However, orphanin has been reported to reversibly 
inhibit voltage-gated calcium channels in pyramidal neurons from area CA1 and CA3 (Knoflach et al., 1996) and to inhibit synaptic transmission and long-term potentiation in area CAl of Ammon's horn and the dentate gyrus (Yu et al., 1997). The latter effect is thought to be presynaptic in nature. Microinjection of OF Q into the CA3 region of adult rats has been shown to impair spatial learning (Sandin et al., 1997). These findings remain controversial, because effects of orphanin on motor behavior were not taken into account (see below). However, in support of the findings by Sandin et al. (1997), a recent study on knockout mice lacking the orphanin receptor demonstrated enhancement of spatial attention in the water-finding test (Mamiya et al., 1998). Initial studies clearly support a role for this peptide in learning and memory function, and its anatomic distribution supports this concept as well.

Thalamus. In general, ORL1 receptor binding is prominent in the thalamus, but OFQ expression is very low, with peptide and mRNA expression mostly confined to the paraventricular nucleus, paratenial nucleus, posterior nucleus, reticular nucleus, zona incerta, and medial habenula. The reticular thalamic nucleus contains high orphanin mRNA and peptide expression, and moderate ORL1 receptor mRNA expression and binding. This nucleus has an abundance of GABA-ergic neurons and receives inputs from both thalamocortical and corticothalamic fibers (Price, 1995). Thalamocortical cells in each nucleus of the dorsal, intralaminar, and anterior thalamic group projects to the cortex and to a restricted part of the reticular nucleus, which in turn projects back to that specific nucleus. Brainstem inputs into this nucleus and reciprocal projections with specific thalamic nuclei may play a role in the sleep-wake cycle, and orphanin may be involved in modulation of this system.

The zona incerta, a perithalamic structure lying at the ventral extension of the reticular thalamic nucleus, has numerous orphanin-containing cells and fibers, and moderate orphanin binding. This structure has direct projections to the parabrachial nucleus and spinal cord, regions with dense ORL 1 receptor binding. The afferent projections into this nucleus and possible functions remains unclear, but stimulation of this structure does lower heart rate and blood pressure (Spencer et al., 1988), supporting a role for orphanin in cardiovascular control. In support of this notion, ORL 1 activation has been shown to decrease blood pressure and cardiac output (Champion and Kadowitz, 1997a,b; Champion et al., 1997; Gumusel et al., 1997) and to inhibit cardiomotor neurons in the rostral ventrolateral medulla (Chu et al., 1998) in rats. Orphanin's effects on blood pressure may be by means of direct vasodilatation of the arterial bed, probably by means of dilation of resistance arteries (Champion et al., 1998)

Tectum and pretectum. Orphanin FQ receptor mRNA and binding, and OFQ peptide are observed throughout several visual system nuclei in the mesencephal on, including the pretectum, the nucleus of Darkschewitsch, and the superior colliculus. Although orphanin peptide is observed throughout the pretectal region, ORL1 binding is mostly confined to the olivary pretectal nucleus. This nucleus receives strong bilateral retinal inputs, with smaller inputs from the cerebral cortex and lateral geniculate nucleus, and it appears to be involved in mediation of the light reflex, because electrical stimulation of this nucleus induces pupillary constriction (Trejo and Cicerone, 1984; Sefton and Dreher, 1995). The nucleus of Darkschewitsch has the heaviest orphanin peptide and mRNA content in the midbrain. This nucleus receives afferent input from the superior colliculus, deep cerebellar nud ei, and prepositus hypoglossus and is thought to be involved with integration of visual information (Steiger and Büttner-Ennever, 1979). The efferent projections of this nucleus are not well understood, so although orphanin peptide and mRNA content is very high in this nucleus, what role OFQ plays in its circuitry is unclear.

The superior colliculus contains only scattered OFQ immunoreactivity, confined primarily to the optic nerve and intermediate gray layers, but very high levels of binding are noted in its zonal and superficial gray layers. The afferents and efferents of the superior colliculus are numerous and complex (Sefton and Dreher, 1995), and generally, afferents to the superficial layers originate in the cortex, pretectum, lateral geniculate body, raphe system, locus coeruleus, and prepositus hypoglossus. M ost of these structures have abundant OFQ content that may directly activate ORL 1 receptors in the zonal or superficial gray layers. Efferents from this region are primarily to the intralaminar nuclei of the thalamus, medial pons, medulla, and spinal cord, in regions involved with orienting reactions and eye movements. Although orphanin content within these regions is moderate, receptor content is high, implicating this peptide for a modulatory role in orientation to visual stimuli.

The anterior pretectal nucleus receives strong inputs from other pretectal nuclei, but does not receive direct retinal inputs (Sefton and Dreher, 1995). This nucleus receives inputs from thesuperior coll iculus and parabigeminal nucleus, and appears to be involved in nociception, because very low levels of electrical stimulation are required for antinociception in its rostral division adjacent to the central gray (Rees and Roberts, 1993). Some ORL1 binding is present in this structure, and OFQ content is prominent (Neal et al., 1999), supporting a possible rolefor the orphanin system in the antinociceptive activities observed in this region.

Central gray. The central gray contains prominent ORL 1 mRNA expression and receptor binding, and robust OF Q expression. The afferent inputs to this structure are numerous and include the cingulate, insular, perirhinal, and frontal cortices, preoptic region, hypothalamus, zona incerta, amygdala, anterior pretectal nucleus, superior and inferior colliculus, deep mesencephal ic nuclei, parabrachial nucleus, dorsal raphe and raphe magnus, locus coeruleus and A5 noradrenergic cell group, cerebellum, prepositus hypogl ossus, cuneiform nudeus, lateral paragigantocellular nucleus, spinal trigeminal nucleus and spinal cord (Beitz, 1982). Most of these structures providing input into the central gray contain OFQ-expressing neurons. Efferent of this region are equally as numerous, with ascending projections to the fields of Forel, zona incerta, lateral septum, nucleus accumbens, olfactory tubercle, frontal cortex, midline and intralaminar thalamic nuclei, preoptic area, numerous hypothalamic nuclei, cuneiform nudeus, pedunculopontine tegmental nucleus, dorsal raphe, deep mesencephalic nucleus, ventral tegmental nucleus, subcoeruleus, interstitial nucleus of the medial longitudinal fasciculus, pontine reticular nucleus, ventromedial medulla, and the raphe magnus (Eberhart et al., 1985; Beitz et al., 1988). M ost structures receiving central gray inputs contain ORL 1 receptor binding. Such a presence of ORL1 and OFQ in the central gray provides 
support for a strong OFQ influence on the proposed role of the central gray in responding to potentially threatening stimuli, by means of direct effects on antinociception, vocalization, and defensive reactions.

Serotoninergic and nora drenergic systems. Orphanin receptor mRNA expression and binding, and OFQ expression are prominent in the serotonergic raphe nuclei and the noradrenergic-containing locus coeruleus and A5 cell groups. The anatomy of the $\mathrm{A} 5$ cell group is less known than that of the locus coeruleus. The A5 cell group has no forebrain projections but does project to autonomic nuclei of the brainstem and spinal cord (Byrum and Guyenet, 1987). Orphanin FQ binding is observed in this cell region, providing a possible modulatory role in A5 control of autonomic function. The locus coeruleus contains numerous OF Q- and ORL 1-expressing neurons, with very dense binding. Within this nucleus, virtually every neuron is noradrenergic (Aston-J ones et al., 1995), making it highly likely that ORL 1- or OF Q-containing neurons within this nucleus col ocalize with noradrenal ine. Major afferents into this nucleus include primarily the lateral paragigantocelIular reticular nucleus, prepositus hypoglossus, paraventricular nudleus of the hypothalamus, A5 cell group, and median raphe (Aston-J ones et al., 1995). These structures providing major inputs into locus coeruleus are al so OFQcontaining regions. Efferents from this nucleus are extensive, including projections into olfactory structures, the neocortex, hippocampus, several thalamic nuclei, thestriatum, medial septum, diagonal band, bed nudeus of the stria terminalis, medial preoptic area, paraventricular nucleus of the hypothalamus, midbrain tectum, central gray, interpeduncular nucleus, cerebellum, and multiple sensory and association nuclei within the pons and medulla (Aston-J ones et al., 1995). Orphanin FQ has been shown to activate inwardly rectifying potassium currents by means of the ORL 1 receptor in locus coeruleus neurons (Connor et al., 1996), providing direct evidence for OFQ modulation of locus coeruleus function. In this manner, OFQ may influence locus coeruleus control of multiple autonomic and behavioral functions.

Orphanin FQ and orphanin receptor binding are prominent in all serotonin-containing raphe regions, including the dorsal raphe, caudal linear raphe, median raphe, raphe pallidus, raphe magnus, and raphe obscurus. The serotonin system provides extensive projections throughout the CNS, with ascending projections to the olfactory bulb, septal area, striatum, globus pallidus, claustrum, bed nucleus of the stria terminalis, nucleus accumbens, medial preoptic nucleus, suprachiasmatic nucleus, dorsal and ventral premammillary nuclei, subfornical organ, intralaminar and midline thalamic nudei, the hippocampal formation, and the neocortex. Descending projections are to laminae I, II, and X of the spinal cord and ventral horn neurons, the reticular formation, solitary nucleus, cranial nerve nuclei, inferior olivary complex, parabrachial nucleus, cerebellum granule cell layer, superior colliculus, interpeduncular nucleus, central gray, and dopamine cell groups (Aitken and Törk, 1988; Halliday et al., 1995). Although the ORL1 receptor is found in most of these efferent target regions, dense ORL 1 binding within the raphe system supports a direct role for OF Q modulation of serotonin-containing projection neurons within the raphe complex. In this manner, OFQ could influence numerous serotonergic functions, including autonomic control of blood pressure and sodium balance, sexual and feeding behaviors, nociception, cognition, arousal, and affective behaviors. In support of this finding, OFQ has been shown to activate inwardly rectifying potassium currents by means of the ORL 1 receptor in dorsal raphe neurons, similar to that demonstrated in the locus coeruleus (Vaughan and Christie, 1996).

Olivary complex and cerebellum. Orphanin receptor and peptide content is very low in the cerebellum, confined to the deep cerebellar nuclei. Afferent input intothemedial cerebellar nucleus is primarily from Purkinje cells within the vermal cerebellar nucleus where no orphanin-containing neurons are noted. The medial nucleus, however, holds numerous OF Q-containing neurons (Neal et al., 1999) and has a diffuse efferent distribution to the deep layers of the superior colliculus, the deep mesencephalic nucleus, the supraoculomotor central gray, the medial accessory optic nucleus, and the zona incerta (Ruigrok and Voogd, 1990), all regions with ORL 1 receptor binding.

Afferent inputs into the cerebellum by means of the inferior olive also may provide orphanin influences. It is important to note here that the inferior olive contains high OFQ expression in its dorsal and principal parts and high levels of ORL 1 receptor binding. It receives afferents from higher cortical centers and the red nucleus, with efferent projections primarily to the lateral cerebellar hemispheres (Azizi and Woodward, 1987). It is interesting to note that the red nucleus contains high ORL1 mRNA expression, but little receptor binding. The inferior olive is a likely distal site where ORL 1 receptor is transported from the red nucleus. Orphanin binding within this region may modulate olivary input to the cerebellar hemispheres, further influencing balance and fine motor function.

In addition to the inferior olive, the vestibular nuclear complex is intimately involved with cerebellar circuitry and function, and several structures within this complex express orphan peptide and receptor. Cerebellar nuclear input to the vestibular complex arises primarily from the fastigial (medial) cerebellar nucleus (Rubertone and Haroian, 1982), which contains high levels of ORL 1 and OFQ expression. Other possible orphanin-containing afferent input to these nucl ei originate from contralateral vestibular nuclei, the reticular formation, B subnucleus of the medial inferior olive, spinal trigeminal nucleus, pars oralis, locus coeruleus, and neocortex. The efferent projections of the vestibular nuclei are numerous and include many areas with ORL 1 receptor expression and binding (Rubertone et al., 1995), including the spinal cord, oculomotor and trochlear nuclei, several thalamic nuclei, including the central lateral, ventrolateral, medial and lateral ventral posterior nuclei, the medial geniculate nucleus, inferior olive, and lateral paragigantocellular reticular nucleus. Influences derived from these structures within the olivocerebellar circuitry are involved in balance and adjustments to proprioceptive cues. By means of this circuitry, the orphanin system may be involved with integration of multiple sensory inputs in refining motor behavior.

Reticular formation. The reticular formation of the midbrain, pons, and medulla provides a substrate for convergence and integration of multiple inputs from fiber bundles traversing the brainstem in an ascending or descending direction. Orphanin receptor mRNA and binding and OFQ peptide are highly expressed throughout these structures, including the deep mesencephalic reticular nucleus, the pontine reticular nucleus, the parvicellu- 
Iar reticular field, gigantocellular reticular field, ventral gigantocellular reticular field, lateral reticular field, and lateral paragigantocellular reticular nucleus. Projections from these structures are widespread, and the ORL1 receptor is observed in most nuclei receiving reticular afferents. If orphanin is indeed playing a modulatory role within these centers, it may influence numerous functions, including orienting movements of the eyes, head and body by means of spinal cord projections, selective attention by means of forebrain inputs into the dorsal thalamus, and the general tonic ascending activating influence of this system on the neocortex (J ones, 1995).

Spinal cord. Thespinal cord contains abundant orphanin peptide and mRNA (Neal et al., 1999) and also expresses high levels of ORL 1 receptor mRNA and binding. The highest OF Q expression is observed in laminaell, III, IV, and X; ORL 1 mRNA is highest in laminae VIII and IX; and ORL 1 binding is most abundant in laminae III III , and IV. Lamina II (substantia gelatinosa) neurons have been shown to respond to brush and pinch stimuli (Woolf and Fitzgerald, 1983), but only relatively few are known to ascend to the ventrolateral reticular formation, lateral cervical nucleus, and thalamus. Lamina III neurons respond only to weak mechanical stimulation and many of these neurons have been shown to project to other regions within the same segment of the spinal cord, the dorsal column nuclei, the lateral cervical nucleus, and the thalamus (Molander et al., 1989). In Iamina IV, many of these neurons only respond to light mechanical stimulation, but many respond to nociceptive stimuli as well. Many of these neurons project locally in the spinal cord, and also to the lateral cervical nucleus and the thalamus. Orphanincontaining neurons within these laminae may be involved in local circuitry, projecting to laminae II and III where ORL 1 receptor binding is high. In addition, they may play a modulatory role in efferent spinal cord projections in response to mechanical and nociceptive input.

Lamina VII is the intermediate zone of the gray matter, and some parts extend into the ventral horn. It contains the intermediolateral and intermediomedial cell columns, which contain no OFQ, but abundant ORL 1 receptor (Molander at al., 1989). Cells within this region respond strongly to noxious stimuli and project to the brainstem, thalamus, and hypothalamus (Nahin et al., 1983). The heavy orphanin content within this region may provide an orphanin influence on processing of noxious stimuli and modulation of efferent relays from this region.

The possible modulatory role for orphanin in spinal cord functions has been examined with respect to orphanin distribution by several investigators (Riedl et al., 1996; Lai et al., 1997; Schuligoi et al., 1997), and orphanin does appear to be intimately involved in the modulation of painful stimuli and the release of endogenous opioids at the spinal level. Recent evidence that used double label immunohistochemistry and confocal microscopy has shown that ORL 1 and $\mu$ opioid receptor antisera label different fibers in areas involved in pain processing, including dorsal root ganglia, superficial laminae of the spinal cord, central gray, raphe magnus, gigantocellular reticular nucleus, and nucleus of the solitary tract (Monteillet-Agius et al., 1998). [It is important to note again, however, that the specificity of the ORL 1 antiserum used is being questioned (see above).] Although orphanin obviously plays a major role in nociception, its effects are likely by means of spinal and supraspinal pathways distinct from that of the endogenous opioid receptors.

\section{CONCLUSIONS}

We have demonstrated that, like orphanin FQ, the ORL 1 receptor is widely distributed throughout the CNS of the adult male rat. We have also established a close correlation between ORL 1 receptor MRNA and ${ }^{125}$ - [ $\left.{ }^{14} \mathrm{Ty} r\right]-$ OFQ peptide binding. Additionally, the distribution of 125 -[14Tyr]-OFQ binding correlates well with the distribution of the ORL 1 receptor protein as demonstrated by immunohistochemistry (Anton et al., 1996), although there are concerns regarding the specificity of the ORL 1 monoclonal antibody (see Comparisons With ORL 1-Like I mmunolabeling section). Orphanin FQ and the ORL 1 receptor are expressed in several CNS circuits, supporting its involvement in multiple functional systems, including nociception, modulation of the L-HPA stress axis, motivation and reward, learning and memory, gross motor control, balance and proprioception, sexual, aggressive and investigatory behaviors, control of autonomic and physiologic functions, and integration of special sensory input. The present anatomic information on the distribution of the ORL1 receptor and the OFQ peptide (Neal et al., 1999) provide the anatomic basis for understanding the many possible behavioral and physiologic roles of this neuropeptide.

\section{ACKNOWLE DGME NTS}

We thank Sharon Burke, Robert Pavlic, Lisa Bain, and J ames Stewart for their superb technical assistance. C.R.N.J . was sponsored by a National Institute of Mental Health Training Grant and a Robert Wood J ohnson F oundation Fellowship, and S.J.W. was sponsored by a National Institute of DrugAbuse grant.

\section{LITERATURE CITED}

Abdulla FA Smith PA. 1997. Nociceptin inhibits T-type Ca++ channel current in rat sensory neurons by G-protein-independent mechanisms. J Neurosci 17:8721-8728.

Aitken AR, Törk I. 1988. Early development of serotonin-containing neurons and pathways seen in wholemount preparations of the fetal rat brain. J Comp Neurol 274:32-47.

Alheid GF, de Olmos J S, Beltramino CA. 1995. The amygdala and extended amygdala. In: Paxinos G, editor. The rat nervous system. Sydney, Australia: Academic Press. p 495-578.

Amaral DG, Witter MP. 1995. The hippocampal formation. In: Paxinos G, editor. The rat nervous system. Sydney, Australia: Academic Press. $p$ 443-493.

Anton B, Fein J , To T, Li X, Silberstein L, Evans CJ . 1996. Immunohistochemical localization of ORL-1 in the central nervous system of the rat. J Comp Neurol 368:229-251.

Ardati A, Henningsen RA, Higelin J , Reinscheid RK, Civelli O, Monsma FJ . 1997. Interaction of $\left[{ }^{3} \mathrm{H}\right]$ orphanin $\mathrm{FQ}$ and ${ }^{125} / \mathrm{Tyr}_{14}$-orphanin $\mathrm{FQ}$ with the orphanin FQ receptor: kinetics and modulation by cations and guanine nucleotides. Mol Pharmacol 51:816-824.

Aston-J ones G, Shipley MT, Grzanna R. 1995. The locus coeruleus, A5 and A7 noradrenergic cell groups. In: Paxinos $G$, editor. The rat nervous system. Sydney, Australia: Academic Press. p 183-213.

Azizi S, Woodward DJ . 1987. Inferior olivary nuclear complex of the rat: morphology and comments on the principles of organization within the olivocerebellar system. J Comp Neurol 263:467-484.

Befort K, Matti MG, Roeckel N, Kieffer B. 1994. Chromosomal localization of the d opioid receptor gene to human 1p343-p361 and mouse 4D bands by in situ hybridization. Genomics 20:143-145.

Beitz AJ . 1982. The organization of afferent projections to the periaqueductal gray of the rat. Neuroscience 7:133-159.

Beitz AJ , Mullett MA, Brandt N. 1988. The relationship of periaqueductal gray projections to bulbospinal neurons: a combined Fluoro-GoldPHA-L analysis. Soc Neurosci Abstr 14:856. 
Boivie J . 1979. An anatomical reinvestigation of the termination of the spinothalamic tract in the monkey.J Comp Neurol 186:343-370.

Bowsher D. 1961. Termination of secondary somatosensory neurons within the thalamus of the Macaca mulatta: an experimental degeneration study. J Comp Neurol 177:213-227.

Brog J S, Salyapongse A, Deutch AY, Zahm DS. 1993. The patterns of afferent innervation of the core and shell in the "accumbens" part of the rat ventral striatum: immunohistochemical detection of retrogradely transported fluoro-gold. J Comp Neurol 338:255-278.

Bryant W, J anik J , Baumann M, Kelley P. 1998. Orphanin FQ stimulates prolactin and growth hormone release in male and female rats. Brain Res 807:228-233.

Bunzow J R, Saez C, Mortrud M, Bouvier C, Williams J T, Low M, Grandy DK. 1994. Molecular cloning and tissue distribution of a putative member of the rat opioid receptor gene family that is not a mu, delta or kappa opioid receptor type. FEBS Lett 347:284-288.

Butour J L, Moisand C, Mazarguil H, Mollereau C, Meunier J C. 1997. Recognition and activation of the opioid receptor-like ORL 1 receptor by nociceptin, nociceptin analogs and opioids. Eur J Pharmacol 321:97103.

Byrum CE, Guyenet PG. 1987. Afferent and efferent connections of the A5 noradrenergic cell group in the rat. J Comp Neurol 261:529-542.

Canteras NS, Simerly RB, Swanson LW. 1994. Organization of the projections from the ventromedial nucleus of the hypothalamus. A Phaseol us vulgaris-leucoagglutinin study in the rat. J Comp Neurol 348:41-79.

Champion HC, Kadowitz PJ . 1997a. Nociceptin, an endogenous ligand for the ORL1 receptor, has novel hypotensive activity in the rat. Life Sci 60:PL241-PL245.

Champion HC, Kadowitz PJ . 1997b. [Tyr1]-nociceptin, a novel nociceptin analog, decreases systemic arterial pressure by a naloxone-insensitive mechanism in the rat. Biochem Biophys Res Commun 234:309-312.

Champion HC, Czapla MA, Kadowitz PJ . 1997. Nociceptin, an endogenous ligand for the ORL1 receptor, decreases cardiac output and total peripheral resistance in the rat. Peptides 18:729-732.

Champion HC, Pierce RL, Kadowitz PJ . 1998. Nociceptin, a novel endogenous ligand for the ORL1 receptor, dilates isolated resistance arteries from the rat. Regul Pept 30:69-74.

Chen Y, Mestek A, Liu J , Hurley J A, Yu L. 1993. Molecular cloning and functional expression of a $\mu$ opioid receptor from rat brain. Mol Pharmacol 44:8-12.

Chen Y, Fan Y, Liu J , Mestek A, Tian M, Kozak CA, Yu L. 1994. Molecular cloning, tissue distribution and chromosomal localization of a novel member of the opioid receptor gene family. FEBS Lett 347:279-283.

Chu X, Xu N, Li P, Wang J Q. 1998. Profound inhibition of cardiomotor neurons in the rat rostral ventrolateral medulla by nociceptin. Neurore port 9:1081-1084.

Civelli O, Nothacker H-P, Bourson A, Ardati A, Monsma F, Reinscheid R. 1997. Orphan receptors and their natural ligands. J Recept Signal Transduct Res 17:545-550.

Connor M, Vaughan CW, Chieng B, Christie MJ . 1996. Nociceptin receptor coupling to potassium conductance in locus coeruleus neurons in vitro. BrJ Pharmacol 119:1614-1618.

Connor M, Yeo A, Henderson G. 1997. The effect of nociceptin on Ca2+ channel current and intracellular Ca2+ in the SH-SY5Y human neuroblastoma cell line. BrJ Pharmacol 118:205-207.

Dawson-Basoa M, Gintzler A. 1997. Nociceptin (Orphanin FQ) abolishes gestational and ovarian sex steroid-induced antinociception and induces hyperal gesia. Brain Res 750:48-52.

Devine DP, Taylor L, Reinscheid RK, Monsma FJ , Civelli O, Akil H. 1996a. Rats rapidly devel op tolerance to the locomotor-inhibiting effects of the novel neuropeptide orphanin FQ. Neurochem Res 21:1387-1396.

Devine DP, Reinscheid RK, Monsma FJ , Civelli O, Akil H. 1996b. The novel neuropeptide orphanin $\mathrm{FQ}$ fails to produce conditioned place preference or aversion. Brain Res 727:225-229.

Doi N, Dutia MB, Russell JA. 1998. Inhibition of rat oxytocin and vasopressin supraoptic nucleus neurons by nociceptin in vitro. Neuroscience 84:913-921.

Dooley CT, Houghten RA. 1996. Orphanin FQ: receptor binding and analog structure activity relationships in rat brain. Life Sci 59:PL23-PL 29.

Dooley CT, Spaeth CG, Berzetei-Gurske IP, Craymer K, Adapa ID, Brandt SR, Houghten RA, Toll L. 1997. Binding and in vitro activities of peptides with high affinity for the nociceptin/orphanin FQ receptor, ORL 1.J Pharmacol Exp Ther 283:735-741.

Eberhart J A, Morrell J I, Krieger MS, Pfaff DW. 1985. An autoradiographic study of projections ascending from the midbrain central gray, and the region lateral to it, in the rat. J Comp Neurol 241:285-310.

Evans CJ , Keith DE, Morrison H, Magendzo K, Edwards RH. 1992. Cloning of a delta opioid receptor by functional expression. Science 258:19521955.

Faber ES, Chambers J P, Evans RH, Henderson G. 1996. Depression of glutamatergic transmission by nociceptin in the neonatal rat hemisected spinal cord preparation in vitro. Br J Pharmacol 119:189-190.

Florin S, Suaudeau C, Meunier J C, Costentin J . 1996. Nociceptin stimulates locomotion and exploratory behaviour in mice. Eur J Pharmacol 317:9-13.

Florin S, Suaudeau C, Meunier J C, Costentin J . 1997a. Orphan neuropeptide Nocll, a putative pronociceptin maturation product, stimulates locomotion in mice. Neuroreport 8:705-707.

Florin S, Leroux-Nicollet I, Meunier J C, Costentin J . 1997b. Autoradiographic localization of $\left[{ }^{3} \mathrm{H}\right]$ nociceptin binding sites from telencephalon to mesencephalic regions in the mouse brain. Neurosci Lett 230:33-36.

Fukada K, Kato S, Mori K, Nishi M, Takeshima H. 1993. Primary structures and expression from CDNAs of rat opioid receptor $\delta$ - and $\mu$-subtypes. FEBS Lett 327:311-314.

Fukuda K, Kato S, Mori K, Nishi M, Takeshima H, I wabe N, Miyata T, Houtani T, Sugimoto T. 1994. CDNA cloning and regional distribution of a novel member of the opioid receptor family. FEBS Lett 343:42-46.

Gintzler AR, Adapa ID, Toll L, Medina VM, Wang L. 1997. Modulation of enkephalin release by nociceptin. Eur J Pharmacol 325:29-34.

Giuliani S, Maggi CA. 1996. Inhibition of tachykinin release from peripheral endings of sensory nerves by nociceptin, a novel opioid peptide. Br J Pharmacol 118:1567-1569.

Grisel J E, Mogil J S, Belknap J K, Grandy DK. 1996. Orphanin FQ acts as a supraspinal, but not a spinal, anti-opioid peptide. Neuroreport 7:21252129.

Guerrini R, Calo G, Rizzi A, Bianchi C, Lazarus LH, Salvadori S, Temussi PA, Regoli D. 1997. Address and message sequences for the nociceptin receptor: a structure-activity study of nociceptin-(1-13)-peptide amide. Med Chem 40:1789-1793.

Gumusel B, Hao Q, Hyman A, Chang J K, Kapusta DR, Lippton H. 1997. Nociceptin: an endogenous agonist for central opioid likel (ORL1) receptors possesses systemic vasorel axant properties. Life Sci 60:PL 141PL145.

Halliday G, Harding A, Paxinos G. 1995. Serotonin and tachykinin systems. In: Paxinos G, editor. The rat nervous system. Sydney, Australia: Academic Press. p 929-935.

Hao J X, Wiesenfeld-Hallin Z, Xu XJ . 1997. Lack of cross-tolerance between the antinociceptive effect of intrathecal orphanin FQ and morphine in the rat. Neurosci Lett 223:49-52.

Hara N, Minami T, Okuda-Ashitaka E, Sugimoto T, Sakai M, Onaka M, Mori H, Imanishi T, Shingu K, Ito S. 1997. Characterization of nociceptin hyperalgesia and allodynia in conscious mice. Br J Pharmacol 121:401-408.

Heinricher MM, McGaraughty S, Grandy DK. 1997. Circuitry underlying antiopioid actions of orphanin FQ in the rostral ventromedial medulla. J Neurophysiol 78:3351-3358.

Herkenham M, Pert CB. 1982. Light microscopic localization of brain opiate receptors: a general autoradiographic method which preserves tissue qality. J Neurosci 2:1129-1149.

Herman J P, Cullinan WE. 1997. Neurocircuitry of stress: central control of the hypothalamo-pituitary-adrenocortical axis. TINS 20:78-84.

Houtani T, Nishi M, Takeshima H, Nukada T, Sugimoto T. 1996. Structure and regional distribution of nociceptin/orphanin FQ precursor. Biochem Biophys Res Commun 219:714-719.

Hunter WM, Greenwood FC. 1962. Preparation of iodine-131 labeled human growth hormone of high specific activity. Nature 194:495-496.

I keda K, Kobayashi K, Kobayashi T, Ichikawa T, Kumanishi T, Kishida H, Yano R, Manabe T. 1997. Functional coupling of the nociceptin/ orphanin FQ receptor with the G-protein-activated K + (GIRK) channel. Brain Res Mol Brain Res 45:117-126.

I keda K, Watanabe M, Ichikawa T, Kobayashi T, Yano R, Kumanishi T. 1998. Distribution of prepro-nociceptin/orphanin FQ mRNA and its receptor mRNA in developing and adult mouse central nervous system. J Comp Neurol 399:139-151.

Inoue M, Kobayashi M, Kozaki S, Zimmer A, Ueda H. 1998. Nociceptin/ orphanin FQ-induced nociceptive responses through substance $\mathrm{P}$ re lease from peripheral nerve endings in mice. Proc Natl Acad Sci USA 95:10949-10953. 
J akab RL, Leranth C. 1995. The septum. In: Paxino G, editor. The rat nervous system. Sydney, Australia: Academic Press. p 405-442.

J enck F, Moreau J L, Martin J R, Kilpatrick GJ , Reinscheid RK, Monsma FJ , Nothacker H-P, Civelli O. 1997. Orphanin FQ acts as an anxiolytic to attenuate behavioral responses to stress. Proc Natl Acad Sci USA 94:14854-14858.

J ones BE. 1995. Reticular formation: cytoarchitecture, transmitters and projections. In: Paxino G, editor. The rat nervous system. Sydney, Australia: Academic Press. p 161-171.

Kachaturian H, Lewis ME, Schafer MK-H, Watson SJ . 1985. Anatomy of the CNS opioid systems. TINS 8:111-119.

Kapusta DR, Sezen SF, Chang J K, Lippton H, Kenigs VA. 1997. Diuretic and antinatriuretic responses produced by the endogenous opioid-like peptide, nociceptin (orphanin FQ) Life Sci 60:PL 15-PL21.

Kerr FW. 1975. Neuroanatomical substrates of nociception in the spinal cord. Pain 1:325-356.

Kieffer BL, Befort K, Gaveriaux-Ruff C, Hirth CG. 1992. The $\delta$-opioid receptor: isolation of a cDNA by expression cloning and pharmacological characterization. Proc Natl Acad Sci USA 89:12048-12052.

King MA, Rossi GC, Chang AH, Williams L, Pasternak GW. 1997. Spinal analgesic activity of orphanin $\mathrm{FQ} /$ nociceptin and its fragments. Neurosci Lett 223:113-116.

Knoflach F, Reinscheid RK, Civelli O, Kemp J A. 1996. Modulation of voltage-gated calcium channels by orphanin $\mathrm{FQ}$ in freshly dissociated hippocampal neurons. J Neurosci 16:6657-6664.

Konya H, Masuda H, Itoh K, Nagai K, Kakishita E, Matsuoka A. 1998. Modification of dopamine release by nociceptin in conscious rat striatum. Brain Res 788:341-344.

Kozak CA, Filie J , Adamson MC, Chen Y, Yu L. 1994. Murine chromosomal location of the $\mu$ and $\kappa$ opioid receptor genes. Genomics 21:659-661.

Lachowicz J E, Shen Y, Monsma FJ , Sibley DR. 1994. Molecular cloning of a novel $\mathrm{G}$ protein-coupled receptor related to the opiate receptor family. J Neurochem 64:34-40.

Lai CC, Wu SY, Dun SL, Dun NJ . 1997. Nociceptin-like immunoreactivity in the dorsal horn and inhibition of substantia gelatinosa neurons. Neuroscience 81:887-891.

Liebel J T, Swandulla D, Zeilhofer HU. 1997. Modulation of excitatory synaptic transmission by nociceptin in superficial dorsal horn neurons of the neonatal rat spinal cord. Br」 Pharmacol 121:425-432.

Lou LG, Ma L, Pei G. 1997. Nociceptin/orphanin FQ activates protein kinase $\mathrm{C}$ and this effect is mediated through phospholipase $\mathrm{C} / \mathrm{Ca} 2+$ pathway. Biochem Biophys Res Commun 240:304-308.

Ma L, Cheng ZL, Fan GH, Cai YC, Jiang LZ, Pei G. 1997. Functional expression, activation and desensitization of opioid receptor-like receptor ORL 1 in neuroblastoma $x$ gl ioma NG108-15 hybrid cel Is. FEBS Lett 403:91-94.

Makman MH, Lyman WD, Dvorkin B. 1997. Presence and characterization of nociceptin (orphanin FQ) receptor binding in adult rat and human fetal hypothalamus. Brain Res 762:247-250.

Mamiya T, Noda M, Takeshima H, Nabeshima T. 1998. Enhancement of spatial attention in nociceptin/orphanin FQ receptor-knockout mice. Brain Res 783:236-240.

Mansour A, Kachaturian H, Lewis ME, Akil H, Watson SJ . 1987. Autoradiographic differentiation of mu, delta, and kappa opioid receptors in the rat forebrain and midbrain.J Neurosci 7:2445-2464.

Mansour A, Thompson RC, Akil H, Watson SJ . 1993. Delta opioid receptor mRNA distribution in the brain: comparison to delta receptor binding and proenkephalin mRNA. J Chem Neuroanat 6:351-362.

Mansour A, Fox CA, Thompson RC, Akil H, Watson SJ . 1994a. Mu-opioid receptor mRNA expression in the rat CNS: comparison to $\mu$ receptor binding. Brain Res 643:245-265.

Mansour A, Fox CA, Meng F, Akil H, Watson S] . 1994b. Kappa ${ }_{1}$ receptor mRNA distribution in the rat CNS: comparison to kappa receptor binding and prodynorphin mRNA. Mol Cell Neurosci 5:124-144.

Mansour A, Fox CA, Burke S, Watson SJ . 1994c. Immunohistochemical

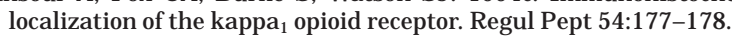

Mansour A, Fox CA, Burke S, Meng F, Thompson RC, Akil H, Watson SJ . 1994d. Mu, delta, and kappa opioid receptor mRNA expression in the rat CNS: an in situ hybridization study. J Comp Neurol 350:412-438.

Mansour A, Fox CA, BurkeS, Akil H, Watson SJ . 1995a. I mmunohistochemical localization of the cloned $\mu$ opioid receptor in the rat CNS. J Chem Neuroanat 8:283-305.

Mansour A, Fox CA, Akil H, Watson SJ . 1995b. Opioid receptor mRNA expression in the rat CNS: anatomical and functional implications. TINS 18:22-29.
Mansour A, Burke S, Pavlic RJ , Akil H, Watson SJ . 1996. Immunohistochemical localization of the cloned kappa 1 receptor in the rat CNS. Neuroscience 71:671-690.

Marchese A, Docherty J M, Nguyen T, Heiber M, Cheng R, Heng HH, Tsui LC, Shi X, George SR, O'Dowd BF. 1994. Cloning of human genes encoding novel $\mathrm{G}$ protein-coupled receptors. Genomics 23:609-618.

Mathis J P, Ryan-M oro J, Chang A, H om J S, Scheinberg DA, Pasternak GW. 1997. Biochemical evidence for orphanin $\mathrm{FQ}$ /nociceptin receptor heterogeneity in mouse brain. Biochem Biophys Res Commun 230:462-465.

Meng F, Xie G-X, Thompson RC, Mansour A, Goldstein A, Watson SJ , Akil $H$. 1993. Cloning and pharmacological characterization of a rat $\kappa$ opioid receptor. Proc Natl Acad Sci USA 90:9954-9958.

Meng F, Taylor LP, Hoversten MT, Ueda Y, Ardati A, Reinscheid RK, Monsma FJ , Watson, Civelli O, Akil H. 1996. Moving from the orphanin FQ receptor to an opioid receptor using four point mutations. J Biol Chem 271:32016-32020.

Meunier J C, Mollereau C, Toll L, Suaudeau C, Moisand C, Alvinerie P, Butour J L, Guillemot J C, Ferrara P, Monsarrat B, Mazarguil H, Vassart G, Parmentier M, Costentin J . 1995. I solation and structure of the endogenous agonist of opioid receptor-like ORL1 receptor. Nature 377:532-535.

Minami T, Okuda-Ashitaka E, Nishizawa M, M ori H, I to S. 1997. Inhibition of nociceptin-induced allodynia in conscious mice by prostaglandin D2. Br J Pharmacol 122:605-610.

Mogil J S, Grisel J E, Zhangs G, Belknap J K, Grandy DK. 1996a. Functional antagonism of mu, delta-, and kappa-opioid antinociception by orphanin FQ. Neurosci Lett 214:131-134.

Mogil J S, Grisel J E, Reinscheid RK, Civelli O, Belknap J K, Grandy DK. 1996b. Orphanin FQ is a functional anti-opioid peptide. Neuroscience 75:333-337.

Molander C, Xu Q, Rivero C, Grant G. 1989. The cytoarchitectonic organization of the spinal cord in the rat. II: the cervical and upper thoracic cord. J Comp Neurol 289:375-385.

Mollereau C, Parmentier M, Mailleux P, Butour J L, Moisand C, Chalon P, Caput D, Vassart G, Meunier J C. 1994. ORL1, a novel member of the opioid receptor family Cloning, functional expression and localization. FEBS Lett 341:33-38.

Mollereau C, Moisand C, Butour J L, Parmentier M, Meunier J C. 1996a. Replacement of $\mathrm{Gln} 280$ by His in TM6 of the human ORL1 receptor increases affinity but reduces intrinsic activity of opioids. FEBS Lett 395:17-21.

Mollereau C, Simons MJ, Soularue P, Liners F, Vassart G, Meunier J C, Parmentier M. 1996b. Structure, tissue distribution, and chromosomal localization of the prepronociceptin gene. Proc Natl Acad Sci USA 93:8666-8670

Monteillet-Agius G, Fein J , Anton B, Evans C. 1998. ORL-1 and mu opioid receptor antisera label different fibers in areas involved in pain processing. J Comp Neurol 399:373-383.

Morgan MM, Grisel J E, Robbins CS, Grandy DK. 1997. Antinociception mediated by the periaqueductal gray is attenuated by orphanin FQ. Neuroreport 8:3431-3434.

Murphy NP, Ly HT, Maidment NT. 1996. Intracerebroventricular orphanin $\mathrm{FQ}$ /nociceptin suppresses dopamine release in the nucleus accumbens of anaesthetized rats. Neuroscience 75:1-4.

Nahin RL, Madsen AN, Giesler G] . 1983. Anatomical and physiological studies of the gray matter surrounding the central canal. J Comp Neurol 220:321-335

Neal CR, Mansour A, Reinscheid R, Nothacker H-P, Civelli O, Watson SJ 1999. Localization of orphanin FQ (nociceptin) peptide and messenger RNA in the central nervous system of the rat. J Comp Neurol 406:503547.

Nicol B, Lambert DG, Rowbotham DJ, Smart D, McKnight AT. 1996. Nociceptin induced inhibition of $\mathrm{K}+$ evoked glutamate release from rat cortical slices. Br J Pharmacol 119:1081-1083.

Nicholson J R, Peterson SJ , Menzies J RW, Corbett AD, McKnight AT. 1998 Pharmacological studies on the "orphan" opioid receptor in central and peripheral sites. Can J Physiol Pharmacol 76:304-313.

Nishi M, Houtani T, Noda Y, Mamiya T, Sato K, Doi T, Kuno J, Takeshima H, Nukada T, Nabeshima T, Yamashita T, Noda T, Sugimoto T. 1997. Unrestrained nociceptive response and disregulation of hearing ability in mice lacking the nociceptin/orphanin FQ receptor. EMBO J 16:18581864.

Norita M. 1977. Demonstration of bilateral claustro-cortical connections in the cat with the method of retrograde axonal transport of horseradish peroxidase. Arch Histol J pn 40:1-10.

Nothacker H-P, Reinscheid RK, Mansour A, Henningsen RA, Ardati A, 
Monsma FJ , Watson SJ , Civelli O. 1996. Primary structure and tissue distribution of the orphanin FQ precursor. Proc Natl Acad Sci USA 93:8677-8682.

Olson CR, Graybiel AM. 1980. Sensory maps in the claustrum of the cat. Nature 288:479-481.

Pan YX, Xu J , Pasternak GW. 1996. Cloning and expression of a cDNA encoding a mouse brain orphanin FQ/nociceptin precursor. Biochem J 315:11-13.

Pan YX, Xu J , Wan B-L, Zuckerman A, Pasternak GW. 1998. I dentification and differential regional expression of KOR-3/ORL-1 gene splice variants in mouse brain. FEBS Lett 435:65-68.

Paxinos G, Watson C. 1986. The rat brain in stereotaxic coordinates. Sydney, Australia: Academic Press.

Paxinos G, Watson C. 1997. The rat brain in stereotaxic coordinates. Sydney, Australia: Academic Press.

Pomonis J D, Billington CJ, Levine AS. 1996. Orphanin FQ, agonist of orphan opioid receptor ORL1, stimulates feeding in rats. Neuroreport 8:369-371.

Price J L. 1995. The thalamus. In: Paxinos G, editor. The rat nervous system. Sydney, Australia: Academic Press. p 629-648.

Raynor K, Kong H, Chen Y, Yasuda K, Yu, L Bell GI, Reisine T. 1993. Pharmacological characterization of the cloned $\kappa^{-}, \delta_{-}$, and $\mu$-opioid receptors. Mol Pharmacol 45:330-334.

Rees H, Roberts MHT. 1993. The anterior pretectal nucleus: a proposed role in sensory processing. Pain 53:121-135.

Reinscheid RK, Nothacker H-P, Bourson A, Ardati A, Henningsen RA, Bunzow J R, Grandy DK, Langen H, Monsma FJ, Civelli O. 1995. Orphanin FQ: a neuropeptide that activates an opioid-like G proteincoupled receptor. Science 270:792-794.

Reinscheid RK, Ardati A, Monsma FJ , Civelli O. 1996. Structure-activity relationship studies on the novel neuropeptide orphanin FQ. J Biol Chem 271:14163-14168.

Reinscheid RK, Higelin J, Henningsen RA, Monsma FJ , Civelli O. 1998. Structures that delineate orphanin FQ and dynorphin A pharmacologic selectivities. J Biol Chem 273:1490-1495.

Riedl M, Shuster S, Vulchanova L, Wang J, Loh HH, Elde R. 1996. Orphanin $\mathrm{FQ}$ /nociceptin-immunoreactive nerve fibers parallel those containing endogenous opioids in rat spinal cord. Neuroreport 7:13691372.

Rossi GC, Leventhal L, Pasternak GW. 1996. Naloxone sensitive orphanin FQ-induced analgesia in mice. Eur J Pharmacol 311:R7-R8.

Rossi GC, Leventhal L, Bolan E, Pasternak GW. 1997. Pharmacological characterization of orphanin FQ/nociceptin and its fragments. J Pharmacol Exp Ther 282:858-865.

Rossi GC, Mathis J P, Pasternak GW. 1998. Analgesic activity of orphanin FQ2, murine prepro-orphanin $\mathrm{FQ}_{141-157}$, in mice. Neuroreport 9:11651168

RubertoneJ A, Haroian AJ . 1982. Cerebellar nucleovestibular projections in the rat: a horseradish peroxidase (HRP) study. Anat Rec 202:162A.

Rubertone J A, Mehler WR, Voogd J . 1995. The vestibular nuclear complex. In: Paxinos G, editor. The rat nervous system. Sydney, Australia: Academic Press. p 782-790.

Ruigrok TJ H, Voogd J. 1990. Evidence for cerebello-midbrain-olivary circuits in the rat using PHA-L anterograde, and gold-labeled WGABSA retrogradetracing. Eur J Neurosci Abstr Suppl 1:24.

Saito Y, Maruyama K, Saido TC, Kawashima S. 1995. N23K, a gene transiently up-regulated during neural differentiation, encodes a precursor protein for a newly identified neuropeptide nociceptin. Biochem Biophys Res Commun 217:539-545.

Saito Y, Maruyama K, Kawano H, Hagino-Yamagishi K, Kawamura K, Saido TC, Kawashima S. 1996. Molecular cloning and characterization of a novel form of neuropeptide gene as a developmentally regulated molecule. J Biol Chem 271:15615-15622.

Saito Y, Maruyama K, Saido TC, Kawashima S. 1997. Overexpression of a neuropeptide nociceptin/orphanin FQ precursor gene, N23K/N27K, induces neurite outgrowth in mouse NS20Y cells. J Neurosci Res 48:397-406.

Sandin J , Georgieva J , Schott PA, Ogren SO, Terenius L. 1997. Nociceptin/ orphanin microinjected into hippocampus impairs spatial learning in rats. Eur J Neurosci 9:194-197.

Schlicker E, Werthwein S, Kathmann M, Bauer U. 1998. Nociceptin inhibits noradrenaline release in the mouse brain cortex via presynaptic ORL 1 receptors. Naunyn Schmiedebergs Arch Pharmacol 358:418422.

Schuligoi R, Amann R, Angelberger P, Peskar BA. 1997. Determination of nociceptin-like immunoreactivity in the rat dorsal spinal cord. Neurosci Lett 224:136-138.

Sefton AJ , Dreher B. 1995. The visual system. In: Paxinos G, editor. The rat nervous system. Sydney, Australia: Academic Press I nc. p 833-898.

Seki T, Minami M, Kimura C, Uehara T, Nakagawa T, Satoh M. 1998. Bremazocine recognizes the difference in four amino acid residues to discriminate between nociceptin (orphanin FQ) receptor and opioid receptors. J pn J Pharmacol 77:301-306.

Sherk H, Levay S. 1981a. Visual claustrum: topography and receptive field properties in the cat. Science 212:87-89.

Sherk H, Levay S. 1981b. The visual claustrum of the cat. III: Receptive field properties. J Neurosci 1:993-1002.

Shimohigashi Y, Hatano R, Fujita T, Nakashima R, Nose T, Sujaku T, Saigo A, Shinjo A, Nagahisa A. 1996. Sensitivity of opioid receptor-like receptor ORL1 for chemical modification on nociceptin, a naturally occurring nociceptive peptide. J Biol Chem 271:23642-23645.

Sim LJ , Childers SR. 1997. Anatomical distribution of mu, delta, and kappa opioid- and nociceptin/orphanin FQ-stimulated [35S]Guanylyl-5'-O-( $\gamma$ thio)-triphosphate binding in guinea pig brain. J Comp Neurol 386:562572.

Sim LJ, Xiao R, Childers SR. 1996. Identification of opioid receptor-like (ORL1) peptide-stimulated [ $\left.{ }^{35} \mathrm{~S}\right] \mathrm{GTP}$ gamma $\mathrm{S}$ binding in rat brain. Neuroreport 7:729-733.

Simerly RB. 1995. Anatomical substrates of hypothalamic integration. In: Paxinos G, editor. The rat nervous system. Sydney, Australia: Academic Press. p 353-376.

Sinchak K, Hendricks DG, Baroudi R, Micevych P. 1997. Orphanin FQ/ nociceptin in the ventromedial nucleus facilitates lordosis in female rats. Neuroreport 8:3857-3860.

Spencer SE, Sawyer WB, Loewy AD. 1988. L-Glutamate stimulation of the zona incerta in the rat decreases heart rate and blood pressure. Brain Res 458:72-81.

Stanfa LC, Chapman V, Kerr N, Dickenson AH. 1996. Inhibitory action of nociceptin on spinal dorsal horn neurons of the rat, in vivo. $\mathrm{Br} J$ Pharmacol 118:1875-1877.

Steiger HJ , Büttner-Ennever J . 1979. Oculomotor nucleus afferents in the monkey demonstrated with horseradish peroxidase. Brain Res 160 $1-15$.

Stratford TR, Holahan MR, Kelley AE. 1997. I njections of nociceptin into nucleus accumbens shell or ventromedial hypothalamic nucleus increase food intake. Neuroreport 8:423-426.

Swanson LW, Cowan WM. 1977. An autoradiographic study of the organization of the efferent connections of the hippocampal formation in the rat. J Comp Neurol 172:49-84.

Swanson LW, Cowan WM. 1979. The connections of the septal region in the rat. J Comp Neurol 186:621-656.

Thompson RC, Mansour A, Akil H, Watson SJ . 1993. Cloning and pharmacological characterization of a rat mu opioid receptor. Neuron 11:903913.

Tian J H, Xu W, Fang Y, Mogil J S, Grisel J E, Grandy DK, Han J S. 1997a. Bi-directional modulatory effect of orphanin FQ on morphine-induced analgesia: antagonism in brain and potentiation in spinal cord of the rat. Br J Pharmacol 120:676-680.

Tian J H, Xu W, Zhang W, Fang Y, Grisel J E, Mogil J S, Grandy DK, Han J S. 1997b. I nvolvement of endogenous orphanin FQ in electroacupuncture induced analgesia. Neuroreport 8:497-500.

Trejo LJ , Cicerone CM. 1984. Cells in the pretectal olivary nucleus are in the pathway for the direct light reflex of the pupil in the rat. Brain Res 300:49-62.

Vaughan CW, Christie MJ . 1996. Increase by the ORL1 receptor (opioid receptor-likel) ligand, nociceptin, of inwardly rectifying $\mathrm{K}$ conductance in dorsal raphe nucleus neurons. Br J Pharmacol 117:1609-1611.

Vaughan CW, Ingram SL, Christie MJ . 1997. Actions of the ORL 1 receptor ligand nociceptin on membrane properties of rat periaqueductal gray neurons in vitro. J Neurosci 17:996-1003.

Wagner EJ, Ronnekleiv OK, Grandy DK, Kelly MJ . 1998. The peptide orphanin FQ inhibits beta-endorphin neurons and neurosecretory cells in the hypothalamic arcuate nucleus by activating an inwardlyrectifying $\mathrm{K}^{+}$conductance. Neuroendocrinology 67:73-82.

Wang J B, J ohnson PS, I mai Y, PersicoAM, Ozenberger BA, Eppler CM, Uhl GR. 1994. CDNA cloning of an orphan opiate receptor gene family member and its splice variant. FEBS Lett 348:75-79.

Wang XM, Zhang KM, Mokha SS. 1996. Nociceptin (orphanin FQ), an endogenous ligand for the QRL 1 (opioid-receptor-like1) receptor; modu- 
lates responses of trigeminal neurons evoked by excitatory amino acids and somatosensory stimuli.J Neurophysiol 76:3568-3572.

Wick MJ , Minnerath SR, Liana X, Elde R, Law PY, Loh HH. 1994. I solation of a novel cDNA encoding a putative membrane receptor with high homol ogy to the cl oned mu, delta, and kappa receptors opioid. Brain Res Mol Brain Res 27:37-44.

Woolf CJ , Fitzgerald M. 1983. The properties of neurons recorded in the superficial dorsal horn of the rat spinal cord. J Comp Neurol 221:313328.

Wu YL, Pu L, Ling K, Zhao J , Cheng ZJ , Ma L, Pei G. 1997. Molecular characterization and functional expression of opioid receptor-like 1 receptor. Cell Res 7:69-77.

Xu XJ , Hao J X, Wiesenfeld-Hallin Z. 1996. Nociceptin or antinociceptin: potent spinal antinociceptive effect of orphanin $\mathrm{FQ} /$ nociceptin in the rat. Neuroreport 7:2092-2094.

Yamamoto T, Nozaki-Taguchi N, Kimura S. 1997. Analgesic effect of intrathe cally administered nociceptin (orphanin FQ), an opioid receptor-like 1 receptor agonist, in the rat formalin test. Neuroscience 81:249-254.
Yasuda K, Raynor K, Kong H, Breder CD, Takeda J , Reisine T, Bell GI. 1993. Cloning and functional comparison of $\kappa$ and $\delta$ opioid receptors from mouse brain. Proc N atl Acad Sci USA 90:6736-6740.

Yasuda K, Espinosa R, Takeda J , Le Beau MM, Bell GI. 1994. Localization of the kappa opioid receptor gene to human chromosome band $8 q 112$. Genomics 19:596-597.

Yu TP, Xie CW. 1998. Orphanin FQ/nociceptin inhibits synaptic transmission and long-term potentiation in rat dentategyrus through postsynaptic mechanisms. J Neurophysiol 80:1277-1284.

Yu TP, Fein J, Phan T, Evans CJ , Xie CW. 1997. Orphanin FQ inhibits synaptic transmission and long-term potentiation in rat hippocampus. Hippocampus 7:88-94.

Zahm DS, Brog J S. 1992. On the significance of subterritories in the "accumbens" part of the rat ventral striatum. Neuroscience 50:751-767.

Zhu CB, Cao XD, Xu SF, Wu GC. 1997. Orphanin FQ potentiates formalininduced pain behavior and antagonizes morphine analgesia in rats Neurosci Lett 235:37-40. 